\title{
RESETTLEMENT \\ EXPERIENCES OF BURMESE WOMEN FROM REFUGEE BACKGROUNDS IN WELLINGTON, AOTEAROA NEW ZEALAND
}

\author{
Una Kamri-McGurk \\ School of Geography, Environment \& Earth Sciences \\ Victoria University of Wellington \\ Aotearoa New Zealand \\ A thesis submitted in partial fulfilment of the Masters of \\ Development Studies Degree
}




\section{ABSTRACT}

The resettlement experiences of Burmese women from refugee backgrounds living in Wellington are the focus of this thesis. Increasing numbers of people are being resettled worldwide, so it is important to consider how that resettlement process is being experienced. Burmese refugees are the largest group to arrive in New Zealand (NZ) since 2000, yet remain relatively unknown. This research explores subjective aspects of resettlement, such as how women feel about life in NZ, the kinds of difficulties faced in their resettlement and what could help to improve their sense of well-being in everyday life.

My intention is to facilitate a collaborative process with a group of ten Burmese women using a qualitative approach that positions former refugees as active participants in their own resettlement. It is guided by a feminist methodology, recognising the significance of women's experiences and the value of their knowledge arising from this. Specifically, I use the photovoice method, whereby the women use photography to record significant aspects of their lives as a vehicle through which we then explore resettlement.

The women's community networks are shown to play a major role in adapting to life in NZ. These networks are a source of support and information and provide opportunities for maintaining language and culture. The women appreciate the opportunities presented by life in NZ, such as education and healthcare for their children, adult education classes and the chance to cultivate their gardens. However, there is a sense of opportunities lost through lack of English language and work opportunities. Where the 
relationships work well, volunteers and home tutors assist the women considerably with adapting to life in NZ. These relationships provide information and assistance, but also help to bridge the gap between former refugees and the host community. Other such initiatives that bring together different sectors of the community would allow the women to participate more fully in the wider host community and create greater awareness of the individual stories of refugee-background communities living in NZ.

Key words: Resettlement, refugee, Burmese, women, photovoice. 


\section{ACKNOWLEDGEMENTS}

It is a pleasure to thank the people who helped me with this thesis.

First, I would like to thank my supervisors, Sara Kindon, for encouraging and guiding me through the thesis-writing process and generally being a source of inspiration, and Alia Bloom, for her valuable advice, support and feedback.

I am especially grateful to Annie Coates, who was always generous with her time and advice, and whose close relationship with the participants gave me the confidence to carry out my research.

I would like to thank my husband, Hicham, for the care and support that helped me see the project through to completion. Special thanks also to my mother, Siobhán, for her constant encouragement from afar, and to my father, Bernard, for his expert proofreading.

Finally, my gratitude goes to all the women who gave their time to take part in this study and shared their thoughts and hopes about their lives. To them I dedicate this thesis. 


\section{TABLE OF CONTENTS}

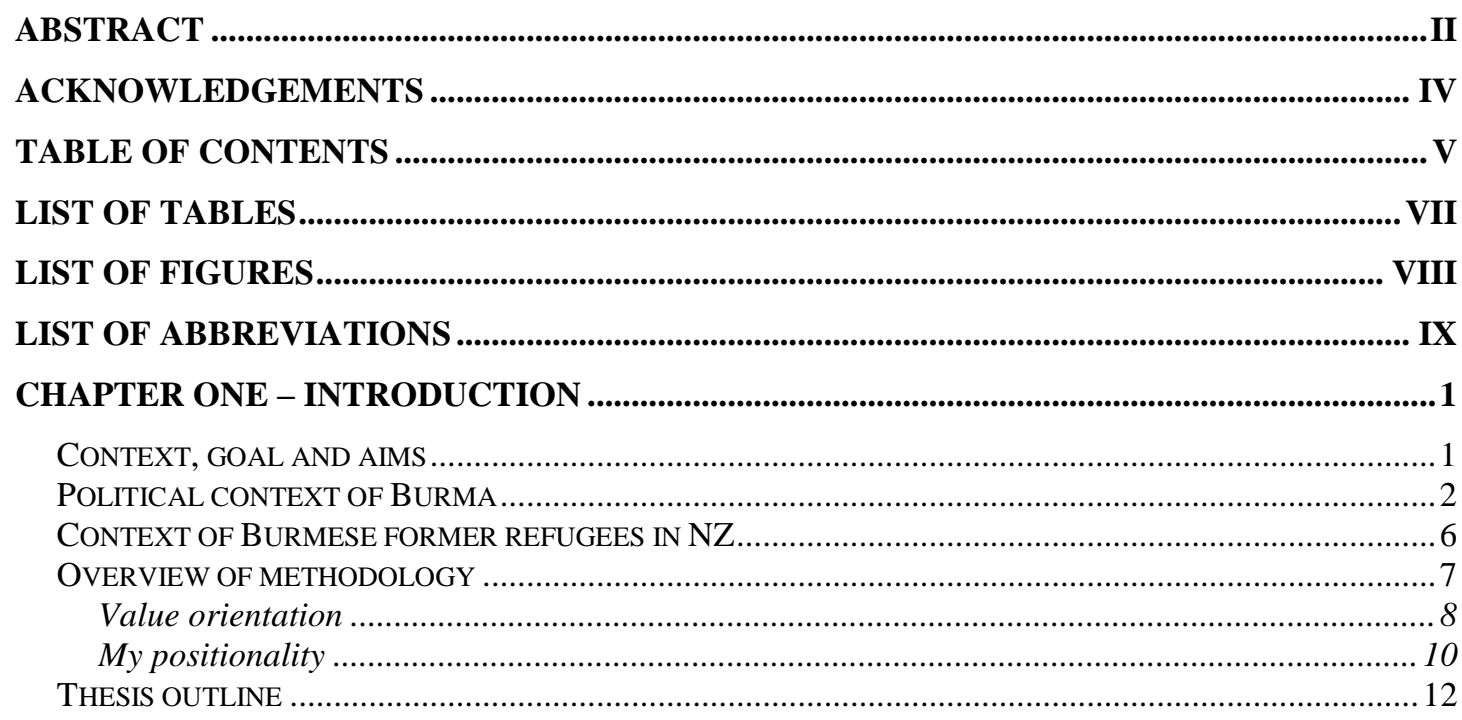

CHAPTER TWO - BACKGROUND AND CONTEXT: POLICIES AND PROCEDURES ........14

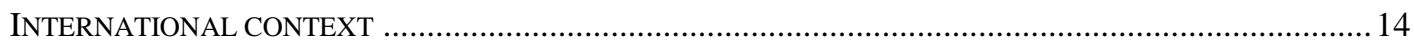

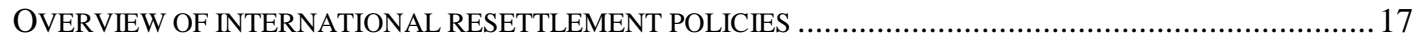

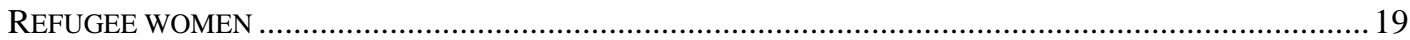

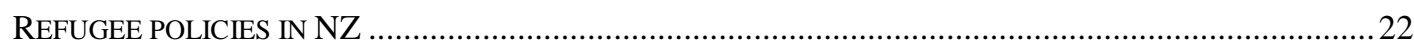

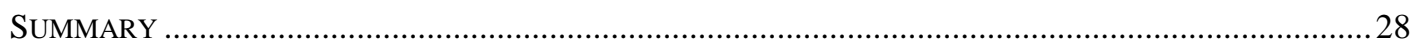

CHAPTER THREE - THEORETICAL FRAMEWORK: KEY TERMS AND THEORIES .......30

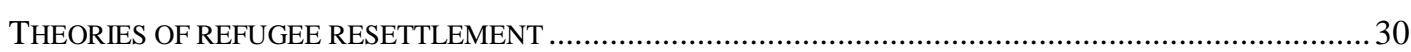

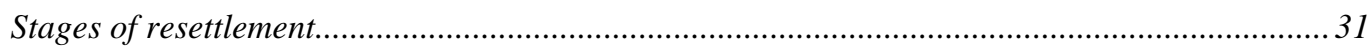

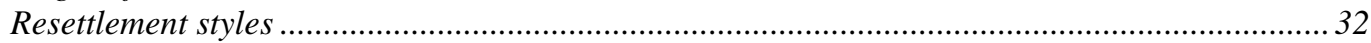

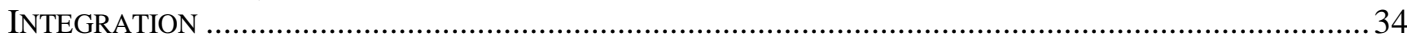

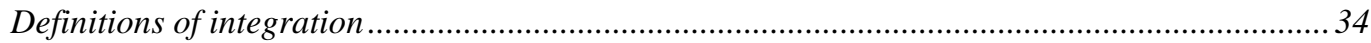

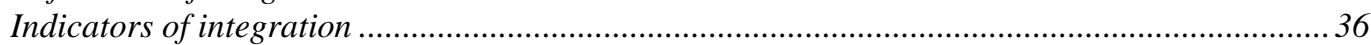

Factors assisting and impeding the process of resettlement or integration ....................................38

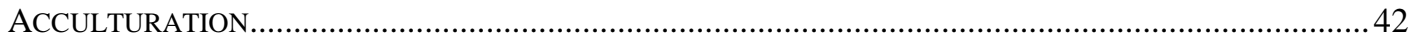

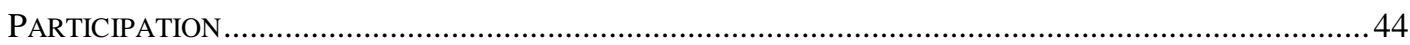

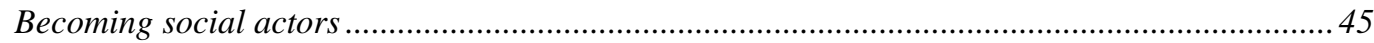

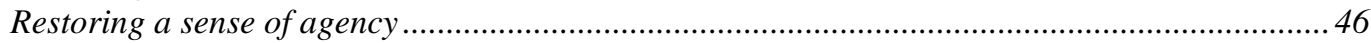

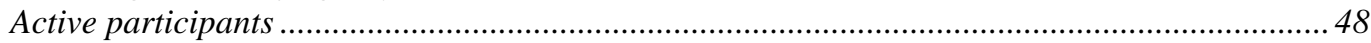

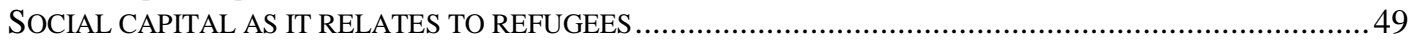

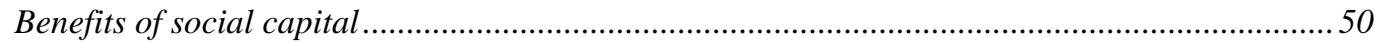

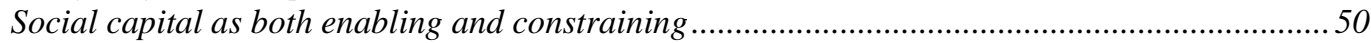

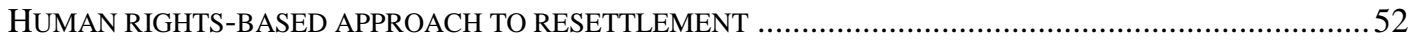

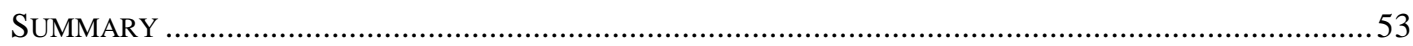

CHAPTER FOUR - METHODOLOGY …...................................................................................54

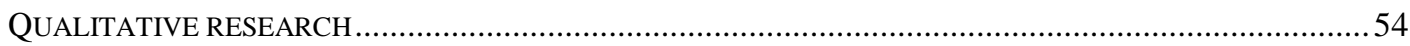

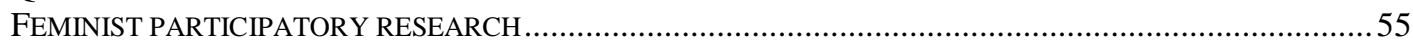

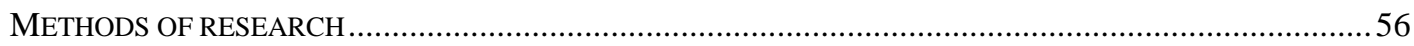

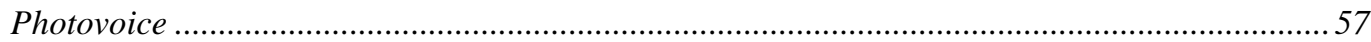

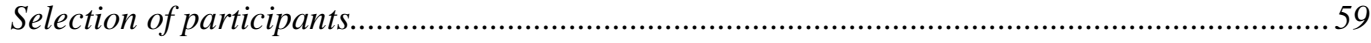

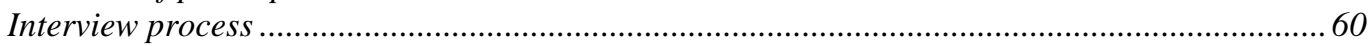

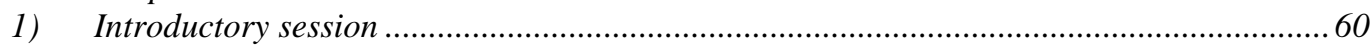

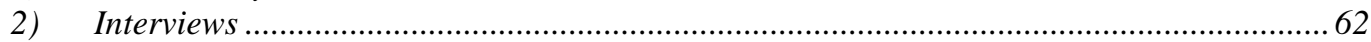

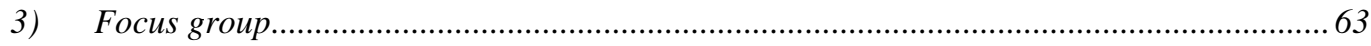

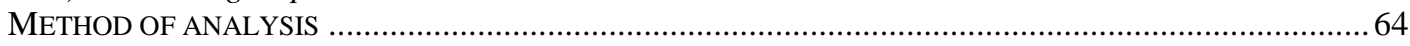

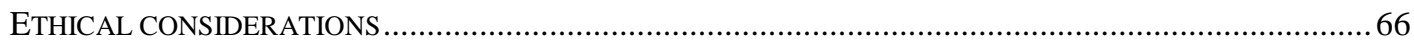




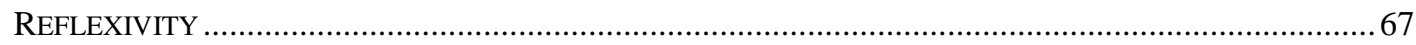

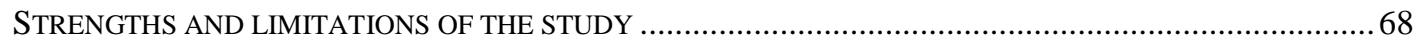

CHAPTER FIVE - 'UNITY’ AND CULTURAL MAINTENANCE ................................................71

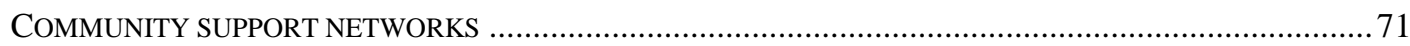

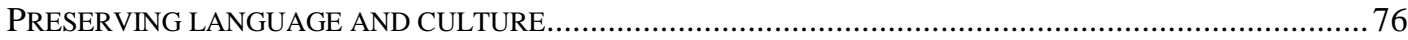

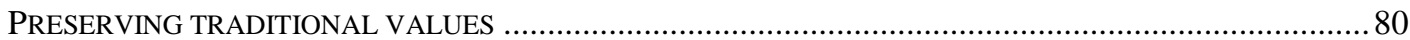

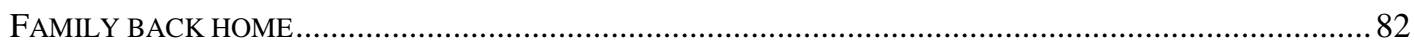

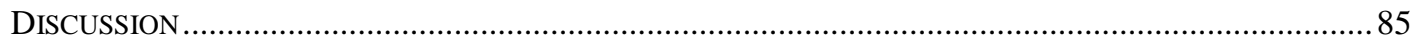

CHAPTER SIX - CONNECTING WITH OTHER CULTURES .........................................8

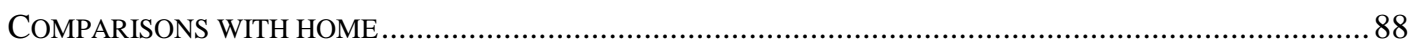

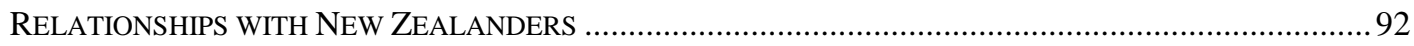

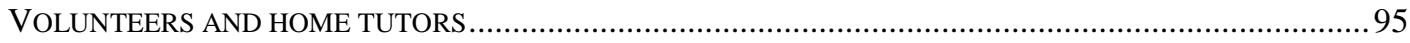

SHARING BURMESE CULTURE WITH NEW ZEALANDERS .......................................................... 100

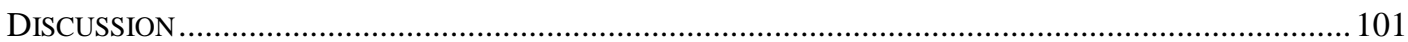

CHAPTER SEVEN - OPPORTUNITIES AND CONSTRAINTS OF LIFE IN NZ ....................105

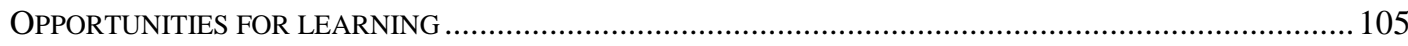

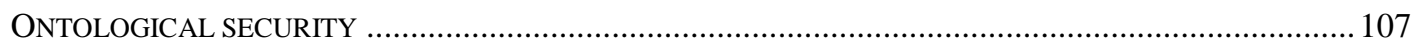

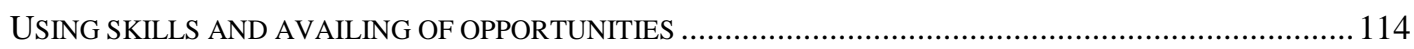

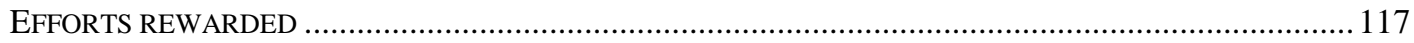

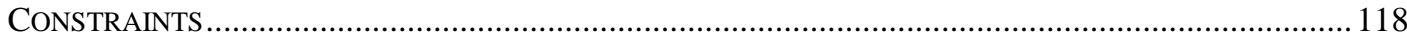

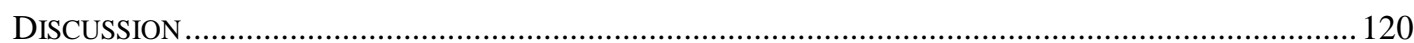

CHAPTER EIGHT - IMPORTANCE OF ENGLISH LANGUAGE ......................................122

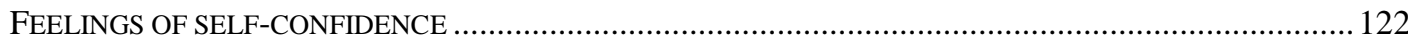

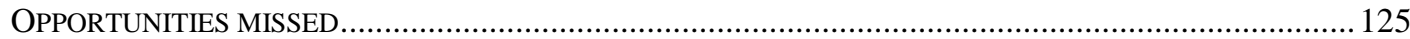

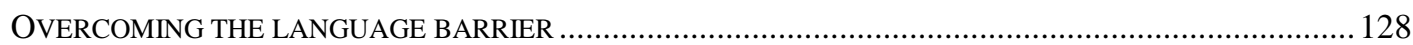

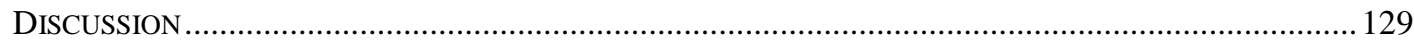

CHAPTER NINE - EMPLOYMENT ..................................................................................... 132

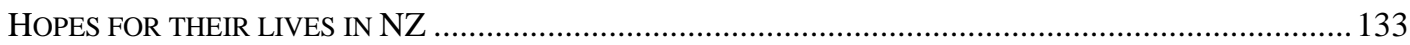

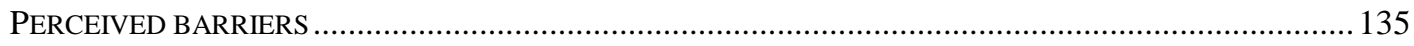

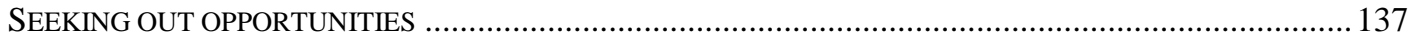

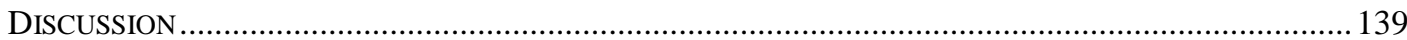

CHAPTER TEN - DISCUSSION, RECOMMENDATIONS AND POSSIBLE AREAS OF

FUTURE RESEARCH ................................................................................................................141

DISCUSSION OF RESEARCH AIMS, PROCESS AND FINDINGS ......................................................... 141

DISCUSSION OF FINDINGS REFERRING BACK TO KEY THEORETICAL IDEAS .................................... 145

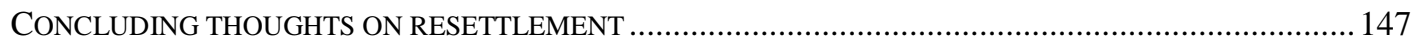

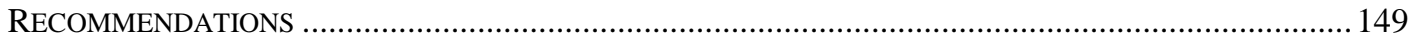

POSSIBLE AREAS OF FUTURE RESEARCH …...................................................................... 154

APPENDIX A

APPENDIX B

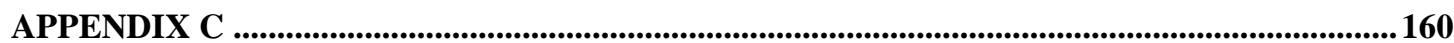

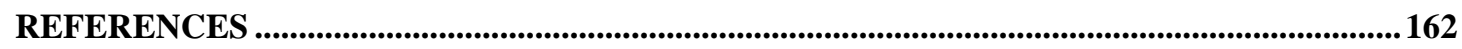




\section{LIST OF TABLES}

Table 2.1: $\quad$ Refugees to arrive in NZ 1930s-1990s.......................23

Table 2.2: $\quad$ Five categories under which refugees entered NZ from July 2009

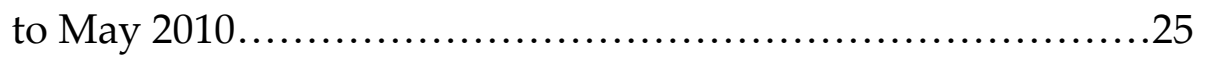

Table 2.3: $\quad$ Top ten quota refugee nationalities to enter NZ between July

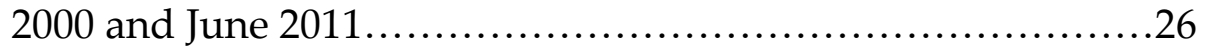

Table 2.4: Number of applications for asylum seekers received by New Zealand Immigration Service between 2007 and 2010..........27

Table 4.1: $\quad$ Overview of research activities - January 2011-March 2011.....56 


\section{LIST OF FIGURES}

Figure 5.1: The Kachin community at the Hosanna Church in Whitby .74

Figure 5.2: Kachin language being taught to children from the Kachin community

Figure 5.3: Puriri's daughter and friend in traditional Kachin dress outside their home in Cannon's Creek. .78

Figure 6.1: Burmese and non-Burmese at the Chin national day .88

Figure 6.2: View of the street taken from Rata's house with the surrounding hills in the background that remind her of home.

Figure 6.3: Standing with home tutor in the front garden .98

Figure 7.1: Puriri's certificate from a flower arranging course at Whitireia College. 106

Figure 7.2: The apple tree in Rata's back garden that yielded a good crop of apples this year

Figure 7.3: Tending to chilli plants in the back garden 111

Figure 7.4: Daughter in the local playground, where the family likes to go in their free time.

Figure 7.5: Weaving in the traditional Kaya/Karenni style and colours 114

Figure 8.1: Hebe's work station where she works on orders from members of the community on Sunday afternoons.

Figure 9.1: Working on the vines in Martinborough during the summer.....132

Figure 9.2: In front of the flowerbed enjoying a break from work. .136 


\section{LIST OF ABBREVIATIONS}

1951 Convention 1951 Convention relating to the Status of Refugees

1967 Protocol 1967 Protocol relating to the Status of Refugees

AMICC American Non-Governmental Organisations Coalition for the International Criminal Court

ASEAN

Association of Southeast Asian Nations

CRF

ChangeMakers Refugee Forum

ESOL English for Speakers of Other Languages

HRC Human Rights Commission, New Zealand

IDP Internally Displaced Person

NZIS New Zealand Immigration Service

SPDC State Peace and Development Council

UNDP United Nations Development Programme

UNFPA United Nations Population Fund

UNHCR United Nations High Commissioner for Refugees

UNRWA United Nations Relief and Works Agency

USDA Union Solidarity and Development Association 


\section{CHAPTER ONE - INTRODUCTION}

\section{Context, goal and aims}

The number of refugees in the world has increased by over 50 per cent since 1985 (Goodkind and Foster-Fishman, 2002). By late 2010, there were 43.7 million forcibly displaced people worldwide, the highest number in 15 years. Of these, 27.5 million were internally displaced persons and 15.4 million were refugees (United Nations High Commissioner for Refugees (UNHCR), 2011). This rising figure increases demand for refugee-related services in host countries, and makes it ever more important to understand the factors contributing to refugees' resettlement.

In this research project, I investigate the resettlement experiences of a small

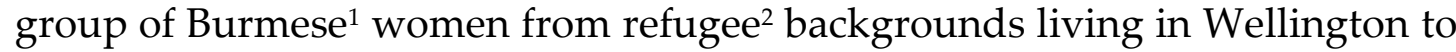
determine the factors that can assist them in leading full and meaningful lives. My work addresses a gap in the existing knowledge, being the first study of its kind with this little known group.

It relates to development studies through its examination of social cohesion, integration and participation and how the research participants are experiencing these issues in the early years of their resettlement in NZ. It fits in with the community development aspect of development studies, which is concerned not just with international development but also how people entering the country are resettling here.

\footnotetext{
${ }^{1}$ As the participants allude to in Chapter 5, Burmese is a contested term. I've chosen to use it because it is in common usage and widely understood.

2 I have chosen to use the terms 'resettled refugee' and 'person from a refugee background' interchangeably at different points in this thesis. These terms recognise that people are no longer refugees but that this experience informs their current realities. Where used, the term 'refugee' refers to people who have not yet been resettled.
} 
The central research question that I seek to answer is how Burmese women from refugee backgrounds living in Wellington are experiencing their resettlement. A number of sub-questions guided my research:

1. What factors contribute to the women's sense of well-being in Wellington?

2. What has helped in dealing with difficult aspects of their lives since their arrival here?

3. What can be done to support the women in living full and meaningful lives?

In this chapter, I set out briefly the historical context of Burma and recent events that have led to so many people leaving the country. This is followed by a brief look at the Burmese former refugee community in NZ and where they have been resettled. I then provide a brief overview of the methodology that underpinned my research and the value orientation that guided how I worked with my participants. I complete the chapter by discussing my positionality and my reasons for choosing this research topic.

\section{Political context of Burma}

Burma $^{3}$ is one of the most ethnically diverse nations in the world with over one hundred distinct ethnic groups and for a long time was a collection of different states and kingdoms. Of the approximately 45 million people in Burma, around one third of them are from ethnic minority groups (NZ Department of Labour, 2010). The larger ethnic groups - the Mon, the Karen, the Karenni, the Shan, Wa and Wahoo - have tended to live in the border

\footnotetext{
${ }^{3}$ In 1989 the ruling military junta changed the name of the country from Burma to Myanmar; the name change was recognised by some countries and not others. In this thesis I will refer to the country as Burma.
} 
areas and keep their own more or less autonomous groups (Coday, 2001). The majority ethnic group are the Burmans, who have tended to dominate the country's political life. Around 89 per cent of Burmese are Buddhists but the various ethnic groups include large numbers of Christians.

Over a series of three Anglo-Burma wars in 1824-1826, 1852 and 1885, Britain gained control over Burma and it became a British colony in 1886. Burma was then briefly occupied by Japan during World War II. It became independent from Britain in 1948, adopting a parliamentary Westminster system of government (New Zealand Ministry of Foreign Affairs and Trade, n.d.).

Between 1948 and 1962, a number of ethnic minority forces took up arms against the central government. In 1962, General Ne Win led a coup which toppled the civilian government of $\mathrm{U} \mathrm{Nu}$ and brought the military-dominated Burma Socialist Programme Party to power. Ne Win continued as President until 1981 and as Party Chairman until 1988 (New Zealand Ministry of Foreign Affairs and Trade, n.d.). During these years there were no free elections and little freedom of expression or association. Any student and worker demonstrations during the 1960s and 1970s were crushed by the military. Guerrilla wars against ethnic opposition groups took place along the country's borders (Burma Campaign UK, n.d.).

Under the regime's isolationist policies, the economy deteriorated until a crisis point was reached in mid-1988. The police killed a demonstrating student, which prompted wide-scale protests across Burma, joined by monks, civil servants, workers, and even police officers and soldiers (Burma Campaign UK, n.d.). On 8 August that year - 8/8/88 as the date has become known in Burma - hundreds of thousands of people marched calling for an elected civil government. Soldiers fired on the crowds, killing thousands. On 
18 September 1988, in response to calls for democracy, the army announced a coup by the State Law and Order Restoration Council (SLORC). However this was followed by huge violence, with the military opening fire on demonstrators in Rangoon and other cities, killing as many as 5,000 and arresting thousands more (Burma Campaign UK, n.d.).

The SLORC pledged that elections would be held once the country had become more peaceful again. A free vote did take place on 27 May 1990. However, in the lead-up to the elections, Daw Aung San Suu Kyi, leader of the main opposition party, National League for Democracy (NLD), was placed under house arrest, and many other senior NLD officials were jailed. SLORC lost the elections by a large majority but subsequently changed the rules and held on to power. Many elected NLD representatives were arrested or fled the country.

The regime set up a National Convention to draw up a new national constitution, enshrining "military dominance of any future government and [... marginalising] Burma's ethnic minorities" (Burma Campaign UK, n.d.). Banki (2006) notes that, in addition to continuing human rights violations, the regime has "burned villages, begun a controversial dam-building project on the Salween River, severely neglected public health and education, and destroyed livelihoods" (p.331).

The number of people displaced within Burma is estimated at over one million, many of whom were forced from their homes into strategic settlements around military posts. People are continuously harassed by government military forces, their property, land, food and livestock are confiscated, and they are forced into portering goods, building infrastructure 
and working in army-owned plantations, sawmills and quarries (Coday, 2001).

It is estimated that there are over 184,000 officially recognised refugees originating from Burma. An estimated two million Burmese migrants are in Thailand and 75,000-100,000 undocumented Chin from Burma are living in the State of Mizoram in India. Approximately 28,000 Burmese have been living in two refugee camps in Bangladesh since 1991 and there are a further 100,000-200,000 Burmese people living in Bangladesh without legal status. There are also roughly 40,000 Burmese living in Malaysia (United Nations Office of the High Commissioner for Human Rights, 2010).

In 1997, the regime renamed itself the State Peace and Development Council (SPDC) in what Coday (2001, p.9) refers to a "thinly disguised public relations move". The SPDC has been promoting the Union Solidarity and Development Association (USDA), an army-backed party, as a political party. It is thought than a second election will be held when they consider that the USDA will gain enough votes to ensure them victory, thus creating a pseudo-democracy.

Burma has been a full member of ASEAN (Association of Southeast Asian Nations) since 1997. Concern has been expressed by ASEAN about its reputation if the slow rate of progress in Burma continues, but they are "positively encouraging of the junta's recent announcements and maintain that the UN-led process must take precedence" (New Zealand Ministry of Foreign Affairs and Trade, n.d., p.6).

The United States and European Union are almost the sole buyers of Burmese goods. In 2000, Burma exported goods worth around USD 84 million, mostly 
clothes and some natural resources. NZ's exports to Burma are small and amount to approximately $\$ 5.8$ million annually.

Coday (2001) notes that the economic repression is as serious as the political repression, with the economy dominated by state-owned enterprises or private enterprises owned by the military. Burma is now the poorest country in Southeast Asia, with the smallest spend of any country in the region on healthcare and education and 40 per cent of the national budget going on the military (Coday, 2001). Burma ranks 132 out of 169 in the Human Development Index (United Nations Development Programme, 2010).

More recently on 7 November 2010, the first election in Burma in two decades was held. Only days later, Suu Kyi was released after seven years under house arrest. Critics say that this was a move by the military to gain credibility in the eyes of the international community (BBC News, 2010). Prior to the election, the military government had drafted a constitution with many proscriptive elements, such as barring candidates who are married to nonBurmese people from participating in the election, thus barring Suu Kyi from participating. Her National League for Democracy party is still banned in the country and a third of the 664 parliamentary seats were reserved for the military (The Guardian, 2010).

\section{Context of Burmese former refugees in NZ}

Refugees from Burma are the largest group to enter NZ over the past decade. Crimes against humanity by the ruling junta in Burma have led to a surge of people leaving the country during this time. 3,094 Burmese came to NZ as part of the government's quota refugees in this period, representing 20.84 per cent of the total number between July 2000 and June 2011 (Immigration New 
Zealand, 2011). The main areas where Burmese have been resettled are Nelson, Wellington, Lower Hutt, Porirua, Palmerston North and Auckland. Porirua has a relatively large community of Burmese, with over forty families settled there.

Despite representing a large percentage of the total refugee-background population, relatively little is known about Burmese refugees living in NZ. Aside from a number of articles in local newspapers featuring the stories of former Burmese refugees living locally (Longmore, 2009; Dando, 2009; BurnsFrancis, De Ridder and Woolcock, 2007), no research to date has focused specifically on their resettlement experiences in NZ.

\section{Overview of methodology}

The research process was designed to be a collaborative and qualitative one, conducted with ten Burmese former-refugee women within a feminist epistemology. Through the use of the photovoice method, the women recorded aspects of their lives that were significant for them. Their photos formed the basis for my discussion with them during semi-structured interviews. A focus group was also held to draw together overarching themes arising from their photos and prior discussion.

As I was choosing my topic, I was aware of a tension between wanting to study the experiences of a group of women who share certain experiences and circumstances, and the potential to 'other' people under the label of 'refugee'. An important aspect of this research for me was to recognise and privilege the individual experience of each of the women taking part in the project. Using photovoice as a method for gathering information helped with this process, as the photos taken by the women were combined with semi-structured 
interviews to provide personalised stories of each woman's life. Eastmond (2007) notes that a focus on individual stories and experience encourages a move away from the:

tendency to think of refugees as an undifferentiated, essentialised and universal category quite irrespective of the different historical and political conditions of displacement and of the individual differences between people who become refugees (p.253).

In my findings I have tried to maintain a balance between drawing conclusions that relate only to the group of women who participated in the research, and being able to draw links to the wider Burmese community and those of other refugee-background communities.

\section{Value orientation}

Much of the discourse around refugee issues tends to take a deficit approach, where the focus is placed on the needs of refugees as opposed to their own strengths and resources. This "burden discourse constructs refugees as passive recipients of welfare rather than acknowledging their resources, resilience and capacity for self-care" (Butler, 2005, p.148). Such an approach leads to welfare-oriented services that create a relationship of dependency between refugees and the agencies providing those services. Thus the approach tends to be problem-focused as opposed to possibility-focused (Joyce, 2004). In considering the Students and Refugees Together (START) project, which began in 2001 and sought to develop mutually beneficial relationships between former refugees and students living in Plymouth in the UK, Butler (2005) refers to both groups as "significant social contributors in transition" (p.149). This research shares a similar standpoint by considering 
the Burmese women taking part as the main active agents in their own resettlement.

There is a growing body of thought now focusing on a human rights-based approach to refugee resettlement, which recognises the rights and responsibilities of refugees as citizens. This approach emphasises empowering people to participate in decisions affecting their lives and seeks wider and longer-term change by looking more holistically at why things are happening and how. It also looks at the power dynamics between former refugees and the agencies and individuals with whom they interact.

In light of this approach, I have attempted to adhere to ChangeMakers Refugee Forum's Guidelines for Research with Refugees in Aotearoa New Zealand ("Guidelines", 2009) while conducting my research. These guidelines share much with a feminist approach. They both privilege working with people, as opposed to on them, being respectful and contributing where possible to people's strengths and well-being. By using the photovoice method and inviting a photographer to provide instruction on the use of cameras, I also hope that I was able to contribute in a small way to expanding the knowledge and skills of the women who participated.

By focusing on women's individual stories through their photos and in-depth interviews, I also hope to convey my recognition that:

Former refugees come from a very wide range of countries, cultures and religions; that we come from a wide range of educational and employment backgrounds; that we have all suffered trauma; and that our experiences of settlement in New Zealand are varied (ChangeMakers Refugee Forum, 2009, p.1). 
In this work, I was assisted by a member of the Burmese community, Annie Coates $^{4}$, who has a strong relationship with the participants, and who was able to invite the women to take part and explain to them the research's form and purpose. She also interpreted where necessary, which was in eight of the ten interviews and during the introductory meeting and focus group. Finally I approached my research as openly as possible and tried not to take anything for granted, while remaining aware that my perceptions and understanding would be influenced by my positionality. When invited to come to community events I attended happily and where possible I shared aspects of my own life as recommended by the Guidelines $(2009, \mathrm{p} .4)$.

\section{My positionality}

Having lived as a migrant in several countries in Europe and Africa, and more recently in NZ, I am interested in the process of becoming established in a new country and negotiating the cultural differences that arise. Through my work at the Yugoslav Tribunal and for an aid agency in D.R. Congo, I've had the opportunity to witness and reflect on the kinds of circumstances that force people to leave their own countries and seek refuge elsewhere. This research project allowed me to gain an insight into how this migration process is working out in one host country, and how representatives of a particular group of people who have been forced to leave their own countries are adapting to life elsewhere.

I chose to work with Burmese women for a number of reasons. Burmese constitute the largest group resettled in NZ since 2000 but no studies exist of

\footnotetext{
${ }^{4}$ Annie Coates was my contact within the Burmese community and my interpreter. She is originally from Burma and has lived in Wellington for over twenty years. She has strong links with the Burmese community and works closely with the community in a personal capacity as well as in a professional capacity through her role with ChangeMakers Refugee Forum.
} 
or with them. Statistics show that the large majority of refugees worldwide are women. Refugees can be considered the most vulnerable group of people migrating to another country and, within this category, women and children are amongst the most vulnerable (Lindgren and Lipson, 2004). Much of the literature relating to refugee studies tends to be gender-blind with little special consideration for the different needs and expectations of refugee women. I hoped that a focus on former refugee women in NZ would help to generate a better understanding of the refugee experience for women. My own personal experience is that women are often involved in work that is unpaid but that contributes greatly to the well-being of society. Lastly, as a woman, although my circumstances are different in many ways, I felt that I could more easily negotiate the different cultural divides between myself and the participants.

When approaching the women I was conscious of how I would be perceived. Although not from NZ, my Irish origins mean that I am not visibly different to many New Zealanders. When the women realised that I was not a New Zealander, I think that it did make it easier for them to voice some of the less positive aspects of their experiences here. However, they seemed to group together Western cultures, so when discussing and comparing Burmese and Western culture, they switched between referring to "your culture" and "New Zealand culture". Nevertheless, the fact that we had all arrived in NZ within the last few years did provide some common ground in our conversations, especially around aspects of life in Wellington, such as the weather. If they were talking about aspects of NZ that I was not familiar with they explained them to me.

None of the women had had the opportunity to attend university but placed much importance on education and many spoke of their aspirations for their 
children. They were supportive of my work towards gaining a Master's degree and some of them encouraged me as I progressed through the work, noting that education was very important in the long-term.

I was mindful of the fact that my culture is a relatively individualistic one, and that the Burmese community I was working with was likely to be more collectivistic. As someone with little experience of living in a communal society, it is difficult to fully comprehend group-oriented behaviour and take this into account in the research process. Being aware of these potential differences throughout the research process helped with my own understanding of the women's experiences.

\section{Thesis outline}

This thesis is divided into ten chapters. After introducing the thesis in Chapter One, Chapter Two looks at some of the policies and procedures relating to refugees internationally and in NZ.

Chapter Three provides the context for this research by looking at the relevant literature. The themes of refugee resettlement and integration are discussed and how they reflect different approaches and processes of governments and service providers. This chapter also considers the concepts of social capital, participation, acculturation and human rights as they relate to former refugees.

Chapter Four describes my methodology, which is feminist, qualitative and participatory and discusses how the photovoice method was combined with semi-structured interviews and a focus group to generate information. The ethical considerations of the study are also set out here. 
Chapters Five to Nine analyse the interviews, photos and focus group discussion under five themes identified by the Burmese women who participated in the study. After each theme I discuss how my findings interact with the literature on refugee studies.

Chapter Ten discusses the key findings of my research in relation to the central goal and key aims of the thesis. I conclude the thesis with some recommendations for providers of services to refugees and possible areas for future research. 


\section{CHAPTER TWO - BACKGROUND AND CONTEXT: POLICIES AND PROCEDURES}

Since the term 'refugee' was given a legal definition in the 1951 Convention Relating to the Status of Refugees and its 1967 Protocol (1951 Convention), a range of policies and procedures for addressing refugee issues have been created by signatory countries. These policies and procedures define how refugees enter those countries and the kinds of support provided for them on arrival. They have also been found to have an impact on how governments, service providers and host communities interact with resettling refugees.

Until recently there has been little recognition of women refugees as a separate group requiring specific support and services. Many countries, such as NZ, now have a women-at-risk category in their refugee quota; however the particularities of the refugee experience for women have yet to be given adequate attention.

\section{International context}

People's flight from places of danger to places of safety has been a constant feature of human history. Essed, Frerks and Schrijvers (2005) note that "migration and flight have always formed an important part of socio-political and environmental change" (p.3). However, processes of nationalisation and decolonisation in the first half of the $20^{\text {th }}$ century left a greater number of people displaced than ever before. While globalization has created possibilities for many, it has also given rise to exclusion and polarization (Essed et al., 2005). Many marginalised minorities have taken up arms in resistance against their governments, and an unprecedented number of 
people have found themselves forced to leave their homes and take refuge elsewhere.

Whereas displaced people had been dealt with on an ad hoc basis throughout history, following the creation of the League of Nations in the aftermath of World War I, the issue of forced displacement came to be viewed as an international problem requiring an international solution. Following World War II, the concept of human rights was incorporated into the refugee system, which is reflected in the definition formulated in the 1951 Convention. This states that a refugee is a person who:

owing to a well-founded fear of being persecuted for reasons of race, religion, nationality, membership of a particular social group, or political opinion, is outside the country of his nationality, and is unable to or, owing to such fear, unwilling to avail himself [sic] of the protection of that country (United Nations, 1967, p.3).

Refugees are distinct from Internally Displaced Persons (IDPs) who may have fled their homes for similar reasons but who are within the territory of their own country. The precarious situation of IDPs has long been recognised but, aside from guidelines issued by UNHCR and the United Nations Relief and Works Agency (UNRWA), little has been done to address it.

Refugee status has been described as "a categorical designation that reflects a unique ethical and consequential legal entitlement to make claims on the international community" (Hathaway, 2007, p.352). Hathaway (2007) asserts that refugees are doubly deserving of the assistance of the international community since firstly they are at risk of human rights abuse, and secondly they are at risk because of characteristics that are unchangeable (race or 
nationality) or should not have to be changed in order to be safe (such as religion or political opinion). One of the significant distinctions between refugees and other forced migrants is that refugees have crossed an international border which allows them "the substitute or surrogate protection of the international community" (Hathaway, 2007, p.353).

It has been noted that the way governments and refugee agencies formulate approaches to refugee problems repeatedly fails to place them in their historical perspective as recurring phenomena; instead they are viewed as temporary and unique events and this "inaccurate perspective is the most corrosive and damaging element that all refugee programs must confront" (Stein, 1981, p.320). More research into the specific issues of certain demographic groups, such as women, children and the aged, as well as into legal issues, questions of definition, and patterns of adjustment, could help in formulating a more holistic and cohesive approach to dealing with refugee issues.

Refugee studies has taken its cue over the years from state policies and can be broken down into four phases (Chimni, 2009). From 1914 to 1945, inter-war problems were addressed with a focus on practical issues, such as absorptive capacity of land, while between 1945 and 1982 people were concerned with the refugee camps left after World War II. The years from 1982 to 2000 saw an expansion of refugee studies in response to the increasing south-north flow of refugees and a number of academic programmes and centres were set up to facilitate the exchange of ideas on the subject. Finally recent years have seen a shift from refugee studies to forced migration studies, in order to "come to grips with current preoccupations of western policy makers with the asylummigration nexus or the fate of growing numbers of IDPs" (Chimni, 2009, p.15). 
While refugee studies has brought to light a great deal of valuable information about refugees, such as the special needs of women and children, the specific psychosocial needs of refugees and the need to adopt participatory approaches, Chimni (2009) argues that the discipline is influenced also by interests of dominant social forces. "The world of displacement has [...] become a site of power to embed selective humanitarian practices that facilitate the exercise of hegemony" (p.24). He stresses the need to bring out the trend within both refugee studies and forced migration studies that supports the empowerment of displaced persons.

The refugee identity takes different forms that have been shaped by the various discourses of stakeholders in the field. Tomlinson and Egan (2002) argue that central government in the UK have tended to prefer a refugee who is helpless, whereas refugee agencies conceptualise refugees as "either 'silent client' or 'vocal constituency'" (p.1023). Former refugee-led organisations, such as ChangeMakers Refugee Forum in NZ, see refugees as active participants in policy development and service delivery (ChangeMakers Refugee Forum, 2008). These labels have important implications for how refugees are expected to act and how others are supposed to engage with them.

\section{Overview of international resettlement policies}

Less than one per cent of the world's refugee population, estimated at 15.4 million people, are resettled in other countries. The average length of time spent in refugee camps by refugees awaiting resettlement is 17 years (Caritas, n.d.). Resettlement is seen as the option reserved for those in most need of protection. The other two options recognised by the United Nations are 
voluntary repatriation, where refugees return home once conditions have become safer, and local integration, where refugees are integrated into the first country of asylum, usually a neighbouring country (Caritas, n.d.). Different countries have different criteria for granting refugee status; the United States, for example, will consider applications from people who are still living within their home country boundaries, which runs contrary to the definition set out in the 1951 Convention.

Fourteen countries resettled refugees in 2006, including Australia $(13,400)$, Canada $(10,700)$ Sweden $(2,400)$, Norway $(1,000)$, the United States $(41,277)$ and NZ (688) (Grogan, 2008). The UNHCR has a number of ways in which it determines the capacity of countries to host refugees. The factors considered include size, Gross Domestic Product measures and population. If we make a comparison between NZ and the U.S. between 2002 and 2006, the ratio of refugee population per 1,000 inhabitants was 1.7 for the U.S. and 1.3 for NZ. Comparing the refugee population to the Gross Domestic Purchasing Power Parity, NZ measures 0.2 and the U.S. measures 11.9 (Grogan, 2008). Thus, both calculations show the U.S. to rank considerably higher than NZ in terms of refugee intake.

Although relatively few countries accept refugees through formal programmes, many other countries absorb large numbers of refugees by virtue of their geographical location. If we again use the Gross Domestic Purchasing Power Parity gauge, Tanzania measures 738 and Pakistan 420, compared to NZ's 0.2 (Grogan, 2008). This puts into perspective the relatively small number, 750, of refugees entering NZ each year.

Whereas resettlement was the preferred solution for refugees between 1945 and 1985, since 1985 only a relative small number are offered resettlement. 
The selection process is based on a range of factors, from a perceived need for protection to political factors, such as integration prospects and foreign policy interests. Moreover, Noll and van Selm (2003) point to a mismatch between the definition of refugee set out in the 1951 Convention and refugee resettlement policies, stating that those:

whose protection needs are in fact quite strong do not necessarily satisfy the international legal interpretations of refugee status, which have chiefly developed in the West in the context of asylum systems following World War II (p.13).

\section{Refugee women}

Research on refugees has generally entailed a discussion of refugees as a "non-gendered phenomenon" (McSpadden and Moussa, 1993, p.203). Of the 42 million refugees and IDPs in 2009, 75-80 per cent were women and children (Unite for Sight, n.d.). Some of the issues identified for refugee women include greater poverty, more health risks, more mental health problems, less information, fewer work opportunities and fewer opportunities for education and training than male refugees (Ganguly-Scrase and Vogl, 2008). UNFPA (2006) notes that in conflict situations when schools and medical facilities close, it is generally women who assume care for children, the infirm and the elderly. Women also have special needs relating to sexual and reproductive health issues, including unwanted or forced pregnancy.

For a long time sexual violence was largely ignored by international law. The 1949 Geneva Convention characterised sexual violence not as a 'grave breach' but rather as outrageous acts on personal dignity or attacks on a woman's 
honour (American Non-Governmental Organisations Coalition for the International Criminal Court (AMICC), 2009). The 1998 Rome Statute, which established the International Criminal Court, is the first international treaty recognising a range of sexual and gender violence as crimes. The definition of sexual violence was also expanded beyond rape to include sexual enslavement, forced prostitution, forced sterilisation and forced pregnancy. Nevertheless, it has been noted that "the international community has rarely prosecuted perpetrators who committed acts against women during conflict" (AMICC, 2009, p.1).

Despite the fact that the majority of the world's refugees are women and children, they are underrepresented in processes for selecting refugees for resettlement. Haines (2003, p.327) holds that decision makers have failed to incorporate a gender lens:

The main problem facing women as asylum seekers is the failure of decision makers to incorporate the gender-related claims of women into their interpretation of the existing enumerated grounds and their failure to recognize the political nature of seemingly private acts of harm to women.

Moreover, some international resettlement policies, such as those of Canada, discriminate against women refugees through their refugee criteria by favouring skills for immediate employability (McSpadden and Moussa, 1993).

Various guidelines have been issued by countries in considering claims for asylum, such as the UNHCR's Guidelines on the Protection of Refugee Women in 1991. In 1993, the Canadian Immigration Board issued Guidelines on Women Refugee Claimants Fearing Gender-Related Persecution, followed 
by the United States Government's Considerations for Asylum Officers Adjudicating Asylum Claims from Women in 1995 and the Australian Government's Guidelines on Gender Issues in Decision Makers in 1996. These do not constitute law, but rather guidelines on how to render the 1951 Convention definition more gender-sensitive, and there is no obligation on countries to follow them.

Australia, Canada and NZ have a 'women-at-risk' programme as part of their broader resettlement programme. Other countries settle women-at-risk as part of their general refugee intake (UNHCR, 2002). Some of the considerations taken into account with the women-at-risk category are that they may have suffered a high degree of trauma and may have less education and prior work experience. Such programmes seek to target these needs through more intensive support.

It is by looking at the particularities of the refugee experience that we can understand better how it differs for men and women. Both gender groups face multiple role adjustments in resettlement. "Refugeeness often takes away the assumed permanence of the social relationships between men and women" (McSpadden and Moussa, 1993, p.205). For women, such adjustments may include a change from more communal responsibility for domestic tasks and care of children and elderly to bearing sole responsibility. Some women may enter paid employment for the first time. Others may have been widowed or separated and become heads of household.

There is evidence of increasing domestic violence in African refugee communities in Canada and the US, which can be attributed to the anger and frustration felt by men who cannot find employment or who are underemployed. This experience is understood to contribute to a loss of social 
status and authority in the home and the public sphere. Women, on the other hand, may find that they have more rights, both at home and in the public sphere. It can sometimes be easier for women to find work, albeit lower paid, which compounds to threaten male power in the family (McSpadden and Moussa, 1993).

The UNHCR (2002) notes the importance of integration planning which embraces women's diverse roles as partners, carers, members of communities and paid workers. Women are an important link between the family and services, such as healthcare and childcare facilities. If women are not working outside the home, they may remain isolated from the larger community, hence the importance of networks amongst home-based refugee women to foster mutual support, recognised by many organisations.

\section{Refugee policies in NZ}

NZ is a signatory to the 1951 Convention and the 1967 Protocol Relating to the Status of Refugees (1967 Protocol). States who sign the 1951 Convention agree to provide protection to people fleeing persecution. Each state has their own process for determining refugee status within their own legal structure; once refugee status has been granted they are obliged to protect refugees by allowing them residence and basic rights (Grogan, 2008).

NZ responds to global circumstances and needs in deciding who to admit. The different waves of refugees who have entered NZ since the 1930s are set out in Table 2.1. 
Table 2.1: Refugees to arrive in NZ 1930s-1990s

\begin{tabular}{|c|c|c|}
\hline Country of origin/Reason for leaving & Year(s) & Number admitted \\
\hline Refugees from Nazism & 1933-39 & 1,100 \\
\hline Poland & 1944 & $\begin{array}{l}\text { 800, including } 734 \\
\text { children }\end{array}$ \\
\hline $\begin{array}{l}\text { Displaced people from Europe following } \\
\text { World War II }\end{array}$ & $1949-52$ & $4,500-5,000$ \\
\hline Hungary & $1956-58$ & 1,100 \\
\hline $\begin{array}{l}\text { 'Handicapped' refugees (those regarded as } \\
\text { difficult to settle for reasons such as ill } \\
\text { health, disability, age, large families) - } \\
\text { country of origin not specified }\end{array}$ & 1959-1963 & 200 families \\
\hline China & $\begin{array}{l}1962 \\
\text { Late 1960s }\end{array}$ & $\begin{array}{l}50 \text { orphans } \\
6 \text { families a year }\end{array}$ \\
\hline China (Russian Christians) & 1965 & 80 \\
\hline Czechoslovakia & $1968-71$ & 125 \\
\hline Uganda (Asians) & $1972-73$ & 244 \\
\hline Chile & $1974-81$ & 354 \\
\hline Soviet Jews & 1974-91 & 355 \\
\hline Poland & & 292 \\
\hline Other eastern European countries & & 507 \\
\hline Iran (Baha'i) & 1987-1989 & 142 \\
\hline Iraq (Assyrian Christians) & Mid 1980s onwards & 140 \\
\hline Cambodia & 1975-94 & 5,200 \\
\hline Vietnam & & 4,500 \\
\hline Laos & & 1,200 \\
\hline Kosovo & 1989-99 & 600 \\
\hline $\begin{array}{l}\text { Small groups from diverse countries } \\
\text { including Ethiopia, Eritrea, Iran and the } \\
\text { Sudan }\end{array}$ & 1992 onwards & \\
\hline
\end{tabular}

Source: Te Ara (n.d.). 
In 1987, the NZ government agreed to accept an annual quota of 800 people classified as refugees by the UNHCR, thereby formalising its previously ad hoc response to refugee situations. NZ is now one of around sixteen countries worldwide with a formal refugee resettlement programme (New Zealand Immigration Service (NZIS), 2002). In 1997, the government reduced the annual quota to 750 but agreed to pay travel costs to those included in the quota.

NZ now allocates a certain percentage of the quota to women-at-risk and medical cases. This is an important point, given that at-risk cases such as these:

experience discrimination by many nations in the refugee selection process [... whose] selection criteria focus on the individual's ability to resettle and provide positive work skills to the nation (Altinkaya and Omundsen, 1999, p.32).

Over the years the quota programme has included a number of categories, such as specific ethnic or national groups, and people with special needs. There are five sub-categories in this quota at present; Table 2.2 sets out the breakdown for the 698 quota refugees who entered the country between July 2009 and May 2010. 
Table 2.2: Five categories under which refugees entered NZ from July 2009 to May 2010.

\begin{tabular}{|l|l|l|}
\hline Category & Number & Percentage of total \\
\hline Protection & 437 & 62.61 \\
\hline Family reunion & 126 & 18.05 \\
\hline Women-at-risk & 118 & 16.91 \\
\hline Medical/disabled & 12 & 1.72 \\
\hline Emergency & 5 & 0.72 \\
\hline
\end{tabular}

Source: RefNZ (2010).

Over 30,000 refugees have been resettled through the quota programme since 1944 (Refugee Services Aotearoa, 2004). Refugees arriving in NZ through the quota programme spend their first six weeks at the Mangere Refugee Resettlement Centre in Auckland, which is managed by the Department of Labour. In the period from July 2000 to June 2011, NZ received a total of 7,797 refugees from 41 countries. The top ten quota refugee nationalities for this period are listed in Table 2.3. 
Table 2.3: Top ten quota refugee nationalities to enter NZ between July 2000 and

June 2011.

\begin{tabular}{|c|c|c|c|c|c|c|c|c|c|c|c|c|}
\hline $\begin{array}{l}\text { New } \\
\text { Zealand } \\
\text { Refugee } \\
\text { Quota }\end{array}$ & 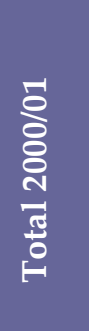 & 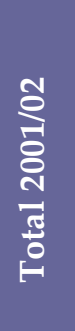 & 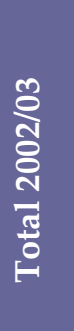 & 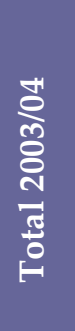 & 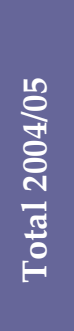 & 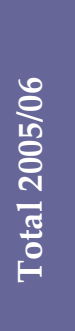 & 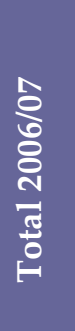 & 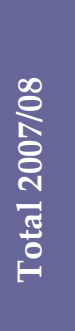 & 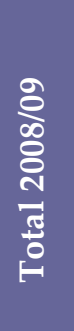 & 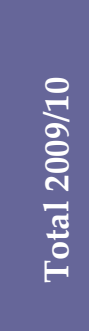 & 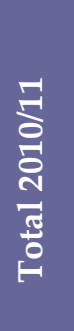 & 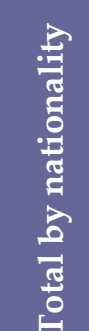 \\
\hline Burmese & 310 & 30 & 4 & 26 & 2 & 174 & 397 & 251 & 152 & 126 & 230 & 1702 \\
\hline Afghan & 46 & 257 & 72 & 386 & 324 & 67 & 199 & 66 & 29 & 55 & 5 & 1506 \\
\hline Iraqi & 82 & 116 & 355 & 88 & 59 & 76 & 6 & 90 & 113 & 36 & 7 & 1028 \\
\hline Bhutanese & 0 & 0 & 0 & 0 & 0 & 0 & 0 & 75 & 195 & 176 & 117 & 563 \\
\hline Somali & 119 & 159 & 25 & 38 & 69 & 13 & 0 & 18 & 0 & 5 & 4 & 450 \\
\hline Iranian & 87 & 42 & 47 & 8 & 24 & 152 & 10 & 11 & 2 & 12 & 0 & 395 \\
\hline Ethiopian & 54 & 134 & 12 & 48 & 67 & 16 & 7 & 12 & 3 & 30 & 5 & 388 \\
\hline Sudanese & 4 & 0 & 11 & 74 & 76 & 54 & 11 & 30 & 2 & 21 & 4 & 287 \\
\hline Eritrean & 15 & 0 & 1 & 85 & 2 & 4 & 1 & 76 & 49 & 23 & 7 & 263 \\
\hline Colombian & 0 & 0 & 0 & 0 & 0 & 0 & 0 & 29 & 48 & 71 & 96 & 244 \\
\hline
\end{tabular}

Source: NZIS (2011).

As illustrated by the table, Burmese are the largest refugee group to arrive in $\mathrm{NZ}$ in the past ten years, followed by Afghans and Iraqis.

A Quota Composition Plan is drawn up every three years by the Refugee Division at the NZIS, which sits within the Department of Labour. This plan sets out the regional and global priorities for NZ each year. In 2007/2008, NZIS set out four priorities for the quota:

- Responding to global priority protection pressures;

- Facilitating family reunification for refugees already in NZ; 
- Resettling emergency protection cases from countries of asylum; and

- Focusing on refugee caseloads where NZ's contribution can make the biggest difference (Grogan, 2008).

In addition to NZ's intake under the quota system, small numbers of asylum seekers have been entering the country since the early 1980s. As a signatory to the 1951 Convention and the 1967 Protocol, NZ is obliged to provide protection for those arriving in the country, if it is established that they have genuine fear of persecution on one of the grounds set out in the 1951 Convention and they do not have the protection of their own country (Refugee Services Aotearoa, 2004). Asylum seekers attempt to establish their UNHCR refugee status after arriving in the country and their claims are assessed by the Refugee Status Branch of NZIS. In recent years, the number of applications for asylum seekers received by NZIS was as shown in Table 2.4.

Table 2.4: Number of applications for asylum seekers received by NZ Immigration Service between 2007 and 2010.

\begin{tabular}{|l|l|l|}
\hline Year & No. of applications from asylum seekers & Percentage approved \\
\hline $2007 / 08$ & 267 & 29.5 \\
\hline $2008 / 09$ & 246 & 30 \\
\hline $2009 / 10$ & 384 & 27 \\
\hline
\end{tabular}

Source: RefNZ Statistics (2010).

The third way that refugees enter NZ is through the Refugee Family Support Category. This programme seeks to help former refugees living in NZ to settle by allowing them to sponsor family members for residence. NZ allows up to 300 sponsored people (including their partners and dependent children) to settle in NZ each year under this category. Caritas (2010) observes that the Family Support Category has very strict eligibility criteria and that very few 
former refugees are successful in bringing over family members through this process. Apart from in 2003/04 and 2004/05, when relatives of the Tampa refugees arrived, the Family Support Category has not been fully utilised (Human Rights Commission (HRC), 2009).

The HRC (2009) notes that the definition of family needs to be made more culturally-sensitive and broadened to recognise wider family interdependence. This is echoed by Adam Awad, Chair of ChangeMakers Refugee Forum, who states that he would like to see "the definition of family widened beyond the 'very Kiwi' nuclear style to include extended family, and paperwork fast-tracked" (Longmore, 2009, p.2). Furthermore, although people may be from the same refugee situations, entitlements to assistance such as welfare and housing may differ depending on the avenue through which people arrive in NZ (NZIS, 2002).

One of the priorities of the last Quota Composition Plan was to facilitate family reunification (Grogan, 2008). The evidence suggests that efforts should continue to be made in this area, both under the annual refugee quota and the Family Support Category. Many of the women I spoke with were awaiting the outcome of applications to bring family members to NZ and described the process as long and unsettling.

\section{Summary}

This chapter has provided a context for this research project by setting out some of the key policies and procedures around refugee issues. Trends over past decades show that we can expect the number of refugees in the world to continue rising, making it all the more essential to ensure that the right processes are being created for those affected. The needs of women and other 
more vulnerable groups need to be addressed as a priority, in order to rectify some of the oversights of the past. Research projects such as this one, that generate information about the first-hand experiences of resettling refugeebackground women, can help to address such gaps. 


\section{CHAPTER THREE - THEORETICAL FRAMEWORK: KEY TERMS AND THEORIES}

A number of concepts have emerged as having particular relevance to the experiences of former refugees who are resettling in a new country. Terms such as resettlement, integration and acculturation are used generally to describe the process of how former refugees are resettling. They cover aspects such as stages in the resettlement process, measurement of resettlement outcomes and the acculturation processes taking place during resettlement.

Concepts such as participation and social capital have been found to be significant in determining how well former refugees adapt to their new lives. Participation in community life has been found to be beneficial both for the social fabric of communities and for restoring a sense of agency and independence to people's lives. Social capital provides a large part of the allimportant support systems when it comes to setting up home and a life somewhere new. Awareness is growing around the importance of underpinning policies and practices with a human rights-based approach.

\section{Theories of refugee resettlement}

The term 'resettlement' is conceptualised in different ways. Refugee resettlement has been defined as "a process during which a refugee, having arrived in a place of permanent asylum, gradually re-establishes the feeling of control over his/her life and develops a feeling that life is 'back to normal'" (Colic-Peisker and Tilbury, 2003, p.62). It is a term that acknowledges that former refugees may have already been 'settled' in their countries of origin in terms of qualifications, jobs, social status and family and social networks (Castles, Korac, Vasta and Vertovec, 2002). It describes both the process of 
resettling in a new country and the outcome of being resettled. Resettlement is generally used to refer to the early stages of living in a country, as opposed to 'integration' which takes place over a longer period of time (Gray and Elliott, 2001).

The Canadian Council for Refugees (1998) echo this when they state that the resettlement process can be viewed as a continuum that starts with acclimatization on arrival, goes through an adaptation period and culminates in integration, where newcomers participate fully in society. Although many factors come into play, the literature agrees on the importance of social connections in the integration process (Dunstan, Dibley and Shorland, 2004; Daley, 2007; Ager and Strang, 2008).

\section{Stages of resettlement}

Five stages have been identified in the resettlement process, each with its own specific and emotional tasks. The first stage is 'pre-departure'. One adaptive mechanism associated with this stage is that of splitting, the idealisation of the future and the denigration of the past, to make it easier to move forward (Hulewat, 1996). The second stage is the physical act of migration itself and, depending on the migration process, there may be little or more transition time on the way to the new country. Hulewat (1996) remarks that, as difficult as refugee camps may be, they do provide a period of transition. It should be noted that in some cases, especially children, camps may be the only life they have known.

The third stage is arrival in the new country and is characterised by the concrete tasks of setting up home. This period is marked by a combination of anxiety and optimism as new arrivals carry out tasks of finding work, setting up home and learning a new language. The fourth stage requires newly 
arrived former refugees to come to terms with the past that has been left behind and accepting the present. Letting go or splitting has been identified as an important defence mechanism and a way of making peace with the changed circumstances. The final stage is a transgenerational one, where issues that are left unresolved may be passed on to subsequent generations (Hulewat, 1996).

The third and fourth stages of Hulewat's (1996) resettlement process are most relevant to this thesis, given that the women have all arrived in the country in the past five years. Although the different phases are presented here as being quite distinct and separate, in reality there is clearly some overlap.

\section{Resettlement styles}

A typology categorising the resettlement experiences of former refugees identifies four resettlement styles, two characterised by a more active approach to resettlement, 'achievers' and 'consumers', and two marked by a more passive approach, 'endurers' and 'victims'. It is stressed that such terms are not meant pejoratively nor do they reflect successful or unsuccessful settlement outcomes. Rather the style adopted depends "ultimately [...] on a combination of cultural, group, and individual factors" (Colic-Peisker and Tilbury, 2003, p.67). Examples of such factors include gender, age, socioeconomic background and community dynamics.

Former refugees with active styles of resettlement tend to be more goaloriented with a generally more optimistic view of their migration experience. Such people may have been quick to leave their homelands and may have spent less time in countries of first asylum (Colic-Peisker and Tilbury, 2003). They tend to take a more long-term view of their circumstances, which includes being prepared to study and learn the language of their adopted 
country, even where there is a temporary loss of status. Colic-Peisker and Tilbury (2003) note that there are many obstacles to such an approach, not least "the pressure from refugee communities on individuals to accept available low-skilled jobs rather than opting for 'delayed gratification' by learning the language or updating their skills in the new environment" (p.70).

'Consumers' tend to live more in line with the expectations of their community group and place a higher value on acquiring material goods. "[I]n contrast with achievers, the job is not a sign of status and a source of identity, but simply a way of earning an income" (Colic-Peisker and Tilbury, 2003, p.70-71).

'Endurers' and 'victims' tend to be less optimistic about their future in their new country and consider their loss of family, property and social status as irreparable. They may have spent longer in transit and may be more isolated from both mainstream society and ethnic communities. Colic-Peisker and Tilbury (2003) note that issues most affecting 'endurers' include "isolation, problems with government bureaucracies, employment problems, and the language barrier" (p.75).

The fourth category, that of 'victims', refers to people who for whatever reason have largely given up hope of regaining control over their lives. There tends to be higher rates of sickness, depression and addictions amongst such groups. This mentality has been attributed to a sense of being disempowered during the flight and resettlement process and the nature of the support provided by welfare and resettlement services. This can leave members of former refugee communities "inert and unable to see themselves as agents of change" (Colic-Peisker and Tilbury, 2003, p.78). This categorisation overlooks the impact that labelling of the host society can have on former refugees. 


\section{Integration}

Integration is a somewhat disputed term with a range of interpretations and connotations. Many NGOs/community organisations find the term problematic and top-down (Castles et al., 2002; Li, 2003). There seems to be a gap in the vocabulary in terms of a word to describe a way of participating in and identifying with both the host and former refugee communities. Castles et al. (2002) question whether inclusion might be a better term; the extent to which newcomers are included in the various aspects of life in a new country could serve as a measure of well-being. Another alternative is the term participation, which would imply a more active role for the group concerned. This term is used increasingly by refugee advocacy groups. The vision statement for ChangeMakers Refugee Forum reads "New Zealanders from refugee backgrounds participating fully in New Zealand life" (ChangeMakers Refugee Forum website, n.d.).

\section{Definitions of integration}

As early as 1952, the United Nations Economic and Social Council defined integration as:

the gradual process by which new residents become active participants in the economic, social, civic, cultural and spiritual affairs of a new homeland. It is a dynamic process in which values are enriched through mutual acquaintance, accommodation and understanding (cited in Kage, 1962, p.165, from Canadian Council for Refugees (CCR) Report, 1998, p.6).

The Canadian Council for Refugees (1998) considers newcomers as integrated when they have become active participants in all dimensions of society. The 
Canadian Department of Citizenship and Immigration (2002) take a slightly different perspective on integration, seeing immigration as a two-way process "that encourages adjustments on the part of both newcomers and the receiving society" (Canadian Department of Citizenship and Immigration, 2002, in Li, 2003, p.318). This view is supported by Phillimore and Goodson (2008) who believe it essential to view integration as a two-way interchange, where adaptation takes place both within the host society and its institutions as well as with the newcomers. This implies that a thorough assessment of the integration process should also evaluate changes within the host community. In practice, however, there is no evaluation of how institutions adjust to accommodate newcomers, or how established communities welcome newcomers.

Berry (2008) places integration within a range of strategies adopted by newcomers: assimilation, integration, separation and marginalisation. In the case of assimilation, newcomers leave behind their cultural links to a large extent. In the case of integration, it is argued that there is more of a balance between original cultural links and the culture of the host country. Separation occurs when newcomers remain distant from the host country; if they are excluded, then this is marginalisation (Berry, 2008). Similarly, integration has been defined as "the ability to participate fully in economic, social, cultural and political activities, without having to relinquish one's own distinct ethnocultural identity and culture" (Valtonen, 2004, p.74).

In Canada, however, the term 'integration' has a strong conformist element and is used to describe the "desirable way in which newcomers should become members of the receiving society" (Lee, 2003, p.315). It implies a shift from culturally different ways of doing things to aligning with mainstream society. Thus what is deemed to be successful integration requires newcomers 
to adopt the English or French language, move away from enclaves and participate in the mainstream social and political life. This stream of immigration discourse sets out that ethnic enclaves are useful as an intermediary measure for helping immigrants to settle in Canada but they should be used only "as stepping stones to join mainstream society and not as a permanent anchor for cultural security" (Li, 2003, p.321).

In the case of Canada, immigration critics justify this approach by stating that it is a culture built around certain values - democracy and individual freedom - and if minority groups settling in the country do not adhere to the same values, Canada's traditions and values, its culture, will be undermined ( $\mathrm{Li}$, 2003). Li (2003) argues that by not challenging this conformist notion of integration, academic discourse of integration accepts it and uses similar measures. Daley (2007) echoes this in the UK when she says that integration as a policy concept "has been applied specifically to the participation and responsibilities of migrants and refugees and linked to the assimilation and control of immigration" (p.159).

In sum, although integration is a problematic term, Castles et al. (2002) argue that to replace it with a new term would not solve the problem, as it would again take on the meaning that powerful groups in society assign to it. They believe that it is by consulting with a broad range of groups and communities that ways can be found to bridge the differences in understanding and formulate fair policies.

\section{Indicators of integration}

One of the concerns in the literature around integration seems to be with trying to measure how people are integrating in their host countries. When looking at measuring integration and the extent to which people are 
integrated, Castles et al. (2002) note the need to consider who is defining integration and for what purposes. They caution that some communities may be perceived as integrating better than others, leading to "hierarchies of 'integratable' communities and individuals" (p.130). Phillimore and Goodson (2008) note the heavy reliance on the functional aspects of integration and the "tangible, quantifiable aspects of the process" (p.308). They point out that there is far less attention given to former refugees' own experiences of the process.

Some common indicators refer to crime levels, levels of inter-marriage, employment, residential concentration, income and language efficiency. However, there are problems in using these kinds of indicators as there may be other factors at play, such as discrimination in the wider community. Similarly, high crime rates could be related to frustrations around or responses to unemployment or housing conditions (Castles et al., 2002).

One measure of economic integration used in Canada requires immigrants "irrespective of the class of admission, to outperform or match the performance of native-born Canadians" (Li, 2003). Underlying this discourse is an unequal relationship between old-timers and newcomers, which allows those who are established in Canada to set the norms and conditions for new immigrants. The extent to which newcomers satisfy these norms and conditions then serves as a yardstick to measure how successful their integration has been (Li, 2003).

Ager and Strang (2004) propose a wide-ranging framework of integration indicators structured around four areas - markers and means (issues such as employment and health), social connections, facilitators (for example, language and cultural knowledge) and foundation (rights and citizenship). 
Moreover, they stress the need to take into account how these areas are interdependent when considering policy and practice implications and note that this is often not the case.

It can be argued that differences amongst refugee-background groups and the variety in the range of places where they settle render generic indicators ineffective. What could help in attempting to measure integration outcomes would be to evaluate programmes for specific groups, as opposed to looking at integration programmes aimed at a general range of refugee-background communities. Setting indicators in consultation with a range of community groups can also help to ensure that they are relevant and accurate (Castles et al., 2002). Castles et al. (2002) suggest that indicators could fall into a number of groups and span a range of quantitative and qualitative measures, such as education, training and employment, social integration, health, legal integration and political integration.

This thesis focuses on subjective indicators of integration by finding out more about how the participants feel they are resettling and experiencing their own environment. Some of the indicators, such as employment and language skills, may overlap with the more objective indicators of resettlement set out above. However, few studies appear to place former refugees' own experiences as their central focus.

\section{Factors assisting and impeding the process of resettlement or}

\section{integration}

Various research considers what can help or hinder former refugees during the process of resettlement or integration. The factors identified in both cases are largely similar so I will address them together. An understanding of the 
conditions that aid these processes is important as it can help to inform efficient policies. It is argued that the foremost issue influencing integration is that of official status and the privileges this entails, such as the right to work and entitlement to social housing and health care (Castles et al., 2002).

In a study of Iraqi former refugees settling in Canada, Michalski (2001) identified five factors assisting resettlement: learning English, familiarisation with Canadian customs and laws, independence or self-reliance, patience and stable employment. When asked the best thing so far in their resettlement experiences, participants said freedom, safety, improved quality of life, being able to find a job and "nothing" (Michalski, 2001, p.216).

It was found that the group as a whole relied mostly on their own resources and their informal networks of support and that "the available settlement services were for the most part inadequate and underutilized, thus rendering their integrative potential rather insignificant" (Michalski, 2001). This is supported by other authors (Castles et al., 2002; Korac, 2003) who identified the importance of the social, financial and human capital of families, with the emphasis less on external factors and more on former refugees' own resources. Korac (2003) refers to this as "the importance of human agency in the process of structuring and re-structuring social relations across space and time" (p.398).

Social interaction has also been identified as a contributing factor to successful integration, including "bonding within communities, bridging between communities and linking with services" (Daley, 2007, p.160). Ager and Strang (2008) echo the importance of social connections as part of the integration process, which they break down into three forms: "social bonds (with family and co-ethnic, co-national, co-religious or other forms of group), social 
bridges (with other communities) and social links (with the structures of the state)" (p.178).

The literature notes that despite research indicating the key importance of social connections in aiding integration, little research has been carried out in the area of social networks between former refugees and little attention has been brought to bear on the issue by those catering to former refugees' needs (Daley, 2007; Ager and Strang, 2008). The importance of social networks in the resettlement process will be further explored later in the section on social capital.

Kunz (1981) points to the cultural compatibility of the resettling refugees and the host country as a factor affecting resettlement outcomes. Similarly, he holds that multi-ethnic and pluralistic societies will tend to be receptive to newcomers and sees this as a factor that aids resettlement. A number of other factors have also been found to play a role: conditions of exit from countries of origin, categories of entrant, legal status, characteristics of entrants, characteristics of ethnic community and the conditions into which refugees are received in the host country (Castles et al., 2002).

Some common barriers to resettlement cited by authors (Neuwirth, 1989; Michalski, 2001) include language learning and accessing the labour market. Amongst those least satisfied with their lives in Canada, the main factors cited were being unable to find a job, their financial situations and differences in culture (Michalski, 2001). Resettling refugees felt that service providers could assist more in terms of finding employment and suitable accommodation as well as increasing financial assistance to meet their needs. Family reunification issues were also cited as contributing to ongoing stress in the lives of resettling refugees. How former refugees are received initially, racism 
and forced dependency have also been shown to impact negatively on the integration process (Phillimore and Goodson, 2008).

Korac's study (2003) of former refugee integration in Rome considers what happens when there is less state intervention in the integration process. She found that one of the potential advantages of this system was an increase in personal agency. Whereas other former refugees in Germany and Scandinavia may receive more material benefits, they may be more limited in terms of where they can travel to or the right to work. She found that not having a 'mediator' in the form of a representative of an NGO or government body mediating between former refugees and the host community meant that relationships were "spontaneous and personalised [and] those involved in such social interaction were usually perceived as individuals, rather than representatives of a culture or society, perceptions of which are often based on stereotyped and biased images" (Korac, 2003, p.417).

Korac (2003) found that the lack of formal assistance also meant that former refugees were forced to engage actively in reconstructing their lives, which prompted them to form networks not only amongst other former refugees in their community, but also within wider former refugee networks and the host community. This study sits is in contrast to most literature, however, which identifies the key importance of having support structures in place.

Most of the factors set out above are relevant to this thesis. The issue of official status does not apply to this study as the participants are all quota refugees and their rights and entitlements are clear cut from the time of their arrival. Although Korac's (2003) findings on social networks tie in closely with this study, her conclusions about the advantages of less state support do not. 


\section{Acculturation}

Given that my research adopts a psychological model and focuses on subjective resettlement experiences, I will consider the acculturation processes which may be at play during this early resettlement period. Redfield, Linton and Herskovits (1936) define acculturation as the "changes that take place as a result of continuous first-hand contact between individuals of differing cultural origins" (cited in Ward, 2001, p.100). This is relevant to my research as the majority of refugees move from non-Western traditional societies to Western industrialised ones (Lindgren and Lipson, 2004).

Berry $(1997,2008)$ identifies four possible outcomes to the acculturation process: assimilation (the homogenisation of cultures, with non-dominant cultures converging towards the dominant culture), integration (where there is some mutual change in both cultures, and both a sharing of common features as well as retaining distinctive features), separation (non-dominant groups reject the influence of the dominant culture) and marginalisation (where non-dominant cultures are destroyed and their members are left without a cultural nexus in which to live their lives). These definitions differ with regard to previous definitions encountered in the literature on resettlement and integration, again pointing to the diversity of meaning attributed to these terms.

Collie, Kindon, Liu and Podsiadlowski (2009) note that the preferred approach amongst migrant populations is typically integration which, in contrast to other top-down definitions, they describe as representing "a desire for both the maintenance of one's heritage culture and the adoption of aspects of the national culture" (p.2). Berry (2008) notes that the way in which 
acculturation processes play out is influenced by a number of conditions. The strategies of wider society influence how non-dominant groups acculturate.

Berry (2008) identifies four such strategies - multiculturalism (when cultural diversity is widely accepted), melting pot (when assimilation is sought by the dominant group), segregation (when it is imposed by the dominant group) and exclusion (when marginalisation is imposed by the dominant group). Collie et al. (2009) cite the example of Assyrian youth in Sweden in noting how pressure from the Assyrian community and the general public is brought to bear on how a different cultural group acts in everyday life. They find it difficult to integrate into society, as Swedes tend to treat them as foreigners despite the fact that they may have only ever lived in Sweden, and their own community group does not want to see them as acting 'too Swedish'. Acculturation stress is the term used for the stress associated with these experiences (Berry, 2008).

Collie et al. (2009) explore how the way in which people act is influenced by their social milieu and how people constantly position themselves depending on the situation and who they are talking to. They found that there is variation and "mindful identity negotiation" (Ting-Toomey in Collie et al., 2009, p.2) within a given situation, as people encounter different cultural norms and expectations in the course of their everyday lives.

In their research with Assyrian youth living in Wellington, Collie et al. (2009) found that two strategies were adopted: either to alternate between the two cultures, depending on the situation, or opting for a fuse or blend of both cultures. Thus, they oscillated "between expressing allegiance with the Assyrian and Kiwi cultures" (p.10). This oscillation could occur not only with different people with whom they interact, but also within a given situation. 
This provides a more detailed perspective on the acculturation strategies presented by Berry (2008) and how approaches and strategies vary based on the situation, audience and conversation.

Many aspects of the acculturation processes described here are relevant to this thesis. The culture of Burma and its distinct ethnic groups is distinctly different to mainstream NZ culture so the concept of negotiating between the two is relevant for the participants of the study. However, as the women are all relatively recent arrivals, some have limited contact with the wider NZ community.

\section{Participation}

Given the challenges for former refugees to establish themselves in a new country, it is important to consider processes that can assist their resettlement. Dunstan et al. (2004) observe that the NZ Government cites "participation in civic, community and social activities" (p.34) as one of the goals of New Zealand's Immigration Settlement Strategy. Goodkind and Foster-Fishman (2002) believe that the integration process can be aided by "really becoming part of their new community - that is actively participating in that community" (p.391).

Similarly, New Zealand's Strategic Social Policy Group (2008) notes the importance of participation in civic and political affairs in bringing about a sense of social connectedness and observes that little has been reported in the area. It is recognised that former refugees receive much support from members of their own ethnic group, and such support networks are very important. However, the extent to which former refugees participate in their wider communities is less well known. Such participation "is essential for the 
development of non-native language abilities and the acquisition of skills and knowledge to succeed in a new country" (Goodkind and Foster-Fishman, 2002, p.391). Lindgren and Lipson (2004) consider community participation as key to improving the health and well-being of communities.

The importance of participation has long been recognised in international development theory and is contrasted with top-down initiatives, driven by experts generally brought in from outside the community. Development theory distinguishes between active involvement and token 'box-ticking', which is based more on consultation than truly community-driven actions. Such participation by former refugees in institutions and programmes that affect them is gaining increasing traction, exemplified in the former refugeeled organisation ChangeMakers Refugee Forum.

Lindgren and Lipson (2004) note that participation is both a process and an outcome, with a range of reported benefits including empowering communities and developing the skills to work collectively. They also note, however, that little research worldwide has focused on refugee-background communities and the internal dynamics that serve to empower or restrict individual members.

\section{Becoming social actors}

Citizen participation is defined by Florin and Wandersman (1990) as "a process in which individuals take part in decision-making in the institutions, programs and environments that affect them" (p.43). Organising around issues such as identity has been common since the 1960s; Miller, Rein and Levitt (1995) cite the example of gay and lesbian communities mobilising around AIDS activism. They note that such groups rely less on geographical location and identity becomes the axis for mobilisation. In responding to 
common needs, identity groups may bring together people from a range of backgrounds. Although the process is driven at the local community level it may be useful to link local actions into wider strategies, as without engaging the state, localized community actions may remain marginalized (Korten, 1995). Moreover, it is difficult for people's movements to achieve long-term change without engaging with wider political processes (Mayo and Craig, 1995).

Participation is said to be beneficial not only for community relations and social fabric, but also for feelings of efficacy and personal achievement (Florin and Wandersman, 1990). Participation can serve to bring multi-ethnic communities together, thus easing ethnic/racial tensions (Goodkind and Foster-Fishman, 2002). O'Neill and Spybey (2003) note that community development and capacity-building with and for refugees can have important consequences for "identity, shared traditions and a feeling of security and belonging" (p.10).

\section{Restoring a sense of agency}

Essed, Frerks and Schrijvers (2005) refer to the fact that agency centralizes people and conceptualizes them as social actors. Given the upheaval and trauma that refugees may have likely experienced in their lives and the differences in language and culture they encounter, developing a sense of control as soon as possible can be central to a sense of well-being.

Participation can be a valuable learning process by providing an opportunity to acquire "the language skills, cultural knowledge, and connections [refugees] need to access resources and adjust to a new, unknown environment" (Goodkind and Foster-Fishman, 2002, p.391). Similarly, Rappaport (1987) suggests that participation is a mechanism by which 
"people, organizations, and communities gain mastery over their affairs" (p.122). Participation can empower by providing individuals with an opportunity to contribute to the community and for their knowledge to be valued by others. This is particularly the case if the result of that participation is "communities that gain power, resources and decision-making influence" (Goodkind and Foster-Fishman, 2002, p.391).

In their study of the Hmong refugee community in the United States, Goodkind and Foster-Fishman (2002) note that factors such as length of time spent in refugee camps can influence the extent to which people feel they have control over their lives. They also raise the question of how participation fits into the cultural context of the Hmong people. As a collective-oriented culture, participation within the Hmong community was assumed to be a fundamental social norm; however given that Hmong lived mostly in homogenous groups the authors raised the question of how participation in a broader multiethnic group would be conceptualised (Goodkind and FosterFishman, 2002).

The study identified several difficulties for the Hmong people in participating, namely language ability, awareness of participation opportunities and lack of time, as many of the women interviewed had children to look after and could not participate in activities. How former refugees were received in their communities was also identified as a key factor in determining their level of participation. This includes the degree to which they are invited to participate as well as the way in which meetings are organised, for example whether they are run in ways that are contrary to their cultural beliefs (Goodkind and Foster-Fishman, 2002), which in turn highlighted the need for support and a culturally appropriate approach in promoting the participation of ethnic communities. 
Thus, there are both concrete individual barriers to participation, such as issues of time and language, as well as contextual factors, such as invitations to participate, genuine opportunities to be part of decision-making processes and general reception by the wider community.

\section{Active participants}

Westoby (2008) stresses the importance of participation for 'refugee recovery', where former refugees are supported in rebuilding their physical, economic, social and moral worlds. He argues that recovery is primarily a social process, which sits in contrast to a therapeutic approach. "Despite the disruption to cultural, community and political resources" (p.491) resulting from forced migration, it is essential to consider the resources that former refugees have available to them.

Daley (2007) and Westoby (2008) believe that Western societies are dominated by a therapeutic culture, which assumes that once damaged, people can never be put quite right. This assumed vulnerability, in turn, justifies a service delivery culture. The concept of "agency forms a sharp contrast to the more established approaches where refugees are pictured as passive victims of violence and disaster, or as mere recipients of aid" (Essed et al., 2005, p.2).

Daley (2007) states that little research has been carried out in the field of community level interaction between groups from different backgrounds. Funding does not stretch to addressing community relation issues so the preferred approach has been to focus on basic needs (Goodkind and FosterFishman, 2002; Westoby and Ingamells, 2009). Moreover, refugee populations in host countries learn that identifying themselves as vulnerable provides access to resources (Westoby and Ingamells, 2009). 
All aspects of the literature on participation are relevant to this thesis as participation has the potential to contribute to feelings of well-being as well as assist in the concrete tasks of becoming settled in a new place. Participation can also help with cultural maintenance, which is often an issue with newcomers from different cultural backgrounds.

\section{Social capital as it relates to refugees}

The networks that refugees form on arrival, often within their own communities, have been shown to provide a source of support and information which plays an important role in resettlement. This section looks at the literature on social capital and how it has been used in refugee studies to analyse the resettlement process.

Social capital is defined in different ways but essentially refers to building networks that can be used for mutual benefit. Bourdieu (1985) defines social capital as a "durable social network that enables individuals to gain access to resources" (cited in Lamba and Krahn, 2003, p.338).

An important aspect of social capital is the networks on which it rests. Networks can be horizontal and vertical. When people gather together, form a network and establish trust and common goals of social change, they create horizontal networks that can effect social change vertically (Putnam, 1995). A good stock of social capital can have multiple benefits for communities. In addition to fostering norms of reciprocity and social trust, they can "facilitate coordination and communication, amplify reputations, and thus allow dilemmas of collective action to be resolved" (Putnam, 1995, p.67). 


\section{Benefits of social capital}

Refugees are often considered as having "left behind or lost the personal capacity and support systems required for self-sufficiency" (Lamba and Krahn, 2003, p.336). Social capital in the form of social support networks is one of the few resources available to former refugees, as opposed to other migrants who may have considerable financial and human capital, such as education, recognised in their new country (Lamba and Krahn, 2003).

In research conducted amongst refugees in Canada to assess the extent to which they rely on their social networks, Lamba and Krahn (2003) asked a series of questions around whom they would turn to in the case of problems around money, health, job and personal issues. They found that all four issues were addressed by relying on people in their family and community, demonstrating the extent to which they utilized their social networks. More specifically, in the case of financial and personal issues, refugees tended to turn to family members, whereas health and employment issues they discussed with people in their wider network (Lamba and Krahn, 2003). Their stocks of social capital were seen as key to the resilience shown by most former refugees.

The study concluded by noting the inappropriateness of classifying former refugees as passive given how "centrally involved [they are] in their own resettlement, taking advantage of all the social networks they can maintain, build and rebuild" (Lamba and Krahn, 2003, p.356).

\section{Social capital as both enabling and constraining}

Lamba's study (2002) considers how social capital can both be an enabling and constraining factor in the resettlement process. She works from a 
perspective of structuration theory, which views networks as being comprised of both resources and rules. As such, they "may enable certain outcomes $[\ldots]$ or conversely $[\ldots]$ engender rules constraining refugees in various aspects of their resettlement" (p.4). Taking on the identity of refugee is already a constraining factor, as their identities are often reduced to a common denominator, thereby submerging distinctive life histories, reasons for escape and personal goals and needs (Lamba, 2002).

While family and ethnic community ties can assist in many ways, such as finding employment, helping out financially and becoming familiar with service provision, they may also act as constraints. For example, "[t]he ethnic enclave may exploit refugees and discourage upward mobility, particularly for female refugees who have few marketable skills" (Lamba, 2002, p.65). Other constraints might include internal tensions within communities and a lack of capacity for informational and economic support. As such, a less dense network may promote greater independence and freedom of movement (Lamba, 2002).

Lamba and Krahn (2003) recommend that service providers be mindful of the ways in which different genders and age groups utilize their social networks and develop their services accordingly. For example, women may find it more difficult to access further education and higher level jobs if embedded in a patriarchal family structure.

The literature on social capital is highly relevant to this thesis, given the importance of former refugees' social networks in the resettlement process. A central aspect of this study was to find out what role they played in Burmese women's resettlement in Wellington. 


\section{Human rights-based approach to resettlement}

There is a growing awareness that policy and service delivery in the refugee sector should be underpinned by a human rights-based approach as opposed to a welfare approach (Refugee Health and Well-being Action Plan Intersectoral Working Group, 2006). CARE (n.d.) states that:

a rights-based approach deliberately focuses on people achieving the minimum conditions for living with dignity (i.e. achieving their human rights). It does so by exposing the roots of vulnerability and marginalisation and expanding their range of responses. It empowers people to claim and exercise their rights and responsibilities (p.1).

A number of principles underpin a rights-based approach: people's right to participate in decision-making processes affecting their lives, seeking to understand and address the root causes of poverty and suffering, a refusal to tolerate discrimination and inequities that impede development and holding everyone accountable for helping to protect and fulfil human rights (CARE, n.d.). Similarly, NZAID (2008) states that a human rights-based approach should be underpinned by the principles of "participation, accountability, non-discrimination, empowerment and explicit linkages to the international human rights framework" (p.17).

The human rights-based approach to policy making is relatively new, and there is still uncertainty around what it is and what it might require (Rother, 2008). Implementing a human rights-based approach will require a shift across all operations and practices and calls for a long-term approach and progressive realisation. By engaging more holistically with those involved, a rights-based approach has the potential to affect wider- and longer-ranging 
changes. "[T]he scope of the needs-based approach is much narrower and therefore cannot attain the same results as the rights-based approach in terms of the sustainability of outcome" (Rother, 2008, p.13). A human rights-based approach also challenges existing power relations and has the potential to create a more equal footing between host and refugee.

\section{Summary}

Resettlement and integration outcomes are influenced by a range of factors, including former refugees' own resources, such as their social capital, and how quickly they learn the local language and find employment. The term integration has a conformist element in some countries, placing the onus on newcomers to align with mainstream society. Multi-cultural societies where diversity is widely accepted make resettlement easier. Nevertheless, however open the host society, recent arrivals with a different cultural background often find themselves negotiating between two cultures. Former refugees who have been resettled recently are generally active in their own ethnic groups and networks. This activity is beneficial for community relations, builds a sense of security and belonging and provides opportunities for cultural maintenance. Participation in the wider community is less common due to issues of such as language, invitations to participate and general reception by the host community.

Whereas many studies focus on what former refugees need to assist them with their resettlement, this research looks also at the skills and resources that they already have available with a view to finding ways of building on them. By focussing on women and their first-hand experiences of resettlement, this study generates information about their specific concerns and the roles the women play within their families and communities. 


\section{CHAPTER FOUR - METHODOLOGY}

This chapter sets out how I chose to generate the information for my research and the reasons for the approach I adopted. I will discuss why photovoice was a useful way of engaging with the ten refugee-background women who participated in the study, and how this method supported the semi-structured interviews and focus group.

\section{Qualitative research}

The aim of my research has been to understand how ten Burmese women are experiencing their resettlement in Wellington and what things have helped them in settling here. This aim has involved understanding the meaning that the women attach to different aspects of their lives and understanding what is essential to their well-being as they settle in a new place. A qualitative approach allowed me to draw that meaning from my discussions with the participants, as it helped to understand "how people interpret their experiences, how they construct their worlds, and what meaning they attribute to their experiences" (Merriam, 2009, p.5). A quantitative approach would not have produced the meaning and depth of understanding that I was looking for in my research. "[Q]ualitative research is about understanding social meaning while quantitative research focuses on patterns and predictability" (Hesse-Biber and Leavy, 2006, p.7).

Qualitative research tends to rely on an inductive approach, where the theory arises from the data, as opposed to the deductive approach that tends to characterise quantitative research, where the researcher sets out to prove or disprove a theory. My research aims were exploratory; I wanted to discover how the women were experiencing their resettlement. An inductive approach 
allowed me to "use the empirical data to develop larger theories about social life that emerge from the people who experience the aspect of social reality being studied" (Hesse-Biber and Leavy, 2006, p.9). However, as I will explain further when I come to the data analysis section, there was an aspect of deductive reasoning in the analysis of my data, based on the themes proposed by the women during the focus group.

\section{Feminist participatory research}

A feminist perspective on research resonated strongly with me through my previous study and shaped the focus of my research. While the concept of feminist research can be used to refer to a large number of methodologies and methods, one of its central tenets is that "traditional 'rules' of research have embedded within them an unconscious patriarchal bias" (O'Leary, 2010, p.126). Feminist research therefore sets out to apply feminist principles to each stage of the research process.

A feminist perspective privileges women's subjective experiences and states that research or projects should be carried out by and with women (as opposed to 'on' them) in ways that "empower people, honour women's intelligence, and value knowledge grounded in experience" (Wang, n.d.). It differs from 'objective' research in that its methods are also part of its findings (Wang and Burris, 1994) and because it strives to be an open, inclusive and dynamic process. It recognises that research is a political process, rather than hiding behind disinterested scholarship or objectivity. An essential aspect of feminist research is the importance of viewing research participants not only as "providers of information but as human agents with potential to exert social change" (Madriz, 2000, p.839). 
Feminist research recognises that traditional positivistic methods of research are unsuitable for exploring women's everyday lives and advocates a more integrative and experiential approach. It blurs the boundaries between thought and feeling, observed and observer and objective and subjective research (Madriz, 2000). "Rather than seeing research as a linear, one-way process, feminist researchers emphasise the contradictions and complexities encountered in their work" (Madriz, 2000, p.838).

Given participants' "active involvement in the various processes and phases of [participatory research]" (Maguire, 1996, p.114), it is an endeavour that takes time. It relies on meaningful and reciprocal relationships, which take time to form. Feminist participatory research is mindful of the power dynamics at play within the research process and seeks to redistribute power by sharing access to resources and including participants in structures, problem-posing and decision-making processes (Maguire, 1987).

\section{Methods of research}

Table 4.1 provides an overview of the activities I carried out in generating my data and when each activity took place.

Table 4.1: Overview of data generation activities - January-March 2011

\begin{tabular}{|c|c|c|c|c|c|}
\hline & $\begin{array}{l}\text { Introductory } \\
\text { session with } \\
\text { participants } \\
\text { and local } \\
\text { photographer }\end{array}$ & $\begin{array}{l}\text { Two weeks } \\
\text { for women } \\
\text { to take } \\
\text { photos }\end{array}$ & $\begin{array}{l}\text { Cameras collected } \\
\text { and photos printed } \\
\text { in preparation for } \\
\text { interviews }\end{array}$ & $\begin{array}{l}\text { Individual } \\
\text { interviews }\end{array}$ & $\begin{array}{l}\text { Focus } \\
\text { group }\end{array}$ \\
\hline Jan 2011 & $x$ & $x$ & & & \\
\hline Feb 2011 & & & $x$ & $x$ & \\
\hline Mar 2011 & & & & $x$ & $x$ \\
\hline
\end{tabular}




\section{Photovoice}

Photovoice is a participatory research method whereby participants are invited to answer a research question by taking photos and explaining them to the researcher. This method was developed initially by Wang and Burris to enable Chinese village women to document their health and work realities (Wang, 1999). Photovoice is a useful method for eliciting perspectives on daily life, and through the decoding of images, allows the researcher to "ground the analysis in subjective perspectives" (Kolb, 2008, p.1). The photos can also give rise to discussion around possible, desired futures and provide a platform for participants to "begin a cognitive process of developing and expressing their ideas, feelings, and concerns" (Kolb, 20008, p.6).

The photovoice process is often longer than other forms of social research, such as a single interview, as it requires participants to take photos over a period of weeks or months. It is important to have a detailed discussion around what is involved at the outset, which includes aspects such as the aim of the study, the subject matter for the photos, how the photos will be incorporated into the study and what will become of them afterwards (Kolb, 2008). Some technical training around the use of cameras is an important part of the preparation, as well as a discussion of different techniques such as close-ups versus photos taken from a distance and how the angle can affect a photo's impact.

During the photo-taking phase, the researcher moves to the background "as participants use cameras to capture their ideas and determine relevant issues from their perspectives" (Kolb, 2008, p.7). As participants reflect on the research questions and go about taking photos, they may discuss the process with family and friends. Kolb (2008) notes that they become researchers of 
their own culture, lives and neighbourhoods and "take on a more active role in their social environment" (p.8).

When it comes to discussing the photos during the interview, the participants are in the role of expert as they explain the photos and the story and intention behind them. A key aspect of photovoice is that the lesson does not reside in its "physical structure but rather in how people interpret the image in question" (Wang, 1999, p.186). After the participant has shared his/her story around the photograph, the researcher can then ask questions to supplement the information.

The Flint Photovoice project (Wang and Redwood-Jones, 2001) focussed on improving community health outcomes and sought to draw out problems, strengths and possible solutions to take to policy-makers. Facilitators in the Flint Photovoice project explored the photos with participants using the mnemonic SHOWeD: What do you See here? What is really Happening? How does this relate to Our lives? Why does this problem or strength exist? What can we Do about it? My research sought to understand women's resettlement experiences and although I used parts of Wang and Redwood-Jones' mnemonic (2001) in my discussion of the photos with the women, I found that I did not need the full level of detail it entails.

Photovoice enables people to record their lives from their own perspectives, providing people with the opportunity to document and discuss aspects of their lives that they take pride in or find challenging, and identify social issues with a view to influencing policy (McIntyre, 2008). Influencing policy lay outside the scope of this project and was not its focus. However, the first two of these issues were central to this research project, as participants were 
invited to record aspects of their lives that were significant for them for discussion during the interviews and focus group.

My personal interest in photography was one of the reasons I was drawn to this method of inquiry. I have always enjoyed taking photos myself and looking at other peoples' photos and, as I learned more about this method, I believed that it would provide a rich learning experience and the kinds of insights I hoped to gain from my empirical research. I also appreciated that it provides a means for participants to be more closely engaged in the process by taking photos around a specific theme or set of questions, and then guiding me as the researcher through an area in which they are experts.

Another outcome I was excited about was the possibility of holding an exhibition of the women's photos to share the research with the wider community. I find there is a lot of misinformation circulating in NZ society around refugee issues and thought that by facilitating a way for the participants to share information about themselves and their experiences, this could in a small way help to create greater awareness and understanding. As noted by Wang (1999), photovoice is rooted in the belief that "people ought to participate in creating and defining those very images that shape the public discourse" (p.191). The exhibition of the women's photos has not yet taken place as I relocated to another city six months before completion of my thesis and travel was difficult because I was pregnant. I hope to organise the exhibition next year while on maternity leave.

\section{Selection of participants}

In recruiting participants I sought Annie's help. Annie is Burmese and has been living in NZ for over twenty years; she has close links with the Burmese community both in a personal capacity and through her work with 
ChangeMakers Refugee Forum. I opted to work with ten participants as I thought this would provide a range of experiences and ideas, yet allow for indepth discussion during the focus group.

I met with Annie a number of times to discuss the project and explain what I hoped to do. Her main criteria for selecting participants were based on who might be interested in taking part and who might have the time. She thought it would be easier if all the women lived in the same area. She also considered the women's level of English - who might be able to talk to me in English without need for an interpreter and who might benefit from practising their English with some of my simpler questions.

Annie spoke with women living in Cannon's Creek and Waitangirua, two suburbs about half an hour north of Wellington city. The women were all keen to know what kind of questions I wanted to ask before committing to participate. I provided Annie with information sheets about the research and the list of questions I wanted to ask. A number of the women she approached initially were busy with seasonal work or looking after children and unable to participate.

\section{Interview process}

\section{1) Introductory session}

At an introductory session attended by all the women intending to participate in the research, plus a number of children, husbands and other Burmese women, we all introduced ourselves and the women each stated which ethnic group they belonged to. I spoke about myself and my life and how I came to be in NZ, my motivation for wanting to conduct the research and my reasons for choosing the topic I had chosen. Some of the women had questions about 
the research and one woman in particular had a lot of questions. Annie explained later to me that she had not had the opportunity to speak with her alone before the session. Some of the questions Annie answered directly and some were translated for me to respond.

We discussed how the photos could be used later on, for example as part of an exhibition to be shown locally. The women seemed enthusiastic about this idea as a way of sharing their culture with the wider community. One of the women referred to an exhibition she had seen about another country, and how she thought that it was a great way to tell others about Burma and Burmese culture. We also spent a while talking about what kinds of things they might capture in the photos.

For the second part of the session I invited a local Wellington photographer, Kirsty Woods, to explain some of the techniques the women might like to think about when taking the photos. Kirsty had drawn out diagrams about perspective and balance and other photography tips on A3 sheets, as an aid for talking about the elements of a good photograph. She had also taken photos with a disposable camera so that she could demonstrate these tips with her own photos, taking into account the drawbacks of using a basic camera. Each of the women was then given a disposable camera and I arranged to collect them from the house of one of the women two weeks later. I also passed around a sheet with possible dates and times and asked the women to fill in when would suit best for me to meet with each of them individually.

I had very positive feedback on Kirsty's session through Annie, who said that the women had really enjoyed learning something new. They were also excited about the prospect of taking photos, as it was usually their husbands 
or children who held the camera. Some of them had never taken photos before.

\section{2) Interviews}

The women had two weeks following the introductory session to take the photos. I then collected the cameras and developed the films, making two sets of the photos (one set for the women and one for me) as well as a CD of the photos that I kept myself. A few days later I started the interviews. They took place at each of the women's homes, mainly for practical reasons but also following Annie's guidance. The interviews were semi-structured and recorded with a tape recorder.

Annie interpreted for me in eight of the ten interviews and accompanied me for nine of them. Sometimes there were children present and on a few occasions, the women's husbands were there for part of the interview. Aside from greeting me and exchanging a few words with Annie, they did not say anything.

I generally went through the questions in order but sometimes the order changed if the conversation naturally took a different turn. I gave the women their set of photos at the beginning of the interview and I discussed the photos with some of the women at that time. Otherwise we came back to them at the end of the interview and discussed them then. I found it difficult to refer to the photos during the interview itself, unless there was something in the photos that related directly to what the women were saying. On each occasion, I was amazed by how a simple explanation of the thought process behind the photos brought them to life and provided additional insights into the women's lives. We often visited the women's gardens after the interview 
and on a few occasions Annie and I were given vegetables to take home with us.

At the end of each interview I explained that I would invite them to discuss those photos with the larger group and that together we would attempt to draw out themes that the women felt captured significant aspects of their lives.

\section{3) Focus group}

After completing the interviews I organised for the women to come to my home, both to hold the focus group and as an opportunity to return their hospitality and prepare food for them. We met for 3 hours on a Sunday afternoon, from 3-6pm, and one of the women had a big car that could transport all the women at the same time. Her husband brought everyone to my house and then returned to collect them later on. One of the women with a small baby brought the baby with her. The other women with children arranged to have them looked after by friends. In preparation for the focus group, I asked the women to bring their set of photos and select up to five of them that they felt were particularly significant to their lives in NZ.

The focus group was semi-structured in that it did not follow a series of questions set out in advance but I had a rough outline that I had discussed in advance with the women. I opened with some general comments about what I hoped we would accomplish that day. I explained that I had completed the individual interviews and would appreciate their guidance in identifying key themes under which to structure the findings. Using the photos that had been selected by the group, the women began identifying headings under which they could be grouped. They wrote these headings on PostIt notes in English and in Burmese so that everyone could follow the process. 
The women guided the discussion, with some facilitation from Annie, and most of the women contributed headings, or arrived at similar headings to others. Thus the focus group enabled 'horizontal interaction' amongst the participants, as opposed to 'vertical interaction', between the researcher and participants (Madriz, 2000, p.840). This has the advantage of flattening the power dynamics between researcher and researched.

I was unsure how freely the women would want to talk about their photos and experiences and thought that some of the women might be more likely to participate than others. I found that some of the shyer or less literate members of the group were happy to contribute when they saw the relevance of their photos to the theme or heading under discussion. As it turned out some of the less vocal women had taken photos or photos that covered a wide range of topics, which gave them confidence in contributing to the discussion.

\section{Method of analysis}

During the three weeks that the interviews took place, I transcribed the tapes and reviewed the notes. I then analysed them using both inductive and deductive reasoning, where I searched for themes that emerged from the notes, but also looked for "deductive confirmation" (O'Leary, 2010, p.262) of the themes identified by the women during the focus group. The women had suggested the following nine themes:

- Unity and cultural maintenance

- Employment

- Transportation/going places

- Education and health 
- Interest in nature and the environment

- Good things to learn from New Zealand

- Women's experience and the role they play

- Connecting with other cultures

- Importance of learning the language

I collated quotes from the transcripts relating to each of the themes and from there I identified sub-themes and arranged the quotes under these subthemes. With the help of Visio, a programme for drawing charts, I mapped out each theme with its corresponding sub-themes; in some cases these were broken down into further sub-themes. I also noted down how often each theme and sub-theme appeared in the interviews. This allowed me to see that 'better opportunities for children', for example, was mentioned twelve times during the interviews, whereas 'difficulty with public transport on arrival', was mentioned only once. One of the themes, "women's experience and the important role they play", did not feature in the photos or the interviews and I decided to leave it out.

On reflection, and after discussion with my supervisor, I decided to collapse some of the themes that fitted together. I decided that 'children's education and health' and 'interest in nature and environment' could be grouped under the theme of 'good things to learn from New Zealand'. I then broadened this theme to include the less positive aspects of 'transportation/going places' and rephrased it as 'opportunities and constraints of life in New Zealand'.

To preserve the anonymity of the participants in the analysis chapters, I selected NZ flowers and trees to represent the women's names. I felt that this would reflect the interest in nature and gardening that came across so strongly in my conversations with them. 


\section{Ethical considerations}

The Victoria University Human Ethics Committee approved my ethics application, which included the study design, information sheets and consent forms (see Appendices A, B, C and D). Before each interview and the focus group each participant was asked to sign the consent form, which Annie explained. I emphasised that the data collected during the interviews and focus group would be accessed only by me and my research supervisors. I asked permission to record each interview and explained that I would use it later to complement my own notes. I felt that it was important to be clear about what exactly would become of the data, as the Department of Labour (2010, p.2) notes that:

Some refugees may associate the recording of personal information with suspicion because of past experiences in their home country. As such, it is important to ensure refugee clients understand why you are recording information, where it will be stored and who it will be shared with.

Although the research did not focus on participants' previous experiences and possible trauma in coming to NZ or time spent in refugee camps, I was aware that sensitive issues might arise in the course of the discussion. At the beginning of each interview, I asked participants to respond only to questions when they felt comfortable doing so. Should the need have arisen, I would have offered to put participants in contact with Refugees as Survivors, an organisation that provides services to refugees entering and resettling in NZ to assist with healing from experiences of trauma or torture. One of the participants did refer to events which she described as distressing but said that it was helpful to have the opportunity to discuss them. I think that 
Annie's presence helped to provide an environment where participants felt secure; I was also able to follow her lead in terms of pursuing a line of questioning or moving to another topic.

\section{Reflexivity}

Embedded in feminist participatory research is the concept that any research that we conduct is influenced by who we are, our background and experiences. Throughout the research process it is important to bear in mind that "what a person sees and understands is always shaped by what one already knows and can articulate" (DeVault and Gross, 2007, p.178). Being mindful of who I am and what I am bringing to the research process in terms of experience and worldview is important in terms of identifying the strengths and limitations of my research. It can help in identifying what I may be overlooking because it is unfamiliar or what I may over-emphasise simply because it is what I know.

Davies (2007) notes that it is important to continue to reflect on our role, how we are impacting on the different situations in which we find ourselves and how we may be perceived by participants. When considering my role in the research process, I thought about potential power dynamics. I was a little uncomfortable with the idea of coming to 'research' women's lives, and spent time reflecting on how I would feel were I in their position.

In my early discussions with Annie, I emphasised my wish to speak only with women who were keen to talk about their experiences. In my initial meeting with the potential participants, I stressed that although I had a set of questions that would guide our discussion, they were only guidelines and they should only share as much information as they wanted. The women had 
expressed to Annie that they would like her to be present for the interviews and she was with me for each interview except one. A number of the women also expressed the desire to help me with my studies if they could, so that I could get my Masters in Development Studies. I liked this framing of my research as it clearly placed me in a position of learning from them and receiving their assistance with my research.

Having emigrated to NZ from Ireland three years previously, I shared the experience of arriving as a foreigner. I shared my experiences of my arrival and what I had been doing since then with the participants at the initial meeting. I also pointed out where I thought that our experience differed, in that I had left my home country because I wanted to come and experience life in NZ before probably returning closer to home. I noted that coming to another English-speaking country where my qualifications and work experience are recognised allowed me to resettle relatively easily. As the women talked about their experiences in more depth we did find more common ground, such as experiences of being in a cross-cultural relationship or living far away from family.

\section{Strengths and limitations of the study}

Annie's strong links with the Burmese community helped to create a relationship of trust between myself and the participants. Several of the women who participated commented at the time of the interview that they appreciated the opportunity to discuss their experiences. Two of the women said that the conversation had brought up memories that they had not talked about in a long time and that this had been beneficial for them. 
My research focussed on a small number of women living in the same neighbourhood of Wellington. The study does not allow for generalisation to an entire population, but rather generates rich data that can be analysed to seek insights into the research questions. There may also be local factors that shaped the experiences of the women living in this neighbourhood so that they are not representative of the wider Burmese refugee community. This said, many of my findings echo and reinforce findings for former refugees elsewhere and so can form the basis for wider claims and recommendations.

From the outset I have been aware of a conflict between doing a thesis as a necessary part of my Master's degree and wanting to conduct research with a community that could be of some benefit. When discussing the potential research with members of the Burmese community, I felt there was an expectation for me to say what it was I wanted to research. Looking back now, I may not have known how to guide the conversation to show that I was interested in whatever interested them. I finally decided upon the general theme of refugee resettlement with a range of questions that would hopefully allow participants to choose aspects that interested them for elaboration. I was prepared also that other themes might arise that I had not envisaged, so was ready to be flexible in terms of the direction the conversations might take.

The use of photovoice meant that participants produced the photos themselves and thus participated in the research in a deeper way than with some other research methods. Moreover, participants had more of an opportunity to introduce new themes and issues into the interview and focus group through their photos than with some other forms of social research (Kolb, 2008). Collie et al. (2009) note that participatory research promotes a better understanding of the issues amongst the participants and thus "strengthens the capacity of participants to face their future" (Collie et al., 
2009, p.2). During the focus group discussion of their photos, the participants together identified themes that are key to their lives in NZ, which provided an opportunity for greater understanding of common issues.

Eight of the ten interviews, and most of the focus group discussion, were conducted in Burmese and interpreted for me by Annie. This process shaped how the women answered the questions and how the information was communicated to me. I may have received different answers had I been able to speak to the women in their first language directly. Moreover, the interpretation was informed but not guided by the ethics of professional interpretation, in that the interpretation was not word for word but rather Annie's rephrasing of what had been said. I believe that these limitations were offset by the fact that the women were free to express themselves in Burmese, a language they spoke well, even if it was not their first language (many spoke their own ethnic language as a first language and Burmese as a second language). The women were also comfortable in Annie's presence, as demonstrated by the fact that they requested she attend the interviews.

I was aware of a cultural divide in terms of values, such as those associated with individualist as opposed to collectivist societies. Given my limited experience of more collectivist cultures, I may not have gained as complete an insight into their experiences as someone from a more similar culture. This may have affected how I represented the women's resettlement experiences and the accuracy of my findings. The participants seemed particularly aware of these cultural differences however, and went to great lengths to explain their cultural values to me. I think that because of the cultural divide they were especially keen to convey to me the perceived benefits of some of their values. 


\section{CHAPTER FIVE - ‘UNITY’ AND CULTURAL}

\section{MAINTENANCE}

Unity and cultural maintenance was by far the most popular theme identified by the women during the focus group, and we spent a lot of time discussing issues related to culture, family and support networks during the interviews. Along with the theme of children's education and health, it was the only theme to be proposed by two women independently. The other wording proposed was 'maintenance of culture and customs' but I opted for the wording that included 'unity' because I felt it important to capture the support provided by the community. However, I have placed the word 'unity' in inverted commas to reflect the at times fragile unity that exists between the different ethnic groups.

The photos grouped under this theme covered a range of topics, from weekly get-togethers with the community at church service, to daily family life, to concerns about language and culture not being passed on to children. A sense of pride, optimism and loss are prominent: a strong sense of pride in their culture and the feeling that they have something to contribute to NZ sits alongside their concern about family left behind and their own feelings of cultural uprootedness in their new surroundings.

\section{Community support networks}

Two main issues emerged in terms of community support - the reassurance and sense of comfort that comes from knowing that help is there when needed and the women's enhanced well-being that comes from regular social contact. 
Most of the women referred regularly to their Burmese friends and neighbours. Talking about how she finds her new life in NZ, Pohutukawa said simply "[w]e have Chin community, we have friends". Similarly, Rewarewa noted that when she first arrived, there were not many other Burmese living close by, but "[t]here's a Kachin family just across the road and other Burmese neighbours too. So I'm happy now." Kowhai remembered being welcomed by the Burmese community living in Porirua:

When we came first we didn't know how to eat bread all the time. We wanted to eat rice, Burmese cooking. So when we came to Porirua, some Burmese friends cooked our dishes, it was lovely, yes. [...] When we first came we were so lonely, scared, feeling homesick. They welcomed us warmly and that was a great time, yes... I loved that.

Hebe was very upbeat about her life in NZ, which she attributed in part to her neighbours. "I have good neighbours so we're happy here." In response to the question of whether she's homesick, she said: "No not missing home, everything is here. Husband here, son here, what else do we need? Sometimes it's very busy so we don't have time to remember or think about home." She enjoyed the proximity of her Burmese neighbours:

Sometimes when there's nothing to do I walk past and visit my friends next door. There are another two [Burmese] families not very far. It's good to have that connection. Sometimes we sit and watch TV together. Sometimes they come over here and look at the garden, we look at the garden together. 
Clematis was particularly pleased to find someone in NZ from her own ethnic group. This may have been a combination of ease of communication, since Clematis did not speak much Burmese on arrival, as well as an increased sense of friendship in coming from the same area and ethnic group. "Once we knew he was here, our eyes lit up and we were happy that we knew there was somebody who we could ask for help."

Rata talked about the support she gets from the community, which was both emotional and practical. "In the neighbourhood we have lots of Kachin and other friends and they all support, helpful, like a community. They told us where the shops are, if we want to go shopping, or if there's a sale on they let us know or take us with them."

Weekly church services and religious celebrations during the year are an opportunity for the women to come together and enjoy each other's company. Kowhai spoke about the enjoyment she derives from doing things together with the community. "On Sunday we go to church and we worship together, our community. That's lovely. During church and before worship, we talk to each other." When asked what kinds of things she enjoyed and looked forward to she mentioned special celebrations during the year. "We went to the beach on Christmas day, and in the evening we all cooked together. Christmas is special and New Year's, those two days." She said that she does not generally see people during the week but "I ring them and they ring me. And I talk while I'm cooking. Talk about what I'm doing, what I'm cooking". She spoke often about not liking her job but noted that it allowed her to attend church and meet with people on Sundays. "On Sunday we pray together, that is my pleasure" (Figure 5.1). 


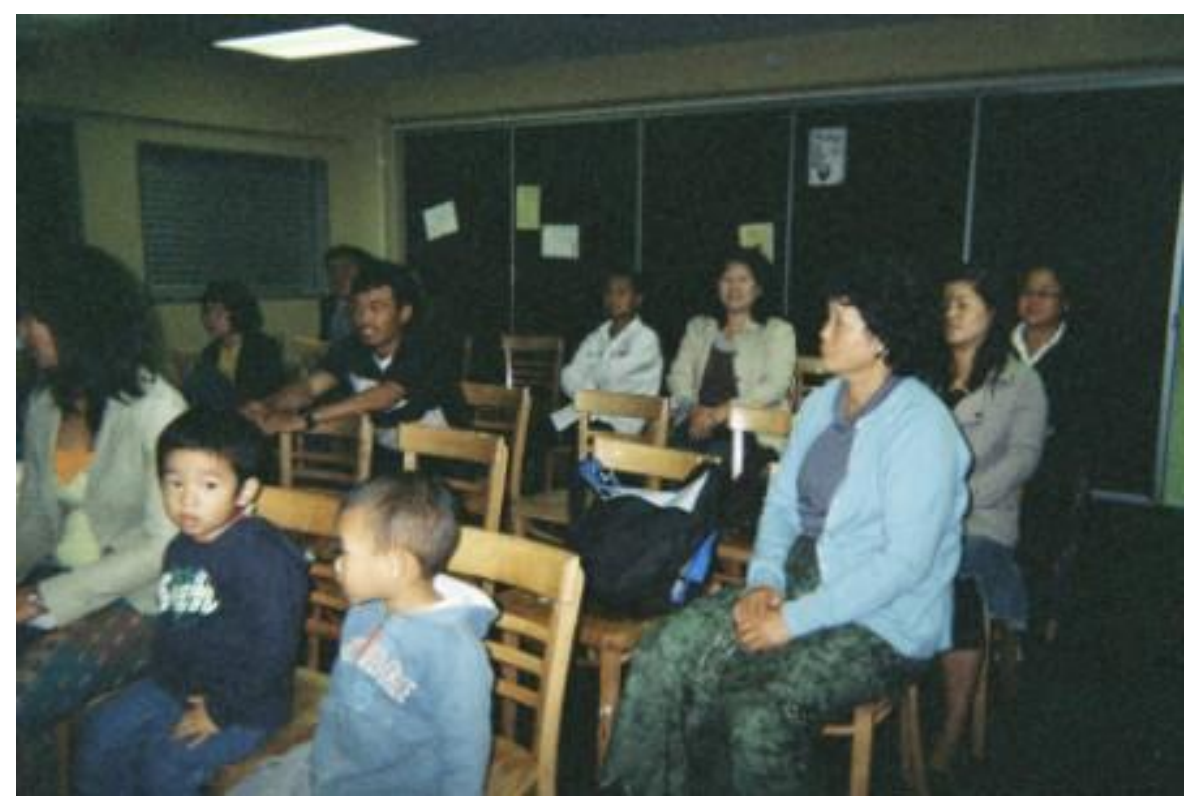

Figure 5.1: The Kachin community at the Hosanna Church in Whitby (Photo taken by Kowhai).

Puriri talked about the annual get-together with the Kachin community as the highlight of her year:

Once a year at Christmas we bring all the people together from our country to celebrate and to exchange different culture and dances and to enjoy the time together. We expect this to become bigger and bigger and to enjoy it more each year.

She noted that there are celebrations both within the Kachin community and across the different ethnic groups that make up the Burmese community:

And also as the whole Myanmar community we have combined Christmas celebrations with the other ethnic groups, it's a kind of big fellowship, dancing together, eating together, in unity. We look forward to that and enjoy it very much. 
Some of the women also referred to occasions when community support networks do not necessarily help. Nikau talked about feeling alone and anxious when things go wrong:

Sometimes I feel lonely. When something happens about the children, looking for a job, how to make contact, who we need to contact and we don't know, sometimes it's lonely. Sometimes when we receive a letter from IRD demanding us to pay $\$ 500$ or $\$ 600$ and we don't know who to contact or we want to ask things, face to face, and we don't know how to contact or who to call. So that upsets us.

Childcare is another area where community support networks in NZ do not always replace those they left behind. Pohutukawa noted that it is difficult "looking after the boys. In my country, my family and my parents, my friends can look after them sometimes. Here it's twenty-four hours looking after them."

While a strong sense of unity was evident within each ethnic group, some separation between the different groups was evident. Kowhai, who is herself Kachin, made reference to reluctance on the part of the Chin community to come together with the other ethnic groups:

Downstairs for one hour we worship in our own language. The Hosanna [Church] is the Chin family. Chin, Kachin and Kaya - we don't have the same language so we can't join together. If we speak Burmese we can understand each other. But the Chin they don't want to speak the Burmese language or whatever... so we can't... 
Hebe spoke about her upcoming ethnic national day where "each township has their own cultural dance participating. At this national day each township is organising its own performance, except [her family's township]". She noted that since she and her husband are the only family from their particular township there aren't enough people to perform their local dance. However, in order to get around this " $[t]$ he same people from different townships are learning their dance so they can perform it". Annie noted to me afterwards that this was positive in terms of community relations that there was this coming together over their traditional dances, which gave me to understand that this might not have been the case in the past.

\section{Preserving language and culture}

Nine of the ten women spoke about being proud of their culture and values and wanting to preserve them. Many referred to pride in the culture of their own specific ethnic group, especially in terms of wanting to preserve their ethnic language and customs. Pohutukawa, for example, said:

[I'm proud] especially [of] Chin because that's our first language, our dialect. Also we maintain the Burmese culture because Chin state is part of Burma, so it's maintaining two things at the same time. We take the good things from Burmese culture, not the bad ones.

She tried to ensure that the children are learning the language both by speaking it in the home and through informal classes by members of the community (Figure 5.2). 


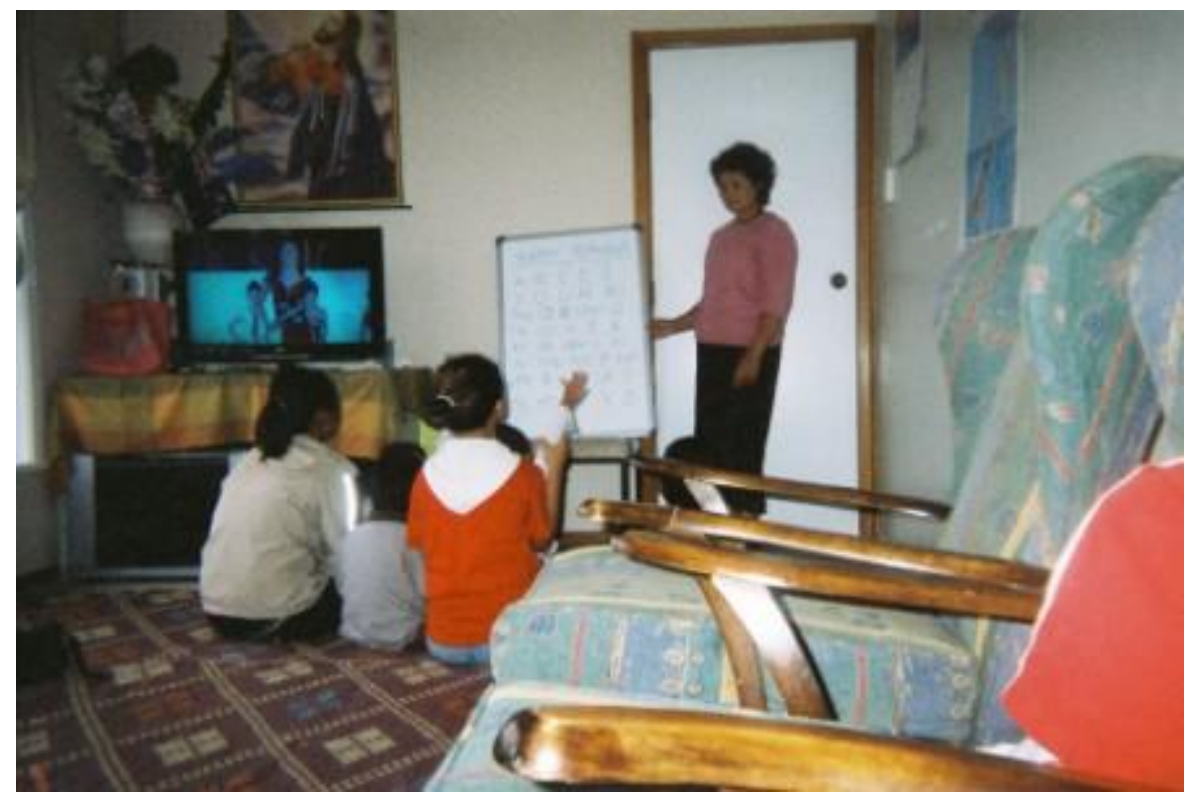

Figure 5.2: Kachin language being taught to children from the Kachin community (Photo taken by Puriri).

Pohutukawa spoke about the fact that here in NZ, they are responsible for maintaining the culture, and how this concern unifies the Chin community:

In Burma everything, the national day, the gathering, was organised by the parents and elders so we went along. But here because we want to maintain our own [Chin] culture, customs and language, we try hard and we make it happen. [...] We're more motivated and want to be proud of our own culture. If we don't do it we'll lose that so we make our own effort and we're more motivated, and everyone acts together.

Several of the women stated their pride in belonging to their particular ethnic group. Puriri noted:

I'm proud to be Kachin, because although we come from Burma, Kachin is one of the ethnic tribes. We are not Burmese Burman, so we want to maintain our own Kachin culture, customs. We want people to know this. I'm proud to be Kachin as Kachin. 


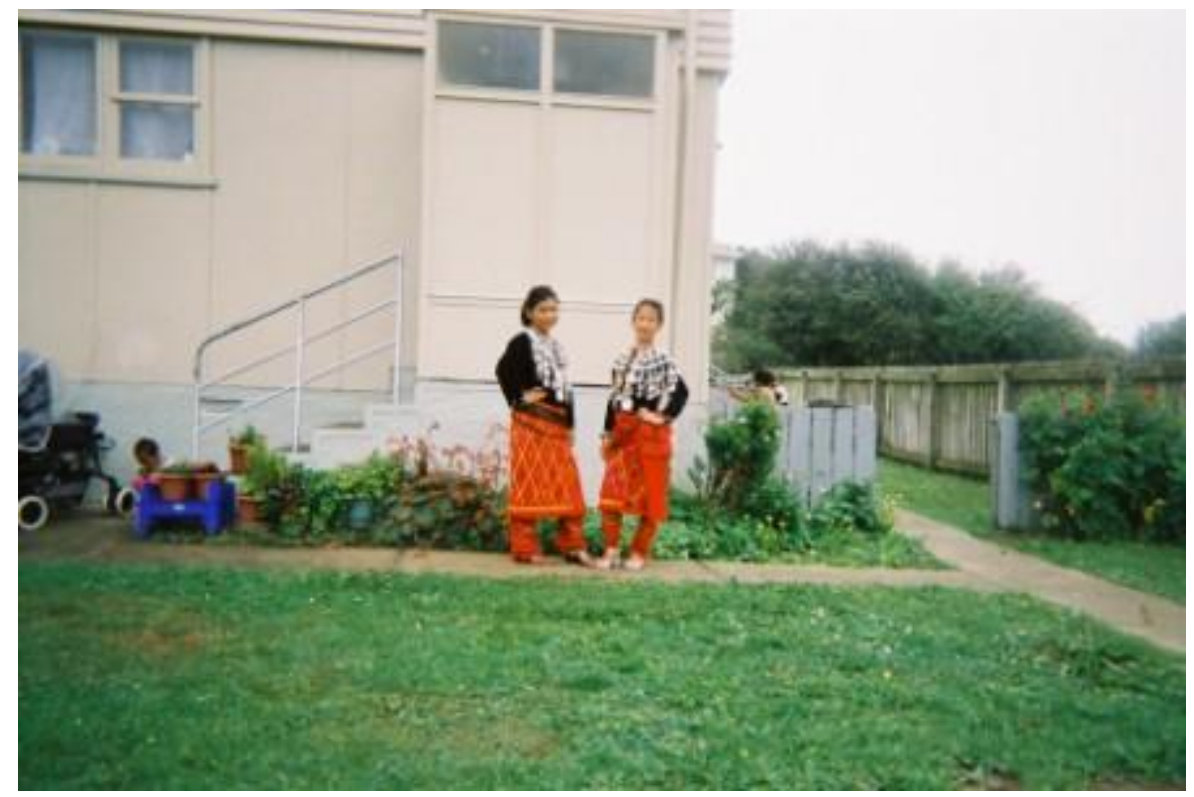

Figure 5.3: Puriri's daughter and friend in traditional Kachin dress outside their home in Cannon's Creek (Photo taken by Puriri).

Similarly, Rata said that she's "from one of the ethnic sub-tribes called Lisu, from the sub-tribe of Kachin. So I feel proud to stay on as a Lisu. [I] would like more Kachin and more Lisu." Clematis referred to the tendency here in NZ for them all to be considered as 'Burmese' whereas she identified strongly with being Kaya/Karenni:

I'm just proud to be Kaya/Karenni. Even back there the title is Karenni [refugee] camp and all my ancestors are Kaya/Karenni. But once we got here because of the situation in the country, we are regarded as Burmese, coming from Burma.

Clematis was concerned with having such a small Kaya/Karenni community around her and talked about the difficulties of preserving their language and having their culture recognised by the wider community. 
We have our own culture but we can't do a lot because we're a very small community. [...C]ulture-wise we can't expose it to other people because in our community we don't have a lot of educated people. So it's a very small and very young community.

The small size of the community was a particular concern for her "because [...] there's nobody who is committed to take the children in to teach them the dialect, apart from the children speaking at home with their parents." Despite their small size, however, she said that:

[w]e have a meeting with our own ethnic group once a month. We talk about how we'll improve the community. If it's coming up to the national day we talk about how we're going to celebrate it, what we're going to plan to do.

Clematis was concerned also with raising awareness of the Kaya/Karenni people, so that members of the host community could know more about the plight of people back home:

Yes I'd like New Zealanders ${ }^{5}$ to know about our people and our culture, that we want to preserve our language and things. If other people can help that exposure of our community, there'll be more pressure to get more people. I can't do that alone by myself, I can't apply or bring people by myself. If other people know and help that would be a big help.

\footnotetext{
${ }^{5}$ This is how the women chose to refer to those often known as the host community. New Zealander is a contested term as it does not recognize the status of Maori as the people of the land. It is commonly used in reference to New Zealand nationality and citizenship. 11 per cent of the population reported 'New Zealander' in the 2006 Population Census.
} 


\section{Preserving traditional values}

Another of the main concerns expressed by the women related to their children and keeping their families intact as they would at home. Kowhai noted that:

[w]e want the locals to know that we have a different culture and we don't want our children, even after [they've turned] eighteen years old, to go to a flat and things. It's a culture where the children stay with us until they get married.

While very positive about many aspects of living in NZ, Puriri became quite worried when she spoke about passing on values to her children. She noted that in NZ:

[t]he culture is very different. It's a worry. We can give advice, tell children what to do or not to do and they always listen. But the culture part here is as soon as you turn eighteen you leave home whether the parents like it or not. That's a worry [...] And we are worried that they'll lose our language, our mother tongue. [...] Especially the children, if we don't tell the children who's going to tell them? You know, who will they listen to? If we don't tell them they won't know. [... If] they go astray we lose everything.

At this point she spoke in concerned tones for a few minutes with Annie, who chose not to explain what was being said. I understood that it was about the issue of child discipline. The only explanation offered by Annie was: "The culture here is you can't even slap a child; they'll call the police and all this 
[kind of] thing. If the children want to be naughty they'll threaten you back and things, they'll call the police."

Kowhai linked her concern with preserving her language and culture with traditional values around marriage and looking after each other:

Culture is important; we don't want to lose our culture. Because in NZ culture is not very.. You see, not married together. In our culture it's not like that. You're not together before you get married. [...] The language is important. If language disappears, culture also disappears. When our Kachin people die, how can we help each other? We meet to talk about this. When we're sick, what happens? And then we agree to pay some money each month, $\$ 10$. [...] We're not very free but we have to obey our culture. [...] Education is good in NZ but the culture is a little bit, we don't like. I don't mean, that is your culture... Our way is a little bit different from NZ. [...] Respect for old people, and each other.

She did say that she appreciated some aspects of NZ culture, such as relations between spouses: "I think husband and wife, I like that. If you understand each other that's very good. In Burmese culture the husband wants to bully the wife and that's no good." She also liked some aspects of how children are raised and educated in NZ. "I think we need to... the English way is they train the children very well." Kowhai gave the impression of wanting to keep the good parts of Kachin/Burmese culture, but also combine it with what she observed as the positive in NZ culture.

Rewarewa and Sophora spoke about the values of helping each other, especially in times of hardship. Rewarewa noted that "Burmese people help 
each other. In our country when anyone needs help or is in trouble, we say we need to help. We help each other. Myanmar people are like this." Sophora echoed this when she spoke about the communal aspect of Burmese culture:

If someone gets sick or goes to hospital, everyone takes turn to go and comfort and support at the hospital. Also when they have funerals, people come to the house and stay there and comfort and cook dinner, and stay there to support the family, sometimes for days and weeks, and that's the beauty of the community spirit.

\section{Family back home}

Concern about family back home came up in various ways. Some of the women were waiting for the outcome of applications for family to come and join them. Others were hoping to return home to visit at some stage, while others were just concerned about and missing family back home.

Sophora had recently received news about the possibility of a relative joining her. "I'm expecting my youngest sister who I haven't seen in five years. I've just been told that she may be able to come this year. That's one of the things I'm looking forward to." She has a son who is with her parents in her home town of Myitchina and was waiting for an opportunity to bring him to NZ. She hoped "to go back home to visit once". Clematis's parents are in the same camp where she and her family were before coming to NZ. She was upset about recent developments concerning her mother:

There's a complicated thing - my mother went to see my sister who lives outside the camp and was seized by the police and she didn't have her UN card, which would have protected her. She has to reapply 
for her card so she's starting from scratch again. You're not eligible for resettlement unless you've had the card for three years. She was imprisoned for twelve days. Whether you commit a crime or not, as soon as you get out of the camp they'll seize you, corruption... They've been there [for] twenty-five years.

Kowhai was also waiting on confirmation of whether a sister would be able to join her and described feeling unsettled and saddened by the situation:

One of my sisters has also now applied for refugee status. [She] is single and has adopted my grandson, but now cannot bring him here because it costs a lot of money to bring him to Malaysia. I am also stuck here, not yet settled and no money so it's difficult for us. It's very sad.

Puriri also voiced her frustration at the uncertainty of her family's situation and the difficulty of waiting:

I get frustrated sometimes because my parents aren't well and are in another place, another country, and [two of my] children are stuck in the refugee camp so that's another worry. We're doing a family reunification.

Rata talked about waiting for her cousin to join her. "I have another cousin waiting who already has a UN number, so I'd like to bring her out through family reunification. So I've spoken to the lawyer about that."

Nikau spoke about family members in Burma she has not seen or heard anything from in a long time: 
In Burma [I have] two brothers and one sister but I haven't had contact with them until now; [for] about twenty-two/twenty-three years I haven't had contact with them. So whether or not they're alive I don't know yet. [... Someone I know from home] sent a photo of my sister's family, which I saw on the internet. Now she's very old. I haven't contacted them because it's very difficult to get the phone there.

Kowhai spoke also about wanting to go home to visit but described how difficult it was to save the money for the trip. She wanted to travel home while she and her family are still in good health but also dreamed of starting a business and felt like she cannot save for both, "I want to go see my grandpa and mum and kids. I don't know when I'll die, now I'm still healthy. I'm not a doctor or an engineer; I can't earn so much money. [...] It's very slow and I need more, it takes time." Rewarewa described a bind between realising the kind of life she'd like in NZ and the need to support family back home. She has had to put on hold her plans to study:

Now I'm already thirty-six years old and we have to support our family living in Myanmar, my parents. And that's why I'm working first, and I can support them first, and [if] I didn't need to look after my parents I'd continue studying to a high level.

Aside from being worried about family at home, some of the women referred to just being homesick. Pohutukawa said: “[ $\mathrm{I}$ 'm] homesick because everything is different between my country and here. Sometimes I miss my family, parents." Kowhai described feeling both happy and homesick but also spoke about the tension that homesickness is causing between herself and her husband. "Sometimes he argues with me and the problem is he's homesick. 
He wants to see his mom also, but no money to go back to see her. We try to keep the money also, but not yet. That's it. Homesick, yes I am."

\section{Discussion}

Community networks play a large role in shaping the women's experiences here in NZ. Community support covers a range of aspects and develops over time. Things such as a familiar meal or information about where to buy what may be important on arrival. As time goes by the community becomes a vital source of companionship and comfort. This role is particularly important given that the women are often homesick, worried about family back home or awaiting news of family reunification applications. The community plays an essential role also in finding ways to preserve their culture and language, particularly within each ethnic group; this is a concern that brings the community and the different ethnic groups closer together.

The findings from this chapter are very much aligned with the literature on social interaction and how it contributes to successful integration. The bonding within communities (Daley, 2007; Ager and Strang, 2008) can clearly be seen in the comfort taken from the company of other Burmese and the priority placed on coming together on Sundays and for other social events.

'Opportunities for preserving culture' is not an issue that came up in the literature and yet this is a huge part of the lives of the women with whom I spoke. Putnam (1995) referred to the space provided by social capital for resolving dilemmas of collective action. The desire to preserve their culture and ensure their children maintain their cultural values is certainly something they are working towards together. 
Social capital is described in the literature as being one of the few resources available to some refugees (Lamba and Krahn, 2003); aside from the psychological comfort offered by the community, some of the women spoke of a fund they are contributing to in case someone gets sick and needs assistance. This means that the community can also offer some financial assistance if needed. This action also illustrates the literature that speaks of the resilience of refugee communities and the extent to which their social capital lies behind this resilience.

I did not find much to support the idea that women are constrained by their networks (Lamba, 2002). Some of the women were concerned with being identified by New Zealanders as 'Burmese' but this would have been an issue regardless of community networks. No mention was made of any tension within the community nor of the conflict that close networks can sometimes give rise to (Lamba and Krahn, 2003).

The literature talks extensively of the importance of participation in determining refugees' resettlement and well-being. Most of the women actively participated in their communities, in the form of meetings to discuss the maintenance of their culture, how to help community members in times of hardship, and preparing for weekly church services. The women were not engaging in any significant way with the wider host community, yet some expressed a desire to do so, particularly in terms of sharing their culture with others. 


\section{CHAPTER SIX - CONNECTING WITH OTHER}

\section{CULTURES}

This chapter explores how the women are interacting with the wider NZ community. In describing their feelings about NZ, several of the women talked about how NZ's nature and peaceful setting reminded them of home, while others talked of being disappointed in their expectations. Relationships with New Zealanders were an important aspect of their resettlement experiences, and the women stressed the important role of volunteers and home tutors in connecting them to the host community. During the interviews and focus group, participants expressed their interest in broadening their contact outside the Burmese community, sharing their culture and learning more about their adopted home. They did not have many photos to illustrate this theme, however. Three photos were presented - one of the Chin national day, showing the audience watching the stage and just off centre a couple of non-Burmese guests sitting with a Burmese person (Figure 6.1), one showing the hills around Porirua, which reminded Rata of home (Figure 6.2), and another of Puriri and her home tutor (Figure 6.3). 


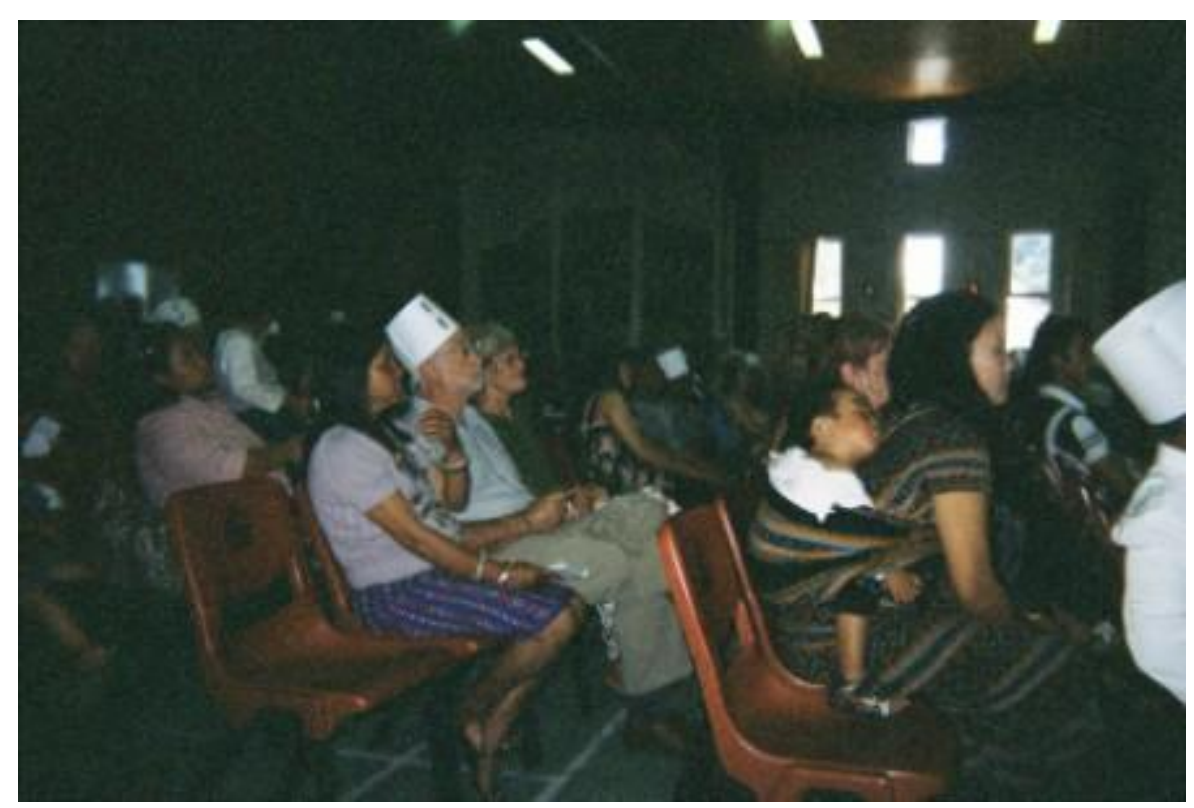

Figure 6.1: Burmese and non-Burmese at the Chin national day (Photo taken by Sophora).

\section{Comparisons with home}

The women had different expectations of what they might find on arrival in NZ. Most of them were struck by the silence. Hebe noted that: "As soon as we arrived in Auckland Mangere camp it was very quiet. Because Malaysia is hustle bustle and very crowded and noisy and we arrived in Auckland Mangere camp and it was very quiet". In response to the question of whether the quiet was good or bad, she said: "It's good but sometimes it's boring because of the silence. I like it now. I don't like it if it's very noisy or very quiet, it's just right now". This may be because she has settled into her home and established a social network for herself and her husband and young son, or it may be part of the process of acclimatising to new conditions.

Rewarewa felt the same stark silence around her:

When we arrived, at times I was very lonely because [it was] very different. Nobody around. In Malaysia also [there were] passing cars, horn-honking sounds. Lot of people in Malaysia and we arrive here 
and everything is very silent. Everything is very silent. I felt shock and loneliness, but now it's ok.

Both Hebe and Rewarewa came to NZ via Malaysia, as opposed to through a refugee camp in Thailand. This experience may have heightened the contrast for them between where they had come from and their initial impressions of NZ. Rewarewa described her feelings:

When I arrived I told my volunteer and my home tutor, I'll go crazy here if I stay a long time. Please take me to another place. Then she took me to the Saturday market and I was very happy. I saw a lot of people! Like Malaysia, lots of people walking, 24 hours.

Hebe and Nikau were both anticipating something less rural with bigger cities and bigger houses, more what they considered "Western". Nikau expressed her disappointment at not finding somewhere more populated:

When I was at Bangkok airport, it was so grand and big and crowded and noisy. I expected New Zealand to be a big city like that. It really upset me; it was disappointing, when it wasn't like that. When I looked down from the plane, I saw cows and some houses and the space, I thought we were wrong to come to this country. It's a mistake. We made a mistake coming because there's nothing here. There's no highrise buildings, no big buildings at all.

Nikau and her family had come through a refugee camp in Thailand, where they had spent seventeen years. Her disappointment stemmed from an assumption that NZ's rural feel and sparse population meant that it was not 
wealthy. She said that the information they received in Mangere helped clear up their misunderstanding:

Until we got to Mangere and it was explained to us that NZ [...] is not a poor 'third world' country and we got information about that, that it's a wealthy western country. And we realised that. After we knew that we felt better.

Clematis echoed others when she described both the quietness of NZ and the feeling of being cut off from other people, with people closed up inside their homes:

NZ is very quiet and silent. If you look at the other places everybody is inside and the house is pretty and comfortable but because there is no sound and the silence, I feel that is there nobody left, not a soul outside. [I] look outside and nobody's going past. I won't have any friends and nobody's living in this place - I just feel like that.

She gave the impression of not yet feeling a part of the community around her. She did say that she has learned ways to deal with this: "[T]he people are helpful, so long as you ask for help you get [it]. [...] So if you ask for help everything goes well, so we just have to learn how to [do that]".

Although NZ did not match Hebe's expectations, she enjoyed being able to see the hills and trees, similar to her home state of Chin (Figure 6.2). She liked "the Chin hills and the towns have little houses and they're very quiet and compact; we imagine that foreign Western countries will have big houses and you know we won't be able to see hills and trees." She said that while she expected a bigger city, she liked being able to see the hills. 


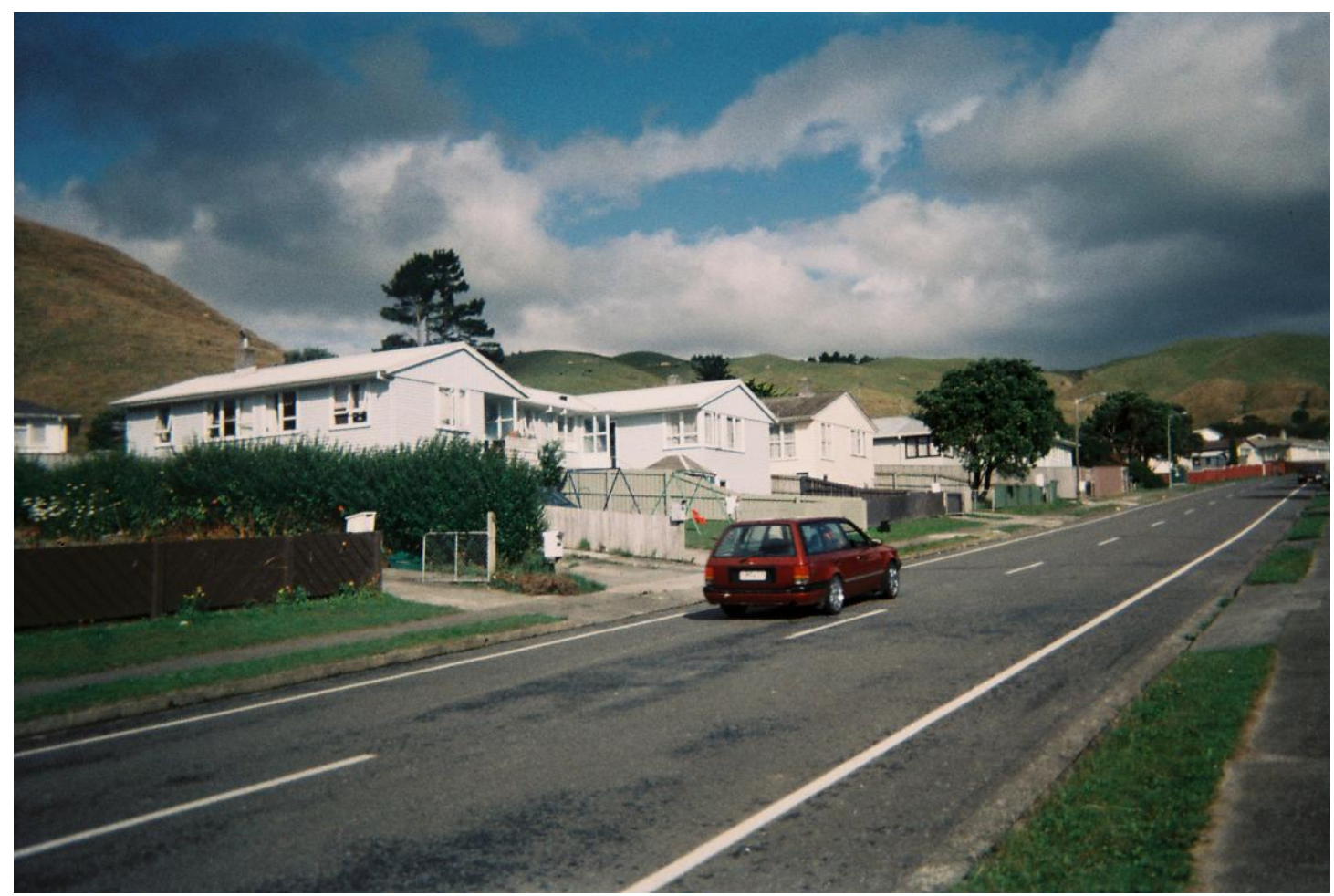

Figure 6.2: View of the street taken from Rata's house with the surrounding hills in the background that remind her of home (Photo taken by Rata).

This feeling was echoed by Puriri who said: "I'm very happy, I just like the quiet and laid back thing". From the initial information she received about NZ being a small, uncrowded country, she felt that it would be a place where she would feel at home:

The immigration told us that we were going to settle in NZ and showed us a photograph and my mind was flying, I was like flying in the air and so happy and excited. He also mentioned that New Zealand is a little small country and not crowded and not many people and that's the way I like it. [...] As soon as he said that it was a small country and quiet, it was my taste. I was so happy and I was praying that I could be in a small, quiet country and it has worked for me. 


\section{Relationships with New Zealanders}

The women described having encountered a range of different reactions from New Zealanders. In the case of those with a designated role, such as Refugee Services volunteers ${ }^{6}$ and English Language Partner home tutors ${ }^{7}$, the relationship was generally described very positively. However, interactions with members of the wider NZ community were sometimes more fraught.

Puriri described feeling out of place and uncomfortable at times:

Sometimes we feel that when go to school, it's the way we dress or our dress code, are we out of place? Are they going to look down if we dress like this? So we feel uncomfortable at times. Sometimes we feel uncomfortable, they must be thinking differently about us or of us.

She followed this by saying that she feels cut off from other students through her lack of English and that this might be why they are not friendlier.

Kowhai found people reserved: “The kiwis are difficult to communicate with. Maybe they're scared of Asian people. I don't know, maybe they don't like us. They don't talk to us much." Kowhai did not perceive language as a barrier and attributed their reserve to assumptions about her background and education. "The first time my boss was a little bit demeaning, looking down at me, because we're Asian and then refugees, and they think we haven't any education." She was frustrated not to be able to portray a more accurate picture of herself and her life before coming to $\mathrm{NZ}$ as a refugee:

\footnotetext{
${ }^{6}$ Refugee Services Aotearoa trains volunteers to support quota refugees during the first six months of their resettlement; volunteers are then placed in a small team and introduced to a refugee individual or family.

${ }^{7}$ English Language Partners trains volunteers to provide one-to-one ESOL (English for Speakers of Other Languages) home tutoring in learners' homes.
} 
[W]e have education in our country. Our living standards also aren't very low. [...] I'm not a village woman, I lived in a city and then I studied. I had a business and then I worked in a big company also. [...] So I'm a little bit.. Here this is so different in my life, you know. It's very hard for me.

Pohutukawa noted that she has had far less contact with anyone outside her Chin community since she stopped attending English classes:

When we were at school we had many friends, from other countries, Kiwis, at English classes. We had contact with other people, people we can speak with. There were more people we could speak with at school, now there are just [the] neighbours. Now there's no kiwis, no English, only Chin.

Sophora, on the other hand, was very happy with her relationship with her non-Burmese neighbours:

The neighbours are very good. On the festive days or the occasional celebration, they bring the food here and we exchange food here whatever we cook. And sometimes we give them produce from the garden, and it's just like the neighbours in Burma. [...] It's just like the neighbours at home, helping and supporting each other.

Whereas most of the women referred to feeling safe in NZ, Flax mentioned past situations where she had been afraid to leave the house: 
I saw that some people were drinking alcohol, sitting on the footpath. And I thought they weren't good people and I was afraid. Sometimes when I go out I see bottles and things around the roadside, and I think oh they might be around this area, so I don't go out. I feel insecure.

She noted that she now knew how to avoid these people and took alternative routes so she does not need to walk past them. Flax referred also to trouble with her neighbours whom she thought were members of a gang and who had objected to their friends parking cars along the footpath outside her house (the neighbours live directly opposite). She said they have argued with them about it and complained to the housing authority: "Sometimes our friend comes and every time they tell us not to park here. [...] There's graffiti, someone came and sprayed graffiti on the wall of the house. We think it was the gang." Mid-way through our interview, Flax left to collect her teenage daughter from school, as she was worried about her safety walking home on her own.

Nikau mentioned various issues that her family had encountered with neighbours in the past:

My younger son was crying and wouldn't stop crying in the garden. So I gave up and came back into the house and he continued crying. So the woman opposite shouted and screamed at me. 'You're not doing anything, your son is still crying.'

Nikau talked about an incident where their fence was damaged by a neighbour's car rolling backwards into it: 
We mentioned to housing and they came and said they'd come and repair it. But it's over a year now and they haven't come to do it. We just leave it like that. It's like they ignore us or don't treat us as equals. It's a kind of racist thing.

Nikau referred to some hostility with the neighbours through incidents such as these, but talked also of reluctance on their part to mix with her family which made her feel left out of the community:

Sometimes the children don't fit in with the locals or with the neighbourhood, [...] we feel that we are a bit left out, or outsiders, that's how we feel. Not very pleasant. Not all but some of them... [it] seems that we feel unwelcome by some of the people.

She felt that this could be because of where they are from:

With our neighbours, if I don't start the conversation, they won't answer you or talk to you. I'd like to be friendly with all the neighbours, as a friend, but it seems like there's a kind of racism, or because of the different culture they don't want to mix or talk to you, or be friends with you.

\section{Volunteers and home tutors}

Most of the women referred to the important role played by volunteers in their lives, both on arrival and in the years following. This role covered both practical aspects, such as accessing services and equipping houses with the necessities, as well as providing company and a link with the wider community. Kowhai noted the help that she had received through her 
volunteer's church, which included securing things for the house and help finding work:

My volunteer's church in Whitby [...] found us things like a bed, fridge, television, heater. They donated many things. So we didn't need to buy things when we arrived. [...] Then I needed some job and my volunteer announced it at the church and we went to clean the garden and earned some money.

She expressed her gratitude in the form of a small gift at Christmas: "Last year what I did was strawberries, I just pack them and say thanks for that. But in my heart there's a big thanks always. Yeah, very special."

Rata pointed to the important role played by volunteers in assisting her to access services for herself and her daughter: "All the services, Work and Income appointments, health appointments, clinic appointments, school they helped with them all."

Hebe focused on a different aspect of the help she received from her volunteer, making particular mention of when her young son is sick:

The volunteer is like a mother, even when the child is sick she always supports and comes, so we feel dependent on her. She's always coming by. When she's there we feel more reassured. It's been four years now and she's still part of the family. She always takes care of all family affairs so we don't have to worry about anything.

She noted that her volunteer provided them with a link to the wider NZ community: 
And some of the volunteer's friends bring all the plants and they come regularly to look at the garden. If there's anything to be done in the garden they put in a lot of effort to help us. [...] We have contact with volunteers who are New Zealanders and their friends and families, so we become friends and they introduce us to their friends.

She recognised that they were lucky in the close relationship they have with their volunteer and that not all refugee families fared as well in this regard. “[S]ome of the neighbours didn't have good people to support them like our family. So we're very happy to have all this support. Not only from the volunteers but her friends [also] come and support us."

Flax was less happy with how things worked out with her volunteers: "My volunteers helped our family, for 6 months. Some volunteers are very helpful, some are a bit ignorant. But we don't want to say anything bad. They helped with setting up home, and enrolling the children at school." Similarly, Puriri recognised that she did not have a good experience with her volunteers. "One came for the first week and then disappeared. The other one stayed for one month and then disappeared." However, she was later matched with a home tutor and the relationship worked really well with regular visits still continuing several years on:

We arrived in October and were matched with a home tutor in December. She has become extended family. She visited and took us to her house, and we spent time there. She comes when she feels free, sometimes weekly, sometimes fortnightly. 
One of Puriri's photos shows her in the garden with her home tutor (Figure 6.3). Puriri pointed to the important role played by her teachers at school and her home tutor: "[T]hey showed us the way and we walked the way. That helped a lot. And we're happy too; because we're happy it's easier for us to settle."

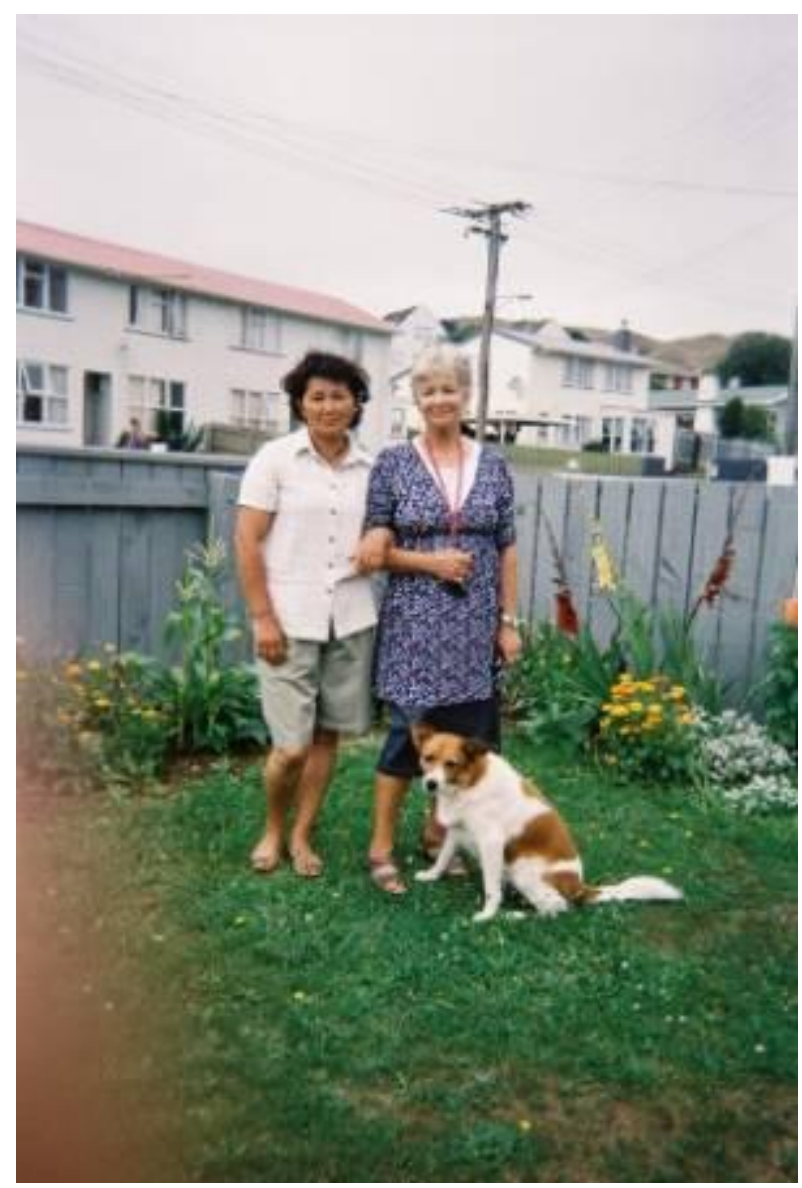

Figure 6.3: Standing with home tutor in the front garden (Photo taken by Puriri's daughter).

Pohutukawa also praised her volunteers, noting both the practical and emotional help they'd received:

They've been very helpful. Sometimes when we wanted to go to the office they help us. Or we can't phone the office and they help us [by] calling for us. Sometimes when we're sad or happy they come for us. They help with appointments. When we're having a very difficult time 
they come and help. Sometimes when we haven't seen them in a long time they come and visit us and we talk about [things].

Rewarewa referred to her volunteer's help in more general terms. When she arrived the Burmese community was small and there wasn't much of a pool of local information. She said:

[the] volunteer is very important for our refugee lives, we [didn't] know anything, how to go to the market, or where to buy something. Now we have some friends. Before there was no one who knew these things so the volunteer was very important. And they can help with things and explain many things, step by step.

Clematis referred to her reluctance to impose on her volunteer's time. Early on her volunteer was very helpful: "Every time we had an appointment, one volunteer took us to go everywhere." However, after the six month point when the volunteer's formal role comes to an end, Clematis was reluctant to call on her for extra help:

One of the volunteers was widowed with grandchildren. After six months, [she said] if you need anything give me a call. But then because she was tied up with her other family things, so we felt a bit bad or embarrassed to ask for her help. We tried everything on our own, tried to get places on our own.

All the women mentioned the importance of the volunteer's role, yet the women's range of experiences shows how arbitrary the quality, longevity and benefits of the interaction with volunteers can be. 


\section{Sharing Burmese culture with New Zealanders}

Many of the women expressed pride in their culture and said how keen they were to share it with the host community. Although many commented on the constraints of unemployment and lack of finance, they also said they had a lot to contribute in terms of the wealth of their culture - the sense of helping others, their cooking, their distinctive traditional clothing and rich handicraft traditions, and the many distinct ethnic cultures of Burma. Kowhai noted that she'd like to share many things about her life with the host community:

[I'd like to] tell them about our family, my life. I'd tell them about my country, our politics. I'd tell them about my culture. Our culture is a little bit different to the Kiwis. Our culture is helping each other, all the time very close and warm.

Puriri said that she'd like to:

show [them] that we're one of the ethnic tribes and we have our own culture. We have our own costumes and we want to showcase our costumes and things for the Kiwis to see and enjoy and know about us. We also want to introduce our traditional food, how we cook.

Rata was interested in conveying that her community wants to work hard and contribute to NZ society. "We want to let Kiwi people know that we're downto-earth people, hard-working and honest people." Clematis wanted to share something of her specific ethnic group:

I don't think New Zealanders know about my people or about us. They just regard us as someone who comes from another country. They 
don't know specifically about Karenni. A lot of people just know about refugee background people, that they come from the country Burma.

She felt that she had a role to play in preserving Karenni culture in NZ and bringing some recognition to her ethnic group:

If we celebrate our own ethnic day or culture or expose it to the people, the community, after many times people will realise that the Karenni community exists or there's a Karenni community and ethnic group. Otherwise nobody will know that we exist.

Sophora was eager to have an exchange of information about culture:

We'd like to know about other people's culture and customs. At the same time, we'd like others to enjoy our customs and culture and costumes. [...] We respect other people's cultures, we want to know and share. We also want to share our culture and things with them.

\section{Discussion}

The women described a range of experiences in their interactions with New Zealanders. In some cases they perceived their own English language skills as the barrier. Some of the women struggled with what they perceived as a 'refugee' or 'Asian' badge, where assumptions were made about their background and education. They also described their own reactions to what they found on arrival in NZ, generally framed against their previous lives, whether in their home places, other Asian cities, or the refugee camps where they had lived prior to NZ. 
Reference is made in the literature on resettlement to cultural compatibility between the host country and settling refugees and how this can affect resettlement outcomes (Kunz, 1981). Whereas many of the women were taken aback by the rural aspect and the quietness of NZ, most of them have since come to feel at home here. A multi-ethnic society is said to help with this Rewarewa felt better here after going to the market and seeing people of many ethnicities. Clematis noted that once she learned to ask for what she needed, that people were generally helpful.

In terms of Colic-Peisker and Tilbury's (2003) resettlement styles, most of the women were optimistic about their move. The information provided prior to arrival played a role in this; some of those who knew less about what to expect, such as Nikau, were disappointed by the rural aspect, whereas Puriri was delighted by the prospect of somewhere small and quiet. There did not appear to be any pattern of attitudes or approaches to resettlement based on who had come through Malaysia as opposed to from a refugee camp. All were pro-active in language learning and taking the necessary steps to establish themselves and make a life here. Participants' relationships with their neighbours varied and depended more on immediate circumstances, or 'luck of the draw' rather than resettlement processes. Castles et al. (2002) also referred to conditions of exit from countries of origin as a factor affecting resettlement, but again there was no pattern evident amongst the women with whom I spoke.

The women's social capital could go further in explaining their resilience in dealing with situations that arose. Although Puriri talked about feeling out of place at school, this did not colour her overall attitude to life in NZ. Puriri spoke often of getting together with the rest of the community and of her close relationship with her home tutor. One of her photos (Figure 5.2) shows 
her teaching the Kachin language to the children and she spoke of feeling well-embedded in the community. Nikau, on the other hand, did not refer to get-togethers with the community and talked of spending her free time going for walks or gardening. Puriri and others who spent more time with the community seemed happier - it is possible that greater social capital helps in overcoming feelings of sadness or isolation.

Korac (2003) argued that a lack of formal assistance meant that refugees would be prompted to create their own networks both within their communities and with the host community. Far from supporting this theory, the women all stressed the importance of a support person, whether a volunteer or home tutor, in all aspects of their resettlement. In Hebe's case this provided her not only with the support and reassurance she needed over the past four years, but also created a link with the wider community through her volunteer's circle of friends. Puriri similarly had received a good insight into the local community through her home tutor, whom she visited in her home and with whom she practised her driving and generally had regular contact.

Others, such as Flax, had remained more cut-off and fearful of her surroundings. She had no support at the time we spoke in terms of volunteers or home tutors and relied on her own resources; she had become more confident in leaving the house and negotiating her way around but more formal support would probably have helped her to adjust more quickly.

The amount of interaction between the women and the wider community, whether through their volunteers, jobs or relationships with their neighbours, would seem to play a role in the acculturation process. For those who remain more isolated, a likely outcome is separation, where non-dominant groups 
reject or remain unaffected by the dominant culture. For those with more contact, integration is more likely. Kowhai, for example, identified parts of NZ culture that she would like to adopt and blend with her own.

The literature points to benefits for refugees in participating in the wider host community, although there has not yet been much research in the area. Benefits include learning the language, skills and local knowledge to succeed in a new country (Goodkind and Foster-Fishman, 2002). Generally the women said they would have liked more contact with the wider community. Some felt cut off for reasons of language, others because they do not have the opportunity to mix more often. Pohutukawa saw no one outside the Chin community since she stopped attending English classes. All the participants' main contact with the host community was through volunteers and home tutors. It is possible that many of the women are still more at the setting up stage (Hulewat, 1996), and focussed on language learning and finding a job, and that the type of participation referred to by the literature will come with time. 


\section{CHAPTER SEVEN - OPPORTUNITIES AND CONSTRAINTS OF LIFE IN NZ}

This chapter brings together the different opportunities and constraints experienced by the women associated with living in NZ. Life in NZ provides a sense of ontological security, defined by Giddens (1991) as a sense of order and continuity in regard to an individual's experiences. Thus the reassurance provided by life in NZ, such as knowing that their children's health and education is assured and having a long-term view of the future, can help in restoring this sense of security. Themes such as adult education courses, the women's gardens, and their children's daily activities feature largely in the women's photos. Although generally positive about their lives here, the women did express some frustration over money issues and transport, which are addressed in the section on constraints.

\section{Opportunities for learning}

One of the aspects of life in NZ that the women particularly appreciated was the opportunity to access different kinds of classes. Women mentioned flower arranging, coffee making, computing classes, interior decorating, as well as some longer courses of study such as nursing. Puriri's flower arranging courses had been a highlight of the last couple of years - the arrangements she made were on display in her home and her certificate featured in the photos that she took (Figure 7.1). 


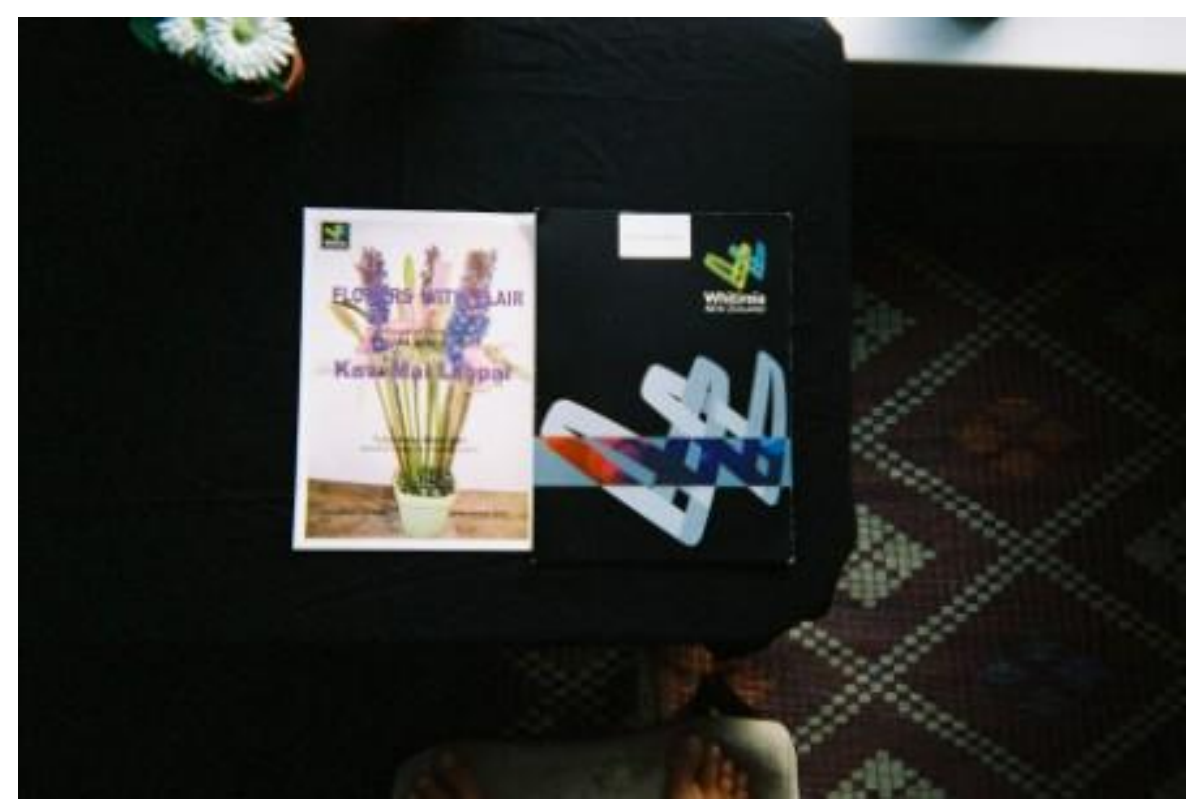

Figure 7.1: Puriri's certificate from a flower arranging course at Whitireia College (Photo taken by Puriri).

Rata has a young daughter at home, which meant that she did not have time to attend all the courses she wanted to but she had plans for the future. She said that once her daughter turns five and starts school, she wanted to "do further study for my future to improve myself. I'd like to do flower arranging, interior decoration [...] in Wellington High School". At the time of the interviews she and Pohutukawa were attending free computer classes. Sophora had taken a break from her computer course as she was expecting a baby shortly but said: "I'm going to a ten-module computer course and finished half of it last year." She hoped to find a way to finish the modules next year. Sophora conveyed how much it meant to her to have the opportunity to learn new skills that she would not otherwise have had the chance to do: "We never thought that we'd use or touch the computer when we were back home, but now we have the chance and opportunity to learn and achieve a new skill, and to learn about the internet." 
For some of the women, the main reason for taking a course was to enhance their chances of finding work. Kowhai said that "[a]fter the ESOL" class I wanted to do a free course. And the coffee course was free." The coffeemaking course teacher put her in contact with her current employer, a café owner. Sophora did the training with Barnardos in order to be able to make some extra money by minding children at home, although it turned out that there were no children available for her to mind. Hebe mentioned study from a more long-term point of view, as a way to realise her dream of becoming a nurse.

Kowhai mentioned how not all learning took place in a formal setting and shared some of the other things that were new to some members of the community upon arrival in NZ. She said:

[we learned] also how to use the stove. In our country we only use the fire. We put coal in the fire and cook on it. [...] Also the shower. We used to use the well. We used cold water to shower. Some of us are still using the cup and pouring it.

\section{Ontological security}

Many of the positive aspects that the women cited about their lives in NZ could be seen as stemming from a sense of ontological security. The opportunities provided by NZ to live a safe life came up repeatedly. One of the key aspects of this security for the women related to their children and the freedom from worry. Rewarewa felt reassured by the services provided. "Refugee Services, the family department, they care for children, they look

\footnotetext{
${ }^{8}$ Schools can apply for ESOL (English for Speakers of Other Languages) funding to provide English language support programmes for eligible students from migrant and refugee backgrounds.
} 
after childcare, it's good for your children, they show the way." Similarly, Hebe said: "[w]e feel more secure about our children, especially education and lifestyle and their future." Puriri described it as a weight off her mind not needing to worry about the children's education and future:

Before it was a worry for the children, but since arriving here I have learned that I don't have to worry about the children and they'll have a job and a good education. So I feel secure and pleased that that's an achievement we have, looking to the future.

Similarly, Nikau was happy about her children's prospects:

They have good health care and good education. There's no need to worry about their education. [...] Our eldest daughter is very clever and works hard and always has top marks and first position since she has arrived, every year. So we're very proud of her future education and we hope that she will achieve something and get a good job. So that's what we're proud of too, to be able to expect a good future for her.

Clematis contrasted the opportunities open to her children here with the situation in the refugee camp in Thailand, where you "need to apply for a pass if you're to study. But you do need money even if you're living in the camp. Only people with money [can afford to study]". She felt secure in the fact that her children now have the same chance to learn as other children in NZ. "I want my children $[\ldots]$ to be able to do things like other children, to learn whatever other children are learning and to be educated." 
Sophora echoed this, referring to the cost of schooling in Burma. She had four children in school, two at secondary level, one at primary level and one in kindergarten, and was expecting her fifth. She said, "[I] like it for the children. [In] NZ education is all free; medical care is free. In Burma we couldn't put our children in school because there's lots of money to pay in school fees. I prefer NZ; it's very good for children". She mentioned some of the ambitions of her children and how she and her husband were focussed on supporting them in their plans:

The eldest child wants to be an engineer and the younger a mechanic; the youngest wanted to be a doctor before but now he has changed his mind to a policeman. We want to achieve this ambition, that's what we're aiming for and we want to give guidance so that it can happen.

Rata also hoped to see her daughter succeed. "I want my daughter to be a doctor. I want to help my daughter to have a good education."

The ontological security experienced by the women can be seen as extending also to the care that they put into their gardens. All the women have gardens and plant flowers and vegetables. Seven of the ten women made frequent references to gardening and how much they enjoy it. This could be seen as part of a process of regaining control over their lives and enjoying the stability of watching the fruits of their efforts grow. Rata noted improvements this year. "Last year [the apple tree] didn't grow very well but this year I put a lot of grass and compost at the base of the tree and [there were] very good apples" (Figure 7.2). 


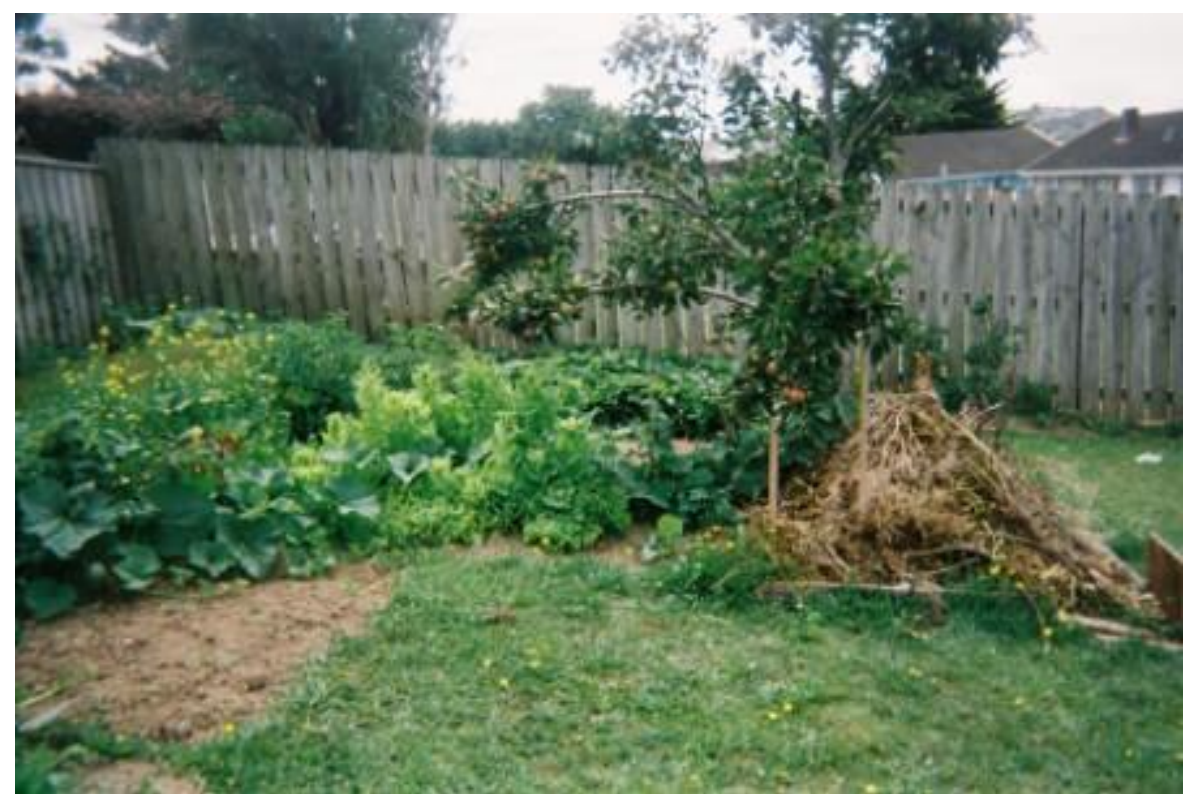

Figure 7.2: The apple tree in Rata's back garden that yielded a good crop of apples this year (Photo taken by Rata).

Rata talked about investing in her garden by planting fruit trees she considered expensive. "I like fruit plants, I want to put oranges but I haven't had time yet and it's a bit expensive, \$20 a plant. But I've just bought a lemon tree, it was on special - \$12 - so I bought that."

Hebe said: "[w]hen we are free we spend more time in the garden, with the whole family, with our son." Similarly, Pohutukawa, Kowhai and Sophora also spoke about spending their free time in the garden. Clematis referred to a sense of reconnecting with her former life in Burma: "Since I was young we also grow in the horticulture context and plant a lot of plants so I like growing things". Flax had not gardened much previously, not having had the opportunity in the camp where she spent the last twenty-five years, but still enjoyed it. "I dig my garden but the plants don't grow! In the refugee camp I never gardened. And now when I come here it's not good!"

Kowhai talked about needing to get used to a different type of soil when they first arrived: 
We loved to garden but the soil is very dry and we need to use compost. We didn't know that. The soil at home is different, all the time ready and the vegetables are also very good. Here it's dry. We didn't know how to make compost, we were just buying. We were spending money and the balance wasn't even. We spent more on the compost. This was an important thing we learned.

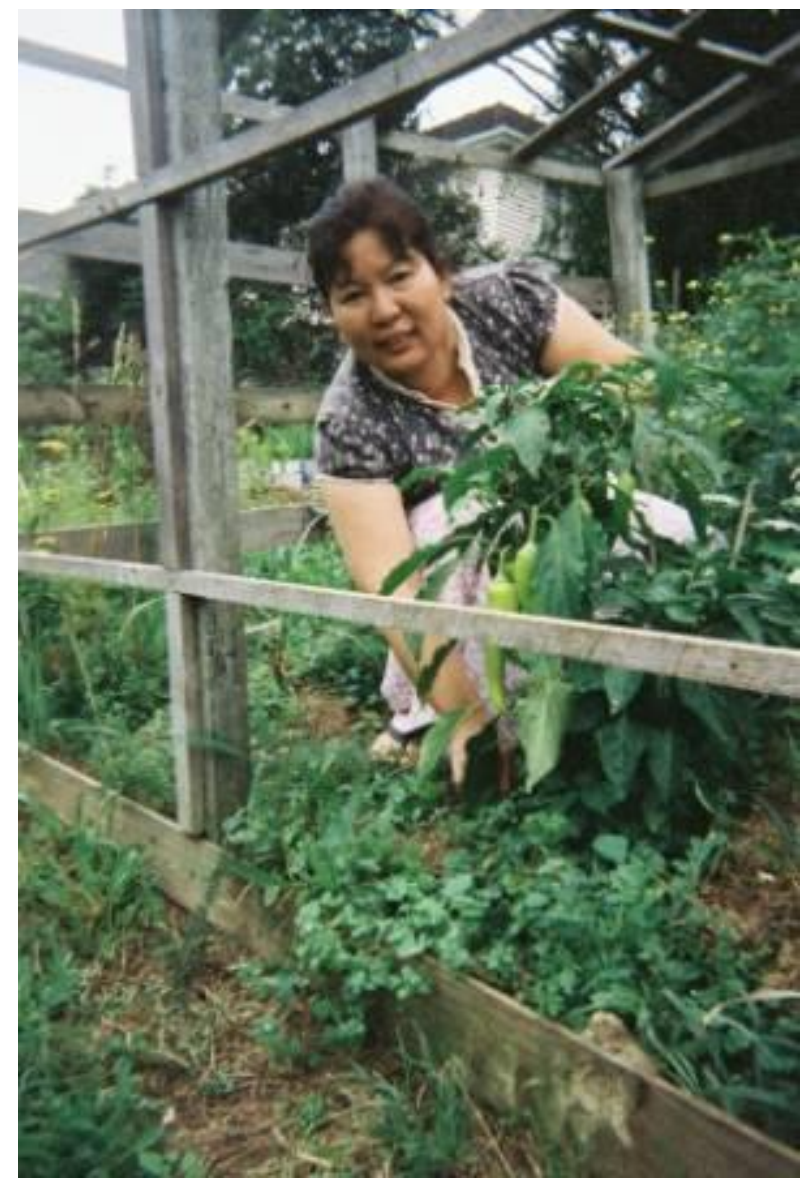

Figure 7.3: Tending to chilli plants in the back garden (Photo taken by Kowhai's husband).

Many of the women referred to how safe they feel in NZ. In many instances they referred to issues of physical safety. Puriri said: "I felt very insecure before I arrived, and unsafe, so looking back that worry has gone. [...] I feel safe living here and it's good for my children's safety too". Similarly, Rata said, "[i]t's quiet and calm and feels secure and no worries to live in NZ." This sense of ontological security was expressed in a different way by 
Clematis: "The playground, we'd never had a playground. You know you walk in the playground and the breeze is blowing onto your face. We had never experienced that before and we have that now" (Figure 7.4).

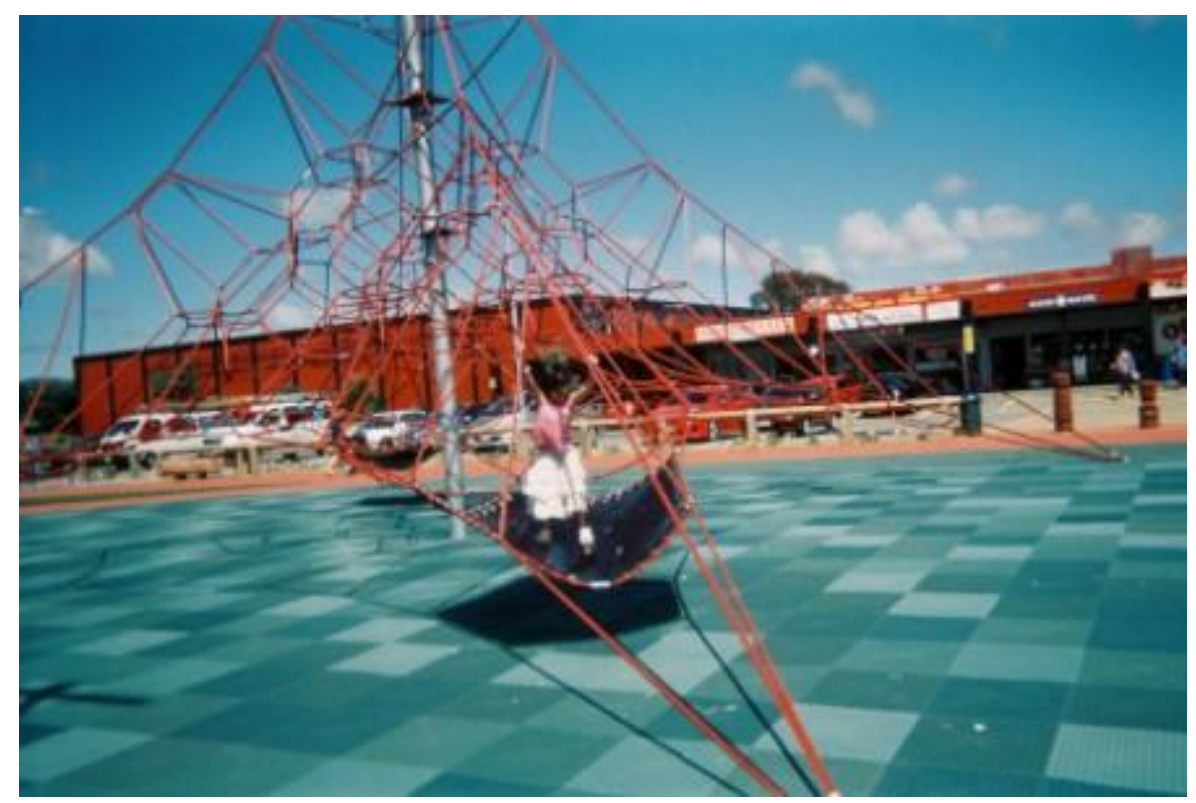

Figure 7.4: Daughter in the local playground, where the family likes to go in their free time (Photo taken by Clematis).

Clematis contrasted the freedom of her life here with the restrictions of life in the camp:

[Y]ou can't contact other people, you're not allowed to go out, you can't do this, you can't say this [...]. So it's not free, you've been trapped there. So since you arrive here you feel free and everything you want to do, if you do it yourself you can get out.

Flax appreciated the lack of tension and continuous fear and insecurity that were part of her life in the camp:

I like it that NZ is a peaceful country. I like my house and home. I spent a long time living in a refugee camp and it's very difficult and 
sometimes dangerous. Sometimes we [used to] hear gunfire outside, at the border. Sometimes Burmese soldiers come to raid the refugee camps.

Rata had little control over her circumstances while living in Malaysia and was largely dependent on her brother:

Before I came here there were difficulties and I had to struggle a lot. I [had] a child and was not allowed to work and my brother had a job [...but] every time the boss growled at him he stopped going to work. You know relying on him, depending on him it's very unsafe and the [lack of] security was hard. It [was] a big struggle.

The newfound sense of stability can be seen reflected in Rata's comments about how she liked to spend her time. "I enjoy listening to music and I've lots of other hobbies, like tapestry; [...] in winter I stay inside and do tapestry."

Nikau enjoyed the opportunity to spend more time as a family:

We didn't have the chance or opportunity when we were in the refugee camp in Thailand but here we have the time and the space and the opportunity so it's very pleasing to go out with the family and enjoy the family, spending time together.

However, Nikau referred to a time when they did not feel secure about their lives in NZ, shortly after they arrived: 
When my husband was studying, he was paid by the student allowance from Studylink. Everything, all the benefit, the whole family relied on him. Sometimes the benefit was cut, or it comes back for a week and then was cut again. We went to talk to the case manager and they say nothing is wrong and they'll put it back on. But the letter still comes that ... and we have no idea what to do or what to do next.

\section{Using skills and availing of opportunities}

A number of the women talked about their handicraft and sewing skills. Clematis liked to weave in order to keep the tradition alive and to be able to show her culture to others. "What I'm weaving now is a traditional handeddown pattern from our own ethnic group. I want to preserve that and keep weaving and I'm proud to wear my own woven pattern. And other people like it too" (Figure 7.5).

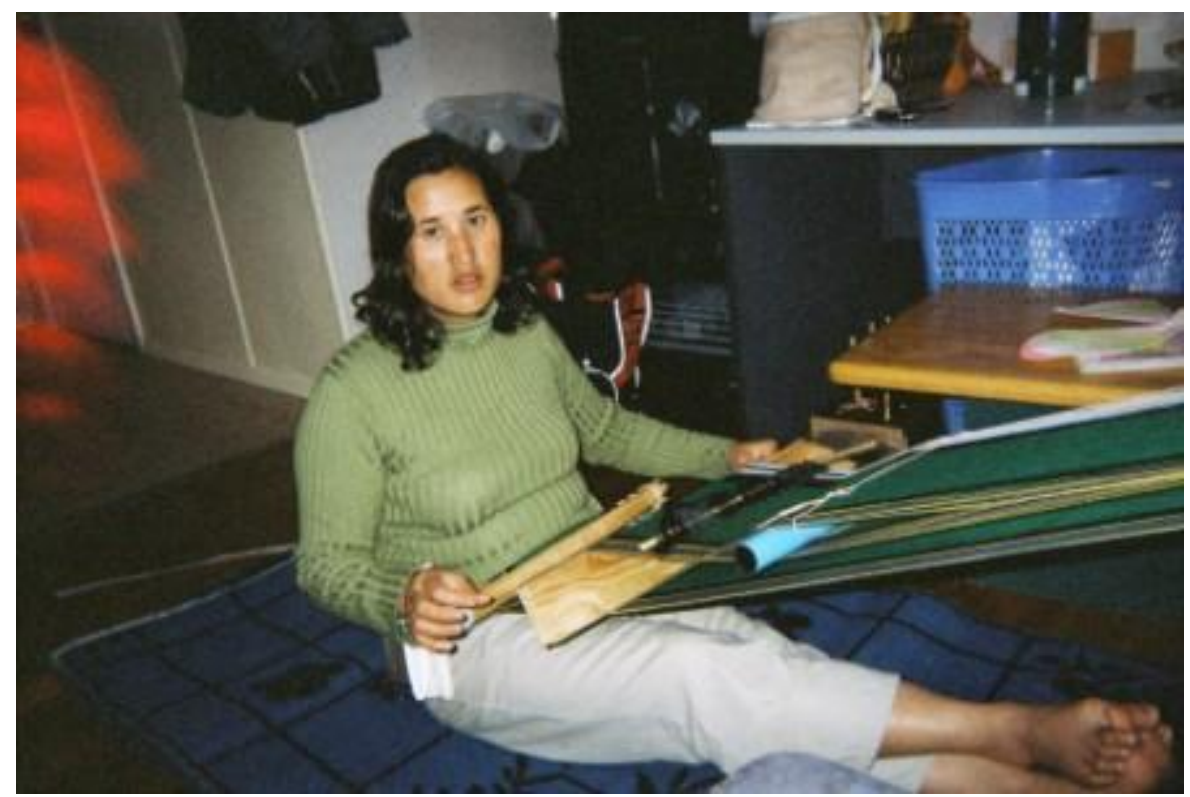

Figure 7.5: Weaving in the traditional Kaya/Karenni style and colours (Photo taken by Clematis' husband).

Hebe had been able to create a small business amongst the Burmese community, sewing for the different ethnic celebrations: 
If people ask us to sew something, if I have the order, I do it on Sunday [...]. Before the festival people, especially Chin people, bring the material and ask me to make a dress or a jacket or skirt. [...] They get the material from back home that they have sent over and I do the pattern and make it up.

Hebe thought through her options for earning money and decided for the time being that she would put on hold her plans for further study and use the skills she had already. "I have sewing skills so I thought it would be better for me to stick to sewing and use my sewing skills."

The women described different hopes they had for their lives in NZ, as well as opportunities that have opened up to them. Nikau spoke of wanting to travel, as did Sophora: "Because Australia is the closest one to visit, I'd like to visit Australia." Hebe talked of owning her own home one day. Flax and Puriri both hoped to learn how to drive. Sophora considered learning to drive as one of her achievements: "And also now driving, getting driving lessons and one day we'll have the driving license, so that's a kind of achievement looking back". Pohutukawa hoped to study some day, when her son is older. "I'm interested in being a radiologist technician, in a hospital, [or] I want to become a nurse too but I think it's impossible [to do that]."

Puriri talked about the ease with which she is able to pursue her hobbies and interests. Now in her sixties, she spoke of opportunities she'd never had before:

In the past it was just in my dreams that I wanted to do sewing, wanted to buy the machine but we never could afford it, I couldn't do anything. But since arriving here I've managed to buy the machine and 
do what I like to do, and I've got the creative thing happening all the time. If I see something new I can do that or want to sew that. I can just reach out and there's the material there.

Other women referred to becoming more confident and resilient since coming to NZ. Pohutukawa had enjoyed the challenges of living more independently:

If we don't try it won't happen. So we try and try and try. [We're] more confident than in Myanmar. In Myanmar if there's something we want to do we tell our parents and family. Here there's nobody we can tell so we have to try ourselves. It's good.

Clematis and Hebe also spoke of new-found independence. Clematis noted:

If I depend on other people, expecting people to help you it's difficult. You don't want to ask for help all the time so you tend to try yourself to find out things, to go where you want to go so it's like strengthening you to find out on your own.

She explained how different this was to life in the camp:

When we were in the camp however hard we work or try we don't have a chance. But here if you want to find out something you try hard and find out yourself so you go and you achieve more things here. So I think that I learned a lot.

Rata found herself forced to learn a lot of new things since moving to NZ with her young daughter: 
Everything is new to us so we have to try very hard and learn a lot of different things. We've found out that we can try hard, we [teach] ourselves that we have to do it on our own and try hard on our own. [...] Bringing up a child on your own is a big step, to do that as a solo parent.

\section{Efforts rewarded}

Sophora saw a strong sense of justice and equality in how things are done in NZ. In Burma she believed that wealthy people could do as they liked, as opposed to in NZ where everyone is treated the same:

I like the law, the law is very good. Everybody has a car [and] the government has the road code so there are very few accidents. Road rules and policy are good, which prevents accidents. In Burma there's no policy, if you're rich and you have money, you can buy a car and drive.

She noted that coming to NZ had given them the opportunity to own a car, which would not have been possible in Burma:

In Burma we never thought of owning or driving a car, but here a car is a kind of necessity so everyone has a car and everybody's equal. In Burma we thought only rich people could have a car and not us, so it's like equal opportunity.

Sophora was keen also to learn more about NZ politics, and was interested to know how she could ask questions of her local politicians: 
I want to learn and know how policy is made and who governs the place, about city council and governance ranking things, how policies are made and what policies. I'm interested in this because we're living here now and we will be citizens soon so we would like to know how NZ [functions].

\section{Constraints}

One of the difficulties cited by the women related to transport and getting around. Clematis noted that there were "[1]ots of difficulties - language, how to get to other places, catching the bus, and the train. In ESOL class we learned how to get the bus and get the ticket, getting the return train ticket". Flax noted that getting around was more of an issue when she first arrived and was nervous about catching buses on her own. She said that she can now:

take the bus into the city centre. I can speak English a little bit. Before I was afraid to go outside and catch a bus to the city centre and to the clinic. Very afraid, for two or three years. I didn't cross the road. Because of the cars coming and going.

Nikau found herself reliant on her husband for getting around because she had never learned how to drive. "Sometimes when I want to go here and there, he says I'm not a driver. I tell him that he's a driver and you need to take me everywhere because you never taught me." Flax noted the difficulties of transport "[e]specially in the winter when it's cold."

Sophora and Kowhai both referred to specific issues they'd had relating to money. Sophora and her husband were both keen to work but had discovered 
there was little to be gained financially from working as opposed to staying on benefit:

It's just balanced, the same, and they'll put up the housing. Once you're earning, the housing goes up and you're not getting any benefit from working. So people say, why should we go to work? If they want people to work they should give a reward. So that's the main problem nowadays, so everyone stays on benefit. It's a policy the government has set up that's not good because they don't reward people.

Sophora believed it was important to work for a number of reasons: "Once you're on benefit you don't move, you don't go out, there are more health and fitness problems, and you don't get experience".

Nikau struggled with some of the ways of doing things in NZ. Whereas Sophora appreciated that everyone had the opportunity to own a car, Nikau resented some of the rules imposed:

I don't like some policies [...] It's really different to at home. You know like expensive. My car, I own my car, but every 6 months I need to pay money, otherwise you can't use it on the road. Sometimes we go to the garage and the tyre is ok but they change it. [...] It's too much.

She also spoke of the problems they encountered when they left their children in the care of their eldest daughter. "Also sometimes [when we go out during the day] we just leave the children here and my daughter she can take care of everything. But when my neighbours see this they tell. It's different to my country." 


\section{Discussion}

The women talked extensively about all the good things about living in NZ the courses they've attended, the opportunities for their children, their homes and gardens and the security and stability of their present lives. On arrival they struggled with getting around and transport, which was compounded by the language barrier, but they have mostly resolved the issue of transport over time. Other issues raised relate to systems and policies that are different to home, such as those related to cars and childcare. Not much reference was made to money and living costs, but Sophora did want to draw attention to the fact that you can earn as much on government benefit as working.

Much of what I learned from their discussion received no mention in the academic and policy literature. The women placed huge value on being able to enjoy hobbies such as flower arranging. These personal interest courses represented highlights in their years in NZ. Puriri was modest in talking about her achievements in the course but I understood from what she said that her skills were valued by the teacher who invited her back to attend the next stage of the course. It is great that these classes are available but the literature on resettlement does not recognise the importance of such initiatives.

Similarly, the women's gardens were a huge source of enjoyment in their lives, in addition to providing a source of healthy food. They spent a lot of time tending and improving them, and tracking their progress from year to year; they are also a huge source of pride. The women I spoke with were living in an area with generous gardens but there was little awareness in the literature on resettlement of the importance of providing an environment where people can use skills such as gardening. Refugee resettlement 
strategies could better acknowledge the skills refugees bring with them, for example by providing an environment where people can use skills such as gardening. Encouraging the use of such skills promotes the agency of refugees as opposed to approaches where refugees are pictured "as passive victims of violence and disaster" (Essed et al., 2005, p.2).

Initiatives that harness such skills could also provide a platform for such women to truly participate in NZ society on a more equal footing. Dunstan et al. (2004) refer to participation in civic, community and social activities as a goal of the Immigration Settlement Strategy. Areas where the women excel such as gardening could be one such activity. This resonates with Goodkind and Foster-Fishman's (2002) recommendation for a culturally appropriate approach in promoting the participation of ethnic communities.

Sophora was interested in finding out more about local politics. The literature talks about the importance of engaging the state in community actions (Korten, 1995; Mayo and Craig, 1995). Although this is still in the early stages amongst the group with whom I spoke, there is an awareness of the usefulness of engaging with formal processes. As Sophora noted, now that she is going to be a citizen, she should know how the system works. Given the differences between the political systems in Burma and NZ, it would be useful to explore how former refugees can play a role in the political system. 


\section{CHAPTER EIGHT - IMPORTANCE OF ENGLISH}

\section{LANGUAGE}

Unsurprisingly, English language issues came up time and time again as the women talked about what they wanted to do and how they wanted to contribute to NZ society. For some of the women, English language was tied in with their feelings of self-confidence as they negotiated their new environment. Difficulty communicating in English contributed to a feeling of being cut off from the world around them, as well as to preventing the women from pursuing ambitions of work and study. Several of the women expressed concern at government cuts to English language classes.

\section{Feelings of self-confidence}

The women described various feelings of shame, frustration and inadequacy that surfaced for them when they struggled to communicate with others. Some of the women were quite self-conscious about their level of English. They described it as affecting their sense of self-esteem. Puriri described her experiences at school where she attends English language classes:

The way they look at us, we feel displeased sometimes. They don't say anything, it's our own feeling, maybe lack of confidence that we have. It's because of a lack of English and we can't speak English that we feel they might not like to talk to us, or be friendly with us. It's our own weakness that we feel.

Puriri gave the impression that she would interact differently with the world were English not an issue. "Because there's an English language barrier I don't feel confident to go out and meet other people, it's a bit uncomfortable." 
Similarly she noted that "[s]ometimes I want to have long conversations and talk with other people but I can't find the words." Puriri noted how much she missed the classes during the holidays and the effect this had on her confidence in English: "Because we have school holidays for three months, we're out of touch with English. That's the time we lose our practice. Now if I start writing, even my hands shake because I've lost confidence over the three months."

Clematis described feeling down because she felt cut off from people around her. "Sometimes I feel frustrated because I want to... I don't know how to ask questions, so not enough language to ask. Sometimes I want to tell people but not enough English, so that frustrates me and I feel a little bit down." ${ }^{9}$ Clematis also noted feeling "like an idiot" for not understanding letters she received: "Education is the most important thing. I want to learn more. Every time a letter comes [that] you can't read or understand [...] you feel kind of idiot. So I don't want to feel that, I want to get more education." Similarly, Rewarewa recounted an incident with a friend who could not make herself understood at the local clinic and the feeling of frustration of being able to talk to some people but not others: "She's ashamed to say also that she can't understand. [...] My friend was very angry. She phoned me and I interpreted for her. She said, 'always I say the same thing, why didn't she understand?'”

Pohutukawa echoed this idea of some people making more of an effort to reach out and communicate with them appropriately:

\footnotetext{
${ }^{9}$ I had the impression during the interview that Clematis really appreciated the opportunity to be able to express herself through Annie and talk about her experiences. She also said at the end of the interview that she had enjoyed it.
} 
There are some people who understand and sympathise with us and know that we're from a different country so they speak slowly until we understand. But some of the service providers they don't care where you come from. That's a time when we have difficulty.

Rewarewa herself spoke English very well and we conducted her interview in English; she described her attitude very differently:

Kindergarten, Work \& Income, I just made appointments and went to talk to them face to face. Sometimes I can't understand some words, and I don't get shy I just say can you explain? I just say like this. Sometimes I use hands and body language.

Having studied in Burma and used English while working in Malaysia, she had greater fluency in English than most of the women with whom I spoke, which may have explained her confidence.

Flax and Rewarewa both noted the extent to which they are dependent on others if they don't speak English. Flax said: "[s]ometimes when I go to offices it's difficult - Work and Income... hospital, clinic, dentist. I never call [Language Line or] an interpreter, sometimes my husband helps me but when he's not well I go on my own." Rewarewa noted that it is difficult for others around her who did not have much English. She pointed to the differing experiences of those arriving in NZ:

Yes because different lives and if you're not used to studying it must be very hard. [Otherwise] every day you need somebody. Different kinds of people, some have no education, they must have someone with them all the time. 


\section{Opportunities missed}

What came through continually during the interviews was the sense of missed opportunities caused by the language barrier. Many of the women's dreams and aspirations were on hold due to a lack of English, ranging from finding work, to studying, to following a career in a given area, to volunteering to help other former refugees. When asked whether anything was difficult here in NZ, most of the women responded with something related to English. Rata was the exception to this when she said: "education was arranged for us to learn English so there's nothing to worry about".

Overall the women expressed their satisfaction with their lives in NZ; the fact that most identified English as the main difficulty for them in a certain way confirmed this and pointed to an absence of other major issues. Hebe was particularly upbeat about her life in NZ so far, saying "I haven't got good English yet so that's been difficult. There's nothing much that's difficult apart from the language".

Rata and Clematis both had concerns about the classes they can access. Rata recounted how the ESOL grant had ended so she couldn't attend classes free of charge anymore: "You can enrol but you have to pay school fees. So I said I don't have the money for fees. Although they allow student loans but some people didn't want to take out a loan so they opt out and don't go to school." Clematis was worried about future cuts that might impact on her: "I want to carry on learning English to improve my English but I heard that we have to stop learning after 2013 so I feel a bit sad and upset about that." Pohutukawa mentioned cuts to childcare, which meant that she had been unable to attend classes this year. She noted that she would need to be able to afford childcare if she wanted to go to English classes: “Last year we went to school and there 
were people to look after the children. [...T]he government paid for childcare at the school. They've stopped this now."

Clematis, from a small village in rural Kaya State, pointed out that she is dealing with a double language barrier. Not having learned Burmese before arriving in NZ, but only her local Kaya language, she had to learn Burmese in order to be able to communicate with the Burmese community:

When I arrived, before that I only spoke Kaya, but here the crosscultural worker speaks Burmese, when you go to [... see the doctor] the interpreter speaks Burmese. So I'm forced to speak Burmese. When I meet up with the Chin and Kachin to make friends, they only speak Burmese; Burmese is the general language. Otherwise I won't have any friends.

As mentioned in the previous chapter, Hebe had been doing some sewing for members of the Burmese community, including traditional costumes for the Chin national day. She had a work station set up at home and was in the habit of spending Sunday afternoon working on various projects (Figure 8.1). She wanted to make more use of her skills by seeking out work in the wider community but felt restricted by her level of English. “Once I have good English I want to find a job. I want to do some more sewing. I want to use the skills that I have." 


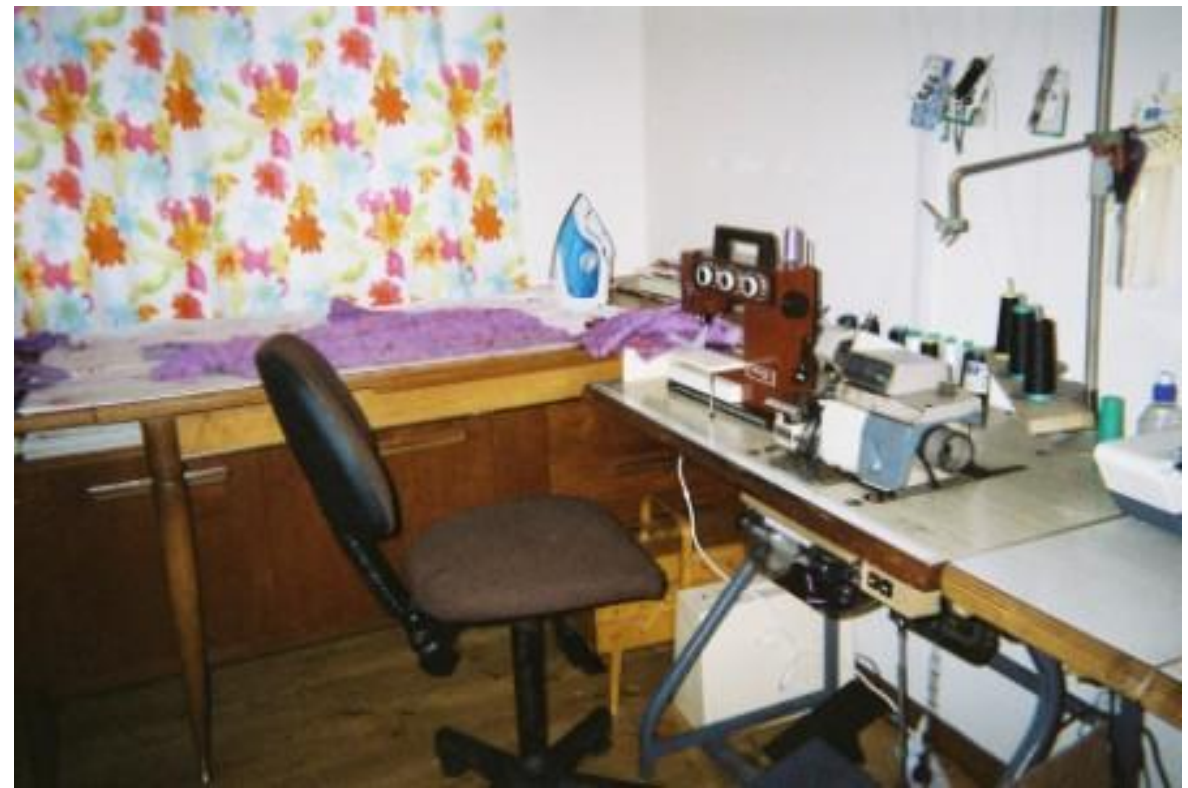

Figure 8.1: Hebe's work station where she works on orders from members of the community on Sunday afternoons (Photo taken by Hebe).

Puriri did not have aspirations to find paid employment but was very keen to volunteer with Refugee Services and assist other former refugees. In order to be a volunteer for non-Burmese families she noted that she needed to improve her English and ideally also get her driving licence. "Once I have enough English I want to help other newcomers. [...] If you have English you can go with people from other countries." She stressed that this was a way in which she could give back in return for all she had gained since arriving in NZ.

Insufficient English prevented several of the women from pursuing their hobbies and from accessing courses of study in order to find work. In response to the question of what kinds of thing she enjoyed doing here, Pohutukawa felt that her options were limited by her English. "It's very hard for us because not enough English. So we need to learn more English. Yeah, I'm not sure what we can do." Rata said that she wanted "to do further study for my future to improve myself. [...] Because I haven't enough English I can't 
get to the level to apply yet. They have an English assessment [at Whitireia]. When they give a refugee grant I'll re-enrol for ESOL."

Hebe wanted to study nursing but felt that it was out of reach for the time being. "One of my hobbies is nursing. Because of childcare and the English barrier I won't be able to pursue what I want to do in nursing." Sophora referred more vaguely to how her struggle with English was impacting on her life in NZ. "For me it's very hard and very difficult having English as a second language, so we haven't enough skills, or something like that..."

There was a feeling amongst several of the women that New Zealanders speak too fast. This may indicate a feeling that people are not making enough effort to speak slowly and clearly with people for who English is not their first language. Kowhai was puzzled with how communication is easy with some people and difficult with others. "Because my English is, you said very good, and then the others don't understand [...] And then New Zealanders speak very fast and I can't get it. They don't understand us and we have difficulties speaking." Similarly, Rata said that "[t]here have been difficulties in the past with the language barrier, because Kiwis speak very fast and I can't pick up the words and things."

\section{Overcoming the language barrier}

Several of the women pointed to progress they had made in terms of overcoming the challenges of English. Kowhai noted that watching local television had really helped her English. Rather than watching Burmese films with her husband she said: 
I love English movies only, and [watch] TV all the time. Because [I can hear] the pronunciation and [...] I need to listen to their accents. I learned English from the TV. My husband doesn't like to watch English movies. He and [I] are a little bit different. He loves Myanmar culture. I love my culture but you know I need to study. Because if I'm not good enough at English I can't [work].

Sophora felt that she had made good progress since first arriving. "Before the volunteer [used to make appointments on the phone] for us but now we can make our own decisions and make the appointments ourselves. Even if our English isn't that good we're understood at the other end." She noted that she was now able to attend the parent teacher meetings for her sons without the volunteer. "Although we don't have enough English, we try and go anyway without the volunteer. We make an effort to try and understand and they try and understand us. So that's a big achievement." Rewarewa noted that she could now understand the letters she received: "Now I understand any letters; last year I studied and now I understand them. The important thing is English, we must learn English".

\section{Discussion}

It is easy to see the challenge of not being able to communicate easily or directly with the wider community. As Puriri noted, "[t]he language is my barrier, it's the hardest, most difficult part. If I know and conquer the language, I can ask anything I want to ask." All the women were concerned with improving their English, and were held back only by constraints such as limited classes, class fees or needing childcare. In addition to making their daily lives easier, English is a platform for enabling them to live full and 
independent lives in NZ: to avail of study options, follow careers, and find work to better support their children in achieving their ambitions.

The literature is united in the emphasis it plays on language learning and the role this plays in aiding all aspects of resettlement. For example, in Michalski's (2001) findings amongst Iraqi refugees in Canada, language was listed as both the primary factor aiding resettlement and the primary challenge. The social interaction and bridging between communities (Daley, 2007; Ager and Strang, 2008) that is considered key to successful integration refers not only to interaction with other members of the community, but also with the wider community. As some of the women mentioned, this is very difficult without enough English to be able to carry on basic conversation. Rewarewa referred to the misunderstandings that this could give rise to. She felt as though people were looking down at her at school, but she could not resolve the situation because she had not enough English to engage them in conversation.

Language has a role to play in acculturation theory, given that the potential for integration is lessened without a common language. The women have learned a certain amount about NZ culture, mainly from their volunteers, home tutors and English language classes, but would have learned more had language not been a barrier. This is less likely to be conducive to Collie et al.'s (2009, p.1) definition of integration: "a desire for both the maintenance of one's heritage culture and the adoption of aspects of the national culture".

Language may again have a role to play in the theory around participation. Where all the women spoke of participating actively in their own communities, few spoke of participation in the wider community. Sophora asked about political processes and how she could engage with local 
politicians and, while she did not cite language as being a barrier to participation in this setting, it probably would have been an issue for her if she did not have an interpreter with her. The main way in which the women seemed keen to participate in the wider community was through a sharing of culture. Again language would be a barrier for most of them in doing this. 


\section{CHAPTER NINE - EMPLOYMENT}

The women placed varying degrees of importance on the role of employment in their lives. For Kowhai, finding satisfactory work was of utmost importance and the conversation continually returned to this challenge. Kowhai said "[t]he job, New Zealand, the job is most important". There were two photos of employment selected by the women during the focus group. Kowhai noted that it was difficult to take photos on this topic because she wasn't sure if she was allowed to take photos at work. Instead she had a photo taken of her during her lunch break, with a flowerbed in the background that she enjoys while on her break (Figure 9.2). The other photo shows seasonal work on a nearby vineyard (Figure 9.1).

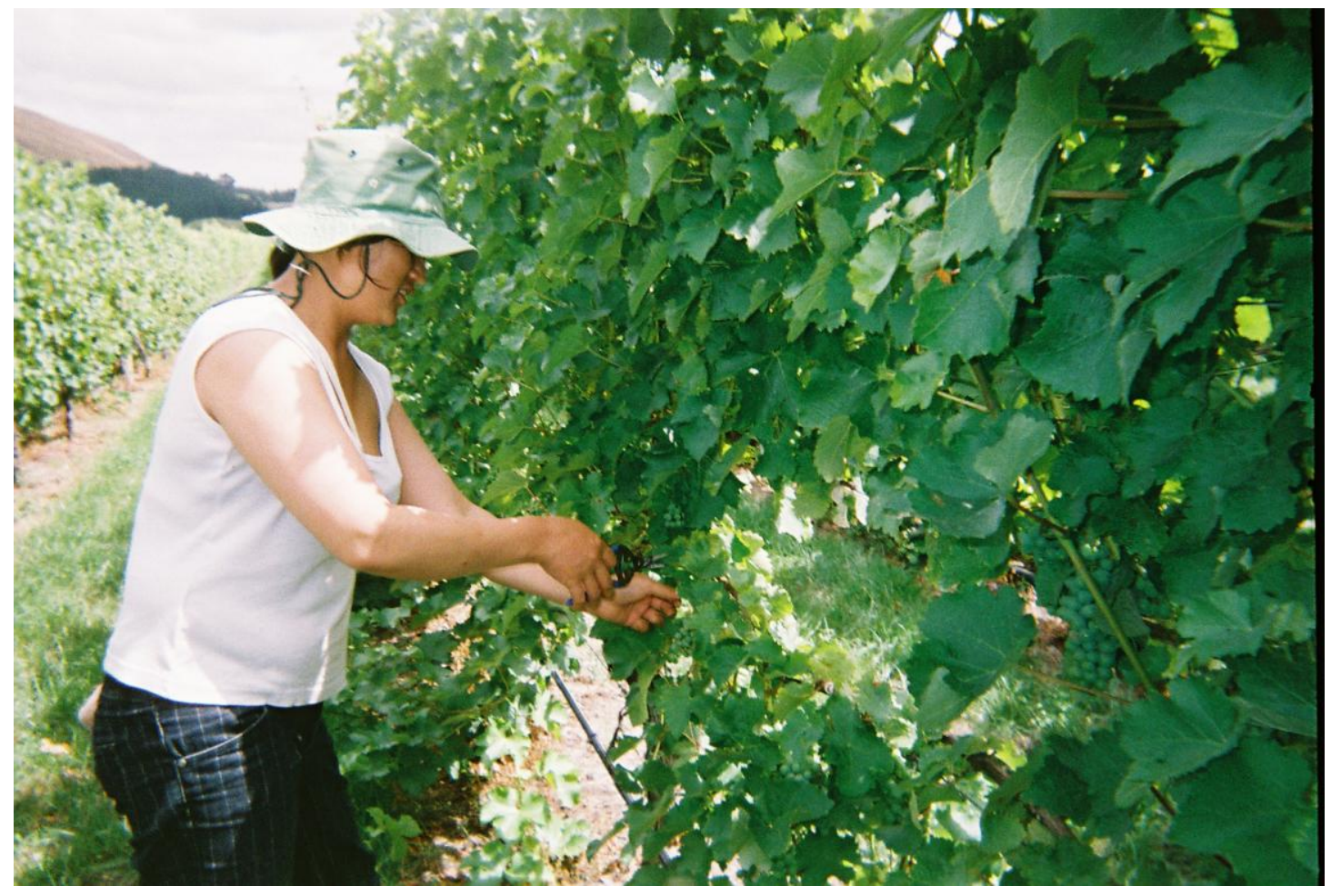

Figure 9.1: Working on the vines in Martinborough during the summer (Photo taken by Clematis' friend).

For some of the women with young children, or those who believed they had little hope of finding work, the issue was referred to only in passing or not at 
all. In these cases, work was a means to an end, for example to enable their children to do well. For many of the women, however, work was tied in closely with the idea of being well established in NZ and getting set up for the future. I had the feeling that it was a key determinant for them in terms of feeling settled here and really being able to make NZ their home.

\section{Hopes for their lives in NZ}

Several of the women hoped that it would be possible to own their own business someday. Kowhai had owned her own business on two occasions in Burma. In response to how she liked life in NZ she said: "I love it but [it's] very hard to, I mean very hard to, in my country my path is, I can open my own business. Before I had a small restaurant, fried noodles and rice, and kebab, kind of like that". She also said that "I opened a beauty salon. But I [couldn't] do it, economy sort of down, so not enough... So I sold that shop, the restaurant also I sold. And I left for Malaysia". Since starting work in NZ she had been working in the café attached to a museum, where she found that she was mostly in the kitchen and washing dishes. She contrasted the level of responsibility she had as a restaurant owner in Burma with her present role in the café.

Clematis had been working part-time in the vineyards. Kowhai pointed out the different backgrounds and variety of experience amongst the Burmese women settling in Wellington and noted that: "I cannot work in a farm or picking apples in the sun and I never worked in that in my country also. I can't do those very hard jobs." Rewarewa also indicated that the job was far from perfect for her, stating that "my friends had already found this job [covering vines at a vineyard in the Wairarapa] and I followed. I don't want [it for a] long time. I want to come in and deal with other people." Rewarewa 
mentioned a couple of ideas for working with other people, saying that she'd like to be a nurse or work in a rest home. She felt that to be a nurse would be difficult:

Yes I'd like to do that but my education is not higher. I want to become a nurse but I'm not... (laughter) step by step English is very hard for me. I need more time; I can't give the time because I have to look after the children or my family.

She also said she'd like to work in a resthome: "I want to work like this but I don't know how to get this job. It's very difficult."

In response to the question of whether NZ is how she expected it, Kowhai noted that the NZ context presents different challenges:

I need to take time to try to do my own business because it's not easy, investment, language, education or experience, or culture. Everything I still have to learn. I'm not yet ready to do my own business, so little bit hard. Yeah, mmm, hard for me.

Rata stated that: "I want to have my own business, a kind of shop, like a superette. I like selling - I want to be a shopkeeper." Rewarewa and Kowhai also talked of opening their own businesses some day. Sophora was concerned with getting established in some line of work. "We are getting older each day but as we grow older I would like to get into something, to do something, get experience, work that I can do in the future." 


\section{Perceived barriers}

A number of the women mentioned some of the reasons they believed finding work in NZ was difficult. Rewarewa noted that "[i]n my country and Malaysia we just go face to face, it's ok. Just in NZ it's very difficult to find a job." She noted that meeting with someone in person was more likely to be successful than sending in an anonymous CV. Flax felt that without knowing someone who can help you, it's difficult to secure a job: "I want to find a job as a shelf packer at the supermarket. But it depends on who you know".

Some of the women felt that their age was a barrier, either because they felt it made it difficult to study or just a barrier to finding work. Flax noted that: "I can't say that I'll go to work because it's difficult to get a job, with our age. Even a university student has difficulties finding a job so we won't aim to get a job." Kowhai was worried by her age saying that: "I worry because you know it's difficult to study when you're old because of the memory [...] We need more education I think, but our age [is a problem]. I can't reach what I need to do. Now is not a good age for study."

Kowhai also gave the impression of being overwhelmed at times with everything else going on in her life and her concerns for both her life here in NZ and her family back home:

Many problems, family, work, money, house, job problems. So many problems. The memory is stuck there. If I'm peaceful and without worries. We have many problems, not big problems, but human problems. So for us, the Asian people, we're stuck here and life is hard. 
She appeared caught between making ends meet and doing a job that was far below her expectations and previous work experience. When asked whether she had been applying for other jobs she answered: "Yes I did but no answer. Nothing, I'd call and then just... All the time I'm looking in the newspapers..." She also spoke about the lack of opportunities where she is currently working:

Some people they change their staff sometimes, at the front, doing dishes, warming them and serving the customers. For me no, just doing the dishes and cutting or helping or cleaning, that's boring, I'm bored. So I hate my job but I can't move. I need [money] to survive.

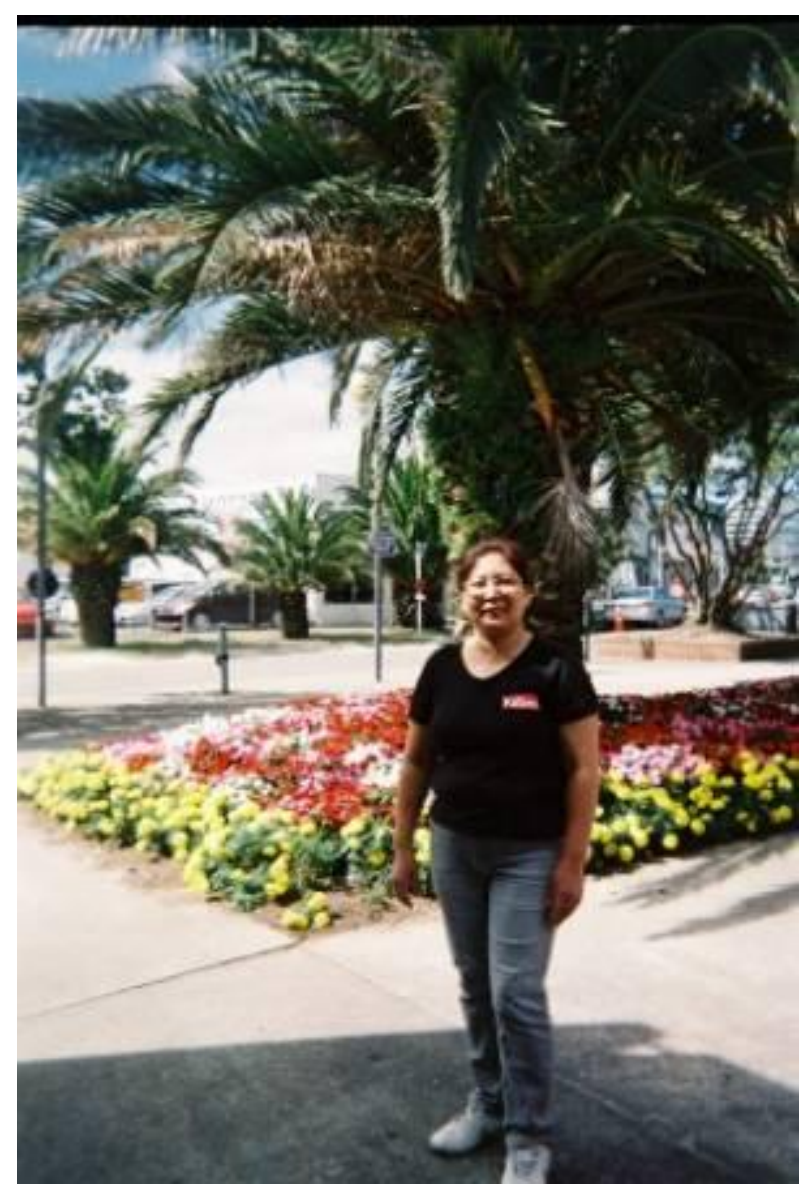

Figure 9.2: In front of the flowerbed enjoying a break from work (Photo taken by Kowhai's friend).

After realising that she could not work as a school teacher as she had in Burma, Sophora got a child-minding certificate from Barnardos. However, as 
mentioned previously, she was unable to find work as a caregiver and felt there was favouritism in how children are allocated:

I was told that there weren't enough children and too many caregivers. All the children have been given to 'who you know, not what you know' so I didn't get a chance to have any children. If I had two or three children that would be a bit of extra income. So that's what I've been aiming for, but that's the difficulty I've faced.

A number of the women mentioned not being able to find work in the supermarkets such as Countdown. Sophora noted: “[...I also tried] to apply at Countdown and I was told that I hadn't enough qualifications".

\section{Seeking out opportunities}

During my conversation with Kowhai, her focus on seeking out new opportunities continually came across. She had attended a number of free courses since arriving in NZ, including a coffee-making course. She was given a computer when she first arrived that she used to spend an hour every evening familiarising herself with, opening the computer, sending emails. She said that her self-taught knowledge was not enough: "I think now I want to learn some computers also, I need to. I can [use them] but not good enough [to be able to work with them]".

She explained also that there had been some discussion of opening a Burmese community shop:

We can sell Burmese food and everyone would be interested. I think we can do the business. But what's difficult is investment, 
management. So [I need to study] business management [...] if I'm going to do the business, because it's different from my country. [...] So you can't run the business if you're not good enough in management.

A number of the women felt that there were opportunities for getting into the workplace through government assistance. Sophora placed less importance on the kind of work she was looking for and said that she and her husband would be happy with any kind of work. She believed that some of the barriers they faced in finding work could be overcome if the government assisted them in their job search:

We don't want to sit at home idle but if we have to find our own jobs and apply for them we never get it because of lack of English, because of interviews and things. But if the government said there's a job here, come and do it. If they place us we'll accept any job and we want to do that - gardening and cleaning and whatever. We want to do that instead of just sitting on the benefit.

She felt that they were not chosen for work because of English language barriers but argued that English was not needed for lots of different types of jobs: "There are a lot of jobs that [we can do] without speaking English".

Sophora also hinted at a role for the government in helping them get established in NZ. "We don't have benefit anymore so we have to pay all our own bills. Just enough, no extra money, so we have to, maybe they have to give us more support, so we can step up some more." She did not mention the exact form she thought the assistance should take but believed firmly in the importance of working. "I'd like encouragement to go to work so you get 
work experience and meet other people. It's networking. If you stay home you can get sick."

\section{Discussion}

Much of the conversation around employment signalled the women's frustration around wanting to work and not having the opportunity, or not being able to contribute to the workforce at a higher level. Above all, they gave the impression of very determinedly continuing to seek out opportunities. As noted by Kowhai: “I'll try to. If not I won't stop, I'll keep going, looking for the best way."

Some of the literature refers to the importance of employment both in terms of aiding resettlement and having financial capital. The two ideas place different emphasis on the importance of work in contributing to a sense of well-being. Employment was one of five factors assisting resettlement identified in Michalski's study (2001) of Iraqi former refugees in Canada. This is certainly reflected in how frequently the theme was discussed by the Burmese women. Similarly, not finding a job was identified as a barrier to resettlement and in both cases it was felt that government could play a greater role in helping them into the job market.

The literature (Essed et al., 2005; Daley, 2007; Westoby, 2008) criticises what they see as a service delivery culture. However, the women's experiences in finding work would suggest that rather than detracting from their agency, this would help them overcome an obstacle on which they might otherwise remain stuck for some time. Aside from allowing them to fulfil their potential and feel better about themselves generally, it would also assist them to demonstrate greater agency in other areas of their lives. This would also be 
consistent with a human rights-based approach through its potential to create a more equal footing between host and refugee.

Although the women did not refer overtly to the issue of discrimination, two of them talked of employers hiring based on 'who you know, not what you know'. Kowhai voiced her frustration at not being rotated in the other roles at the café, despite her previous experience and English language skills. Sophora talked of not being considered for jobs, even if they do not require English. As a way around this, she suggested that the government could play a greater role in providing them with a footing in the job market.

Social capital played a role in helping some of the women to find work, mainly the temporary work in the vineyards that some of the women had been doing. This was organised by a member of the Burmese community and anyone interested could sign up for it. In this case, the initiative came from a community member and the government did not need to play a role. However, relying on the initiative of one individual in this way leaves it more to chance and it would be useful to make this role more regulated.

Li (2003) referred to a measure of economic integration in Canada, whereby refugees were successfully resettled when they had reached or surpassed the performance of native-born Canadians. Certainly the experiences of the women in overcoming barriers of language, work experience considered relevant by NZ employers, and non-recognition of previous qualifications were evidence of the extent to which this measure is unrealistic. Even where the women were very determined in seeking out qualifications they could afford, such as Kowhai's coffee-making course and Sophora's Barnardos certificate, and where their English language skills were adequate, they were unable to find work using those skills. 


\section{CHAPTER TEN - DISCUSSION, RECOMMENDATIONS AND POSSIBLE AREAS OF FUTURE RESEARCH}

\section{Discussion of research aims, process and findings}

In this research project, I investigated how ten Burmese women from refugee backgrounds are adapting to life in Wellington, using photovoice, interviews and a focus group to explore their experiences. I considered some of the key policies and procedures around refugee issues and reviewed the literature relating to different aspects of the resettlement experience. This reading informed the questions I chose to discuss with the women during the interviews and focus group, as well as the findings that I drew from those discussions. I used the themes proposed by the women during the focus group to structure my findings' chapters. In these chapters, I drew on extensive quotes from the interview transcripts, illustrated by the women's photos. This ensured that I privileged the women's narratives, while also including my own perspectives based both on the literature I had read and my own observations.

This research project filled a number of gaps in the existing knowledge. It is the first study to focus on the Burmese community in NZ, who are the largest group to arrive in NZ since 2000. Little research has focused to date on the first-hand experiences of resettling former refugees. Similarly, the particularities of women's experience have not been given much attention. This qualitative study captured these women's subjective experiences in the early years of their resettlement. It generated information about their specific concerns and the roles they play within their communities, and contributed to 
new understandings of former refugee women's well-being. While considerable literature exists on social capital and the potential benefits for former refugees, few studies have looked at how this plays out in practice. This research shows how the women's social networks contribute to their well-being.

The central question I had sought to answer was how the women were experiencing their resettlement, with a view to understanding what can help in supporting them to live full and meaningful lives in NZ. The sub-questions that guided my research were:

1. What factors contribute to the women's sense of well-being in Wellington?

2. What has helped in dealing with difficult aspects of their lives since their arrival here?

3. What can be done to support the women in living full and meaningful lives?

To answer these questions, I asked the women to take photos of everyday things in their lives that had particular significance for them. In individual semi-structured interviews, I discussed a series of questions designed to explore their feelings about their lives in NZ, to identify things they like here as well as what has been challenging, and what has helped in overcoming those challenges. The women used the photos to illustrate and/or elaborate on points they made.

My research highlighted the important role played by community networks and how they assisted the women in adapting to life in NZ. These networks meet various needs, which include practical information and assistance on arrival, a source of companionship and a means of preserving their ethnic 
cultures and languages. Some of the women were making financial contributions to a savings fund, should a community member need it. Thus social networks also contribute to the women's resilience by providing a source of financial support if really needed.

An additional benefit of the women's community networks lay in the act of participation itself, which is said to foster a sense of empowerment and feelings of inclusion. The women who were more involved with the community reported greater levels of satisfaction with life in general. Although most of the women talked of participating within the Burmese community, they reported little or no participation in the wider host community. Many of the women spoke of wanting to share their culture, which they consider rich and imbued with worthwhile values, with the host community but so far had had little opportunity to do so.

Some of the women referred to feeling looked down upon by other New Zealanders, and felt that assumptions were made about their education and background based on the fact that they had arrived in NZ as refugees. This was a source of frustration for them, and while some of the women felt that they were overcoming such assumptions through their contact with New Zealanders, others felt cut off from the wider host community and unable to represent themselves more accurately.

The women's sense of connectedness with the host community is greatly enhanced through the role of volunteers and home tutors. Almost all the women stressed the important role of these volunteers in aiding the resettlement process. They provided both concrete assistance in terms of information, help with accessing services and getting around, as well as a source of friendship and a connection with the wider host community. 
Life in NZ can be seen as providing the women with a sense of ontological security, or a feeling of order and continuity in their lives. The women valued greatly the opportunities available to their children, such as education and healthcare. They also enjoyed being able to cultivate their gardens, and track the progress of their crops and fruit trees through the seasons. Adult education classes, such as flower arranging and sewing, allowed the women to pursue their hobbies. However, they struggled with issues of transport, and with different ways of doing things in NZ, such as laws relating to childcare and car maintenance.

Issues relating to English language came up repeatedly during the interviews. The women stressed the importance of improving their English in order to be able to find work, pursue further study, and communicate more easily with the wider host community. In some cases, English language was a barrier to portraying a more accurate picture of themselves to people they meet at school, in their jobs, or on the street. Everything the women said about English language ability pointed to its importance for living full and meaningful lives in NZ. Recent cuts to English classes and/or the childcare that enable the women to attend classes were a cause of concern for them.

Finding work was another major concern signalled by the women - either finding any kind of job or finding work in line with their previous experience and qualifications. The women stressed the importance of work both in terms of leading fulfilled lives and providing financially for their families. This was one area where a number of the women felt that the government could play a greater role in assisting them; although they did not mention discrimination explicitly, they felt they were not being chosen for jobs they could do or, in the case of those with jobs, not being given opportunities for advancement. 
Such government assistance could provide a footing in the NZ job market and speed up the integration process.

\section{Discussion of findings referring back to key theoretical ideas}

The literature on resettlement (Hulewat, 1996; Canadian Council for Refugees, 1998; Gray and Elliot, 2001) notes how the needs and concerns of resettling former refugees change over time, as people acclimatise to their new surroundings, find work, learn the local language and establish themselves in their community. These needs vary also according to individual circumstances, such as the community support networks available, prior language ability and employment opportunities. My research confirmed that resettlement needs vary depending on the individual and that they change over time. This highlights the importance of using former refugees' first-hand experiences to inform resettlement policies and practices.

One particular model of integration talks of a two-way interchange where former refugees, the host community and its institutions are undergoing a process of adaptation (Canadian Department of Citizenship and Immigration, 2002; Phillimore and Goodson, 2008). Former refugees are getting involved in their new communities, through work, school, contact with volunteers and home tutors, and in some cases interaction with the wider host community. According to this model, host community institutions should be changing in response to the population's increasing diversity and catering to the needs and concerns of former refugees. The host community also needs to be identifying ways to be more inclusive of newcomers. An assessment of the integration process would require change to be measured at all three levels. Given the desire on the part of the women I spoke to for greater engagement with the host community, such initiatives for inclusion and reaching out to 
former refugees on the part of the host community would be welcomed by former refugees and would assist the integration process.

Castles et al. (2002) recommends setting indicators to measure integration and resettlement outcomes in consultation with former refugee communities. Whereas some of the indicators mentioned in the literature on resettlement, such as work and language ability, were relevant to the women's sense of well-being, other potential indicators, such as opportunities to attend adult education courses, were not mentioned. This demonstrates the importance of setting resettlement indicators in collaboration with former refugees.

Much of the literature on resettlement and integration is concerned with addressing the needs of former refugee communities, and putting in place appropriate support services (Michalski, 2001; Daley, 2007; Phillimore and Goodson, 2008). While my research confirmed the importance of such support services, it also highlighted the resources and social capital of former refugee communities, and the important role that such resources play in their resettlement. Support services are used and appreciated, and assist the resettlement process. However, it is essential to recognise the role played by former refugees' own resources in this process. Support services should continually seek ways to complement and build on the existing resources of former refugees.

One model of acculturation (Collie et al., 2009) considers how newcomers from a different cultural background negotiate between two cultures. The women all referred to the distinctness of Burmese culture and how different it was to "Western" culture, which shows that they are negotiating between the two cultures in their interaction with the host community. Several of the women spoke of liking certain aspects of NZ culture, and wanting to take this 
on board to blend with their own culture. Whereas the women were not generally concerned with needing to negotiate between two cultures in this way, they were worried about their children losing Burmese values as they grew up. They were doing their best to instil Burmese culture and values in their children but this remained an area of concern for them as they resettled in NZ.

The potential for participation to contribute to successful resettlement outcomes is widely espoused in the literature on resettlement (Florin and Wandersman, 1990; Goodkind and Foster-Fishman, 2002; Lindgren and Lipson, 2004). This was confirmed by my research, which found that former refugees were benefitting greatly from participating in their own communities. Participation in the wider host community is said to present a different range of benefits, such as language skills and local knowledge, but it is recognised that such participation generally takes longer and requires a certain level of language skills. This was borne out by my research, which found that many of the women wanted to engage more with the wider community but found language to be a barrier. Most of the women were not working outside the home; those who were had the most opportunity for interaction with the host community.

\section{Concluding thoughts on resettlement}

In conclusion, my research demonstrates the important role played by community networks in the resettlement process. The women's sense of wellbeing was enhanced through the various ways in which they interact with the local Burmese community: through the immediate support and information provided on arrival, the weekly get-togethers at church service, the celebration of special religious and cultural days and the opportunities 
provided for cultural maintenance. Such networks also helped offset one of the women's main concerns, which is that of passing on their language, culture and values to their children. This highlights the importance of resettling former refugees where they can access such community networks. In the case of the Burmese women I spoke with, having contact with people from their own ethnic group provided an additional source of well-being.

The women I spoke with were in the early years of resettlement, having all arrived in NZ in the last five years. They reported little interaction with the wider host community, and the main source of contact was through volunteers and home tutors. Some of the women had benefited greatly from these roles, others felt they had not been so lucky in the support people they were allocated. Given the different needs presented by former refugees, in terms of language, family size, work skills and previous experience, additional support beyond the six months stipulated in the volunteer agreement may sometimes be advisable.

Language skills are central to the resettlement process and were a constraining factor in many ways. They limited the extent to which the women could interact with the wider host community. This was a source of frustration for the women, especially in situations where they felt that New Zealanders had an inaccurate picture of them based on their refugee backgrounds. Thus even in situations that presented the opportunity for discussion and a bridging of the divide, language was a barrier to communication. A lack of English has implications both for the practical aspects of finding work and studying, as well as for former refugees' sense of confidence and connection to the wider host community. English language classes, with the provision of childcare where necessary, are essential to the resettlement process. 
The women's sense of well-being was greatly enhanced by the opportunities provided by life in NZ. The knowledge that their children's health and education needs were assured was a huge source of well-being. They also appreciated the opportunity to develop personal interests through adult education classes, being able to afford to buy equipment they need, and use their gardening skills. However, some of the women had unrealistic expectations of what they would find on arrival. Those who had a more realistic idea of what to expect resettled more easily. Information prior to coming to NZ is important in creating realistic expectations and can aid the resettlement process.

Some of the women were awaiting the outcome of family reunification applications and were finding this to be a long and unsettling process. As long as they had family members in refugee camps or in potentially dangerous situations, it was difficult to feel well settled in NZ. Expediting the family reunification process is another factor that can greatly assist the resettlement process.

\section{Recommendations}

My research found that the services provided to help with the resettlement process were both fully utilised and appreciated by this group of Burmese women. Most of the women expressed a desire for more support in some form. Below are a number of suggested areas where further support could be targeted:

1. The analysis reveals that language has an importance beyond its purely utilitarian value of allowing the women to seek work and communicate with 
the host community. It also has a large part to play in women's feelings of self-confidence and in creating the potential to engage with the host community in a more meaningful way. Language is a critical part of their resettlement experiences; everything possible should be done to ensure that classes are available to the women at appropriate times to allow them to learn at the speed they wish. Childcare needs to be provided alongside English language classes to allow women with young children to attend.

2. The women are part of close-knit networks, generally based around their own ethnic group. Given the importance of these networks in contributing to the women's well-being, and the important role they play in cultural maintenance, they should be given more recognition in service delivery frameworks. For the women I spoke with, who were all living in the Porirua area, the networks had come about naturally and arrangements, such as the leasing of church space, had been taken care of by more established community members. However, refugees arriving in regions without such established networks and arrangements could be at a disadvantage. Some of the women did refer to not having any or many people from their own ethnic group living in the vicinity. While efforts are made to group refugees of the same nationality, in a country such as Burma where ethnic identities are very strong, ethnic identity is a further factor that should be taken into account.

3. One of the main sources of satisfaction for the women came from the time spent in their gardens. None of the women were dissatisfied with their homes, despite some inconvenience with location and transport, which may have been because of the garden size. Although the women were all content with their gardens, there could be more formal recognition on the part of government and service providers of the importance of gardens for the resettlement process of some former refugees arriving in the country. 
4. There is scope for recognising and building on the existing strengths of people from refugee backgrounds, in line with a strengths-based approach. The women were seeking out and availing of any course possible to assist with finding a job. Increasing the availability of courses, tailoring them to build on existing skills or making it possible to gain additional qualifications recognised in NZ, such as Sophora's qualifications in teaching, Kowhai's business experience or Hebe's sewing skills, could add to their financial and emotional well-being and contribute to the NZ economy.

Several of the women spoke of setting up businesses, such as opening a small shop, and one woman was keen to expand her sewing business beyond the local Burmese community. Workshops with information on business planning, raising capital and compliance issues are run by New Zealand Trade and Enterprise (NZTE). NZTE has recently launched a programme aimed at helping Pacific people improve their business skills (Business to Business, n.d.). Such programmes targeted to meet the needs of former refugee communities would be useful. They would need to take into account constraints such as language skills, childcare and available time. The planning of any such initiatives should involve consultation with the target audience to address any concerns or constraints they might have.

5. Cross-cultural workers are employed by Refugee Services to liaise with refugee families and keep abreast of any issues they may be facing. Annie provides support for other families in the Wellington region. The importance of this role was highlighted for me as I saw how she was received by the women and their eagerness to discuss issues of concern for them, such as their children's health or issues relating to child discipline. This key role should be 
maintained and bolstered, with checks in place to ensure that families and women are really availing of and benefiting from the contact.

6. Women highlighted the important role of volunteers and home tutors in assisting them to adapt to NZ society. They performed an important role in providing both practical assistance and a source of companionship. However, whereas some of the women reported excellent relationships with their volunteers/home tutors, others felt they had not received the help and support they needed. At present the Refugee Services social worker and crosscultural worker check with families on how the relationship is going. One of the women indicated that, although she was not happy with the relationship with her volunteer, she had not wanted to voice her dissatisfaction. Thus, despite the checks in place, issues are not always identified and families are missing out on valuable support. A closer monitoring of this service could help to identify any problems arising.

Relationships worked really well where friendships developed between the women and their volunteers. While this is not something that can be planned for, some families would benefit from assistance beyond the six months stipulated in the volunteer agreement. This may be for reasons of illiteracy, large families, elderly people or low English language skills. The possibility of further support beyond the initial six-month period should be discussed with the volunteer and former refugee family, with the option of allocating another volunteer if necessary.

7. Initiatives for bringing together members of the host community and refugee women and families are invaluable in bridging the gap between the communities. The women reported that where host community members had specific roles, such as volunteer or home tutor, the relationships were 
generally very beneficial and rewarding. More contact through such 'formal' relationships, such as 'buddy systems' in schools or workplaces, could help to create a wider network of relationships between former refugees and the host community.

The various Burmese ethnic groups put great effort into celebrating their national days, which include cultural performances and local food (as shown in Figure 6.3). Greater involvement in and promotion of such events amongst the wider community by local government would provide an opportunity for a sharing of culture between former refugee communities and the host community. Such initiatives could be beneficial in creating greater awareness in the host population of the issues faced by refugee communities. The women felt cut off from the host community partly because they felt there was so little awareness of who they are and where they come from, their specific individual circumstances, as opposed to those of the wider refugee community. A greater awareness about the individual circumstances and the situations that forced them to leave would help in bridging the gap between refugee background and host communities.

Similarly, media has a role to play in influencing how former refugees are viewed and attitudes of the host community. Better media strategies can help to foster understanding of refugee issues and break down stereotypes.

8. Having realistic expectations of NZ and what they would find on arrival was important in helping with the women's early stages of adjustment and resettlement. The women I spoke to had differing expectations and levels of knowledge about NZ. The women who had information about the country before arrival, such as facts about its population, economy and size, were better able to align their hopes and expectations with the reality. Others who 
had less information before arrival were confused and disappointed by certain aspects of NZ; they noted that it was only with time that they came to understand and appreciate the place.

Receiving information about a country prior to arrival contributes to a sense of security and belonging and has an impact on early resettlement experiences. Whereas some of the women had received information about NZ before arriving in the country from NZIS or the UNHCR, others knew very little. Incoming refugees would benefit from learning more about the country in advance: about the economy, culture employment sector, political system, welfare system, and education and health systems.

\section{Possible areas of future research}

This study focussed on a small group of Burmese refugee women. The group size provided me with an in-depth insight into their particular experiences. Future studies could focus on groups of women from other backgrounds. Factors such as time spent in the country, age, language proficiency, level of education and urban or rural background could be varied in order to generate knowledge about a specific group.

A longitudinal study looking at how these women's experiences change with time spent in NZ would provide insights into how their well-being develops over time. It would be interesting to find out whether they resolve some of the challenges facing them and whether different challenges emerge. Such a study could inform long-term funding of initiatives to target the needs of refugee women. 
This study adopted a psychological model focusing on subjective resettlement experiences. Different models for understanding the resettlement experience could be adopted for future studies, such as a mental health model, or a focus on cultural or economic adaptation.

This study did not look at men's experiences - future studies looking at the experiences of men from refugee backgrounds could generate comparisons on gender elements. 


\section{Appendix A}

Semi-structured interview guide

1. Questions about participants' backgrounds.

2. How do you feel about your life in New Zealand?

3. What do you do like most about your life here?

4. What kinds of things do you look forward to?

5. What kinds of difficulties have you encountered since arriving in New Zealand?

6. What things or people have helped you the most in your resettlement?

7. What have you learned about yourself or your culture since coming to New Zealand?

8. What would you like others in New Zealand to know or understand about your experiences and/or lives in New Zealand?

9. What gives you pride about being Burmese?

10. Have you any plans for the future that you would like to share? 


\section{Appendix B}

\section{INFORMATION SHEET FOR PHOTOVOICE PROCESS AND SEMI- STRUCTURED INTERVIEWS}

\section{Title of project: Resettlement Experiences of Burmese Refugee Women in New Zealand}

Researcher: Una McGurk.

I am a Masters student in Development Studies at Victoria University of Wellington, New Zealand. As part of this degree I am undertaking a research project leading to a thesis. The project I am undertaking is to document the resettlement stories of Burmese refugee women living in Wellington. This research sets out to explore how refugees are experiencing life in New Zealand in the early years following their resettlement. By focussing on the stories of ten women from the same community, the project seeks to draw out themes on the kinds of difficulties faced and identify factors which can support women in living full and meaningful lives. The research will employ the photovoice method, whereby the women will record aspects of their lives which are significant for them through photographs.

In September I will look for participants for the project. In late September/early October, a 2-3 hour introductory session will be held with all participants to:

- explain the concept of the photovoice method and how it works;

- distribute the cameras and look at how to use them;

- discuss some techniques on how to take a photograph (facilitated by a professional photographer);

- explain the need to ask permission of anyone photographed;

- explain that the photos will be used as the basis for discussion during the interviews and focus group as well as to put together an exhibition afterwards.

Over a 3-week period following the introductory session, participants will be invited to photograph aspects of their lives which are significant to them. In late October/early November, I will gather the cameras and process the photographs in preparation for the individual interviews. The interviews will take place in November and December. At the beginning of the individual interviews, participants will be asked to select 10-15 photographs which they feel are particularly relevant or like best. These photographs will form the 
basis for discussion during the interview. We will also refer to the questions in the interview question guide (Appendix C).

The photographs and the discussion generated by the photographs during the interviews will form the basis for my research project. After the interviews and focus group a selection of photos will be copied, enlarged and used to form an exhibition which will be shown locally and afterwards donated to ChangeMakers Refugee Forum. Permission for use of the photographs will be sought from participants before the exhibition is put together. The original photographs will be returned to the participants. Participants may choose to keep the photographs confidential, in which no one aside from me and my supervisors, Sara Kindon and Alia Bloom, will see them. For photographs included in the exhibition, participants may be asked to provide an explanatory note to accompany them. Alternatively quotes may be used from interviews/focus group, in which case permission will be sought. The rest of the material collected during the photovoice process and interviews will be kept confidential. No one aside from me and my supervisors, Sara Kindon and Alia Bloom, will listen to the tape recording of the interviews. The thesis will be submitted for marking to the School of Geography, Environment and Earth Sciences and deposited in the University Library. It is intended that one or more articles will be submitted for publication in scholarly journals.

Victoria University requires that ethics approval be obtained for research involving human participants. The project now has the approval of the University's Human Ethics Committee.

\section{What is involved?}

- The interviews are designed to take 2-3 hours and can take place at a mutually agreed time and place. They will be conducted by Una McGurk. Prior to the interviews you will be given further information about the process in a consent form (Appendix C). If you choose to sign the consent form we will be able to carry out the interview.

- Your participation is entirely voluntary. If you agree to take part in the photovoice process and interview you are free to withdraw any information you have provided in the three months following the interview without having to give reasons.

- During the interview we will discuss the photos which you have taken during the photovoice process. We will also include a number of questions prepared in advance. These questions will be open-ended 
and you can say as little or as much as you choose. You can also choose not to answer certain questions.

- If you agree the interviews will be tape-recorded and used to complement the notes taken during the interview.

- Opinions attributed to you in any written reports will be checked for your approval prior to final inclusion.

- Data collected during the interviews will be accessed only by Una McGurk and her research supervisors. These will be stored in a locked filing cabinet or as password protected electronic documents and destroyed after 5 years.

Please feel free to contact Una McGurk or the research supervisors if you have any questions or would like to receive further information about this study.

\section{Researcher:}

Una McGurk

Masters of Development Studies student, Victoria University, Wellington

unamcg@yahoo.com

Ph: 0277402379

\section{Research Supervisor:}

Sara Kindon

Senior Lecturer in Human Geography and Development Studies, Victoria University, Wellington

Sara.Kindon@vuw.ac.nz

\section{Secondary supervisor:}

Alia Bloom

Research Coordinator, ChangeMakers Refugee Forum, Wellington

alia@crf.org.nz 


\section{Appendix C}

\section{CONSENT FORM FOR PHOTOVOICE PROCESS AND SEMI- STRUCTURED INTERVIEWS}

Title of project: Resettlement Experiences of Burmese Refugee Women in New Zealand

- I have read and understood the attached 'Information sheet for photovoice process and semi-structured interviews'. I have had an opportunity to ask any questions I may have about the study and about participating in the photovoice process and interview and have had them answered to my satisfaction.

- I agree to participate in this photovoice process and interview and understand that I may withdraw myself (or any information I have provided) from this project in the three months following the interview without having to give reasons.

- I understand that, if I agree, the interview will be tape-recorded and that only the researcher and her supervisors will have access to this material. Aside from the photographs taken as part of the research process, any information I provide will be kept confidential to the researcher and her supervisors.

- I understand that all written material and taped interviews will be stored in a locked filing cabinet or as password protected electronic documents and then destroyed after 5 years.

- I understand that any photographs to be shown publicly, quotes used to accompany the photographs or opinions attributed to me in written reports will be checked for my approval prior to final inclusion.

- I understand that the data I provide will not be used for any other purpose or released to others without my written consent.

I part in this study by being interviewed. (full name) hereby consent to take

Signature:

Date: 
Interview conducted by:

Signature:

Date:

$\square$ I would like to receive a summary of the research findings Yes / No (Please circle) 


\section{REFERENCES}

Ager, A., and Strang, A. (2004). Indicators of integration: Final report. Research, Development and Statistics Directorate, Home Office, Great Britain.

Ager, A., and Strang, A. (2008). Understanding integration: A conceptual framework. Journal of Refugee Studies, 21(2).

Altinkaya, J. and Omundsen, H. (1999). Birds in a gilded cage: Resettlement prospects for adult refugees in New Zealand. Social Policy Journal of New Zealand, (13): 31-42.

American Non-Governmental Organisations Coalition for the International Criminal Court (2009). Crimes of sexual violence addressed by the International Criminal Court. Retrieved on 11 November 2011, from www.amicc.org/docs/ Crimes of Sexual Violence.pdf

Anderson, K., Armitage, S., Jack, D., and Wittner, J. (1987). Beginning Where We Are: Feminist Methodology in Oral History. Oral History Review, 15(1): 103-127.

Banki, S. (2006). Burmese refugees in Toyko: Livelihoods in the urban environment. Journal of Refugee Studies, (1).

BBC News (7 November 2010). Burma holds first national elections for 20 years. Retrieved on 26 November 2010, from www.bbc.co.uk/news/world-asiapacific-11704738

Beg, N. W. (2005). A qualitative study on the factors influencing the cultural, economic and social integration of Afghan women in Canada. (Master's thesis). Carleton University, Carleton.

Berry, J. W., Kim, U., Minde, T. and Mok, D. (1987). Comparative studies of acculturative stress. International Migration Review, 21(3): 491-511.

Berry, J. W. (1997). Immigration, acculturation, and adaptation. Applied Psychology: An international Review, 46(1): 5-34.

Berry, J. W. (2005). Acculturation: Living successfully in two cultures. International Journal of Intercultural Relations, 29: 697-712. 
Berry, J. W. (2008). Globalisation and acculturation. International Journal of Intercultural Relations, 32: 328-336.

Bloom, A. (2006). The possibilities of peacebuilding among young Palestinian refugees. (Master's thesis). Victoria University of Wellington, Wellington.

Brees, I. (2008). Refugee studies: Strategies of work on the Thai-Burmese border. Journal of Refugee Studies, 21(3): 380-397.

Bryman, A. (2004). Social research methods (2 ${ }^{\text {nd }}$ Ed.). Oxford University Press, Oxford and New York.

Burma Campaign UK (n.d.). Brief History. Retrieved on 22 November 2010, from http://www.burmacampaign.org.uk/index.php/burma/about-burma/ about-burma/brief-history.

Burns-Francis, A., De Ridder, C., and Woolcock, T. (2007). Burmese refugees join melting pot of Kiwi life. Te Waha Nui.

Business to Business (n.d.). Pacific business training programme launched. Retrieved on 24 November 2011, from http://www.btob.co.nz/article/pacificbusiness-training-programme-launched?page $=0,1$

Butler, A. (2005). A strengths approach to building futures: UK students and refugees together. Community Development Journal, 40(2): 147-157.

Canadian Council for Refugees (1998). Best settlement practices: Settlement services for refugees and immigrants in Canada. Retrieved 16 February 2010, from http://www.ccrweb.ca/pbfinal.htm.

CARE (n.d.). Incorporation of a Rights-Based Approach into CARE's Program Cycle. Retrieved on 15 March 2011, from http://pqdl.care.org/CuttingEdge/ Incorporating per cent20RBA per cent20in per cent20CARE's per cent 20Program per cent20Cycle.pdf

Caritas (n.d.). Refugee myths and realities. Retrieved on 13 July 2010, from www.caritas.org.nz/sites/default/files/Refugee per cent20Myths per cent20 and per centRealities.pdf

Castles, S., Korac, M., Vasta, E. and Vertovec, S. (2002). Integration: Mapping the field. Home Office Online Report. Home Office, London. 
Chacko, E. (2004). Positionality and praxis: Fieldwork experiences in rural India. Singapore Journal of Tropical Geography, 25(1): 51-63.

ChangeMakers Refugee Forum (2008). Standards for engagement: Guidelines for central and local government, and NGOs working with refugee background communities. Retrieved on 15 January 2010, from http://www.crf.org.nz/sites /crf.org.nz/files/staff/Standards for Engagement single per cent20pg.pdf

ChangeMakers Refugee Forum (2010). Guidelines for Research with Refugee Background Communities. Retrieved on 15 January 2010, from http://nzrefugee research.wikispaces.com/file/view/Guidelines+for+research+with+refugeebackground+communities.pdf

Chase, S. E. (2000). Narrative inquiry: Multiple lenses, approaches, voices. In Handbook of qualitative research methods. N. Denzin, and Lincoln, Y. (eds.) Sage Publications, Thousand Oaks, California.

Chimni, B. S. (2009). The birth of a 'discipline': From refugee to forced migration studies. Journal of Refugee Studies, 22(1): 11-29.

Coday, D. (2001). Burma - Political history, military rule, forced labour, struggle for democracy. National Catholic Reporter.

Colic-Peisker, V., and Tilbury, F. (2003). 'Active' and 'passive' resettlement: The influence of support services and refugees' own resources on resettlement styles. International Migration, 41(5): 61-91.

Collie, P., Kindon, S., Liu, J. and Podsiadlowski, A. (2009). Mindful identity negotiations: The acculturation of young Assyrian women in New Zealand. International Journal of Intercultural Relations, 1-13.

Collie, P., Liu, J., Podsiadlowski, A. and Kindon, S. (2009). You can't clap with one hand: Learnings to promote culturally grounded participatory action research with migrant and former refugee communities. International Journal of Intercultural Relations, 1-9.

Craig, G., and Lovel, H. (2005). Community development with refugees: Towards a framework for action. Community Development Journal, 40(2): 131136.

Craig, G. and Mayo, M. (Eds.) (1995) Community empowerment: A reader in participation and development. Zed Books, London. 
Dahlberg, L., and McCaig, C. (Eds.) (2010). Practical research and evaluation: A start-to-finish guide for practitioners. Sage Publications, London, Thousand Oaks, New Delhi, Singapore.

Daley, C. (2007). Exploring community relations: Community cohesion and refugee integration at a local level. Community Development Journal, 44(2): 158171.

Dando, K. (22 December 2009). Lian and Lin making Porirua home. Kapi Mana News.

Davies, M. B. (2007). Doing a successful research project using qualitative or quantative methods. Palgrave Macmillan, Hampshire and New York.

DeVault, M. L., and Gross, G. (2007). Feminist interviewing: Experience, talk and knowledge. In Handbook of Feminist Research: Theory and Praxis. S. H. Hesse-Biber (Ed.) Sage Publications, Thousand Oaks, London, New Delhi.

Dibley, R., and Dunstan, S. (2002). Refugee voices interim report: A journey towards resettlement. New Zealand Immigration Service, Wellington.

Dunstan, S., Dibley, R., and Shorland, P. (2004). Refugee voices: A journey towards resettlement. International Migration Settlement and Employment Dynamic, Department of Labour.

Eastmond, M. (2007). Stories as lived experience: Narratives in forced migration research. Journal of Refugee Studies, 20(2): 248-264.

Essed, P., Frerks, G. and Schrijvers, J. (2005). Refugees and the transformation of societies: Agency, policies, ethics and politics. Berghahn, New York and Oxford.

Florin, P. and Wandersman, A. (1990). An introduction to citizen participation, voluntary organisations, and community development: Insights for empowerment through research. American Journal of Community Psychology, 18(1): 41-52.

Fontana, A. and Frey, J.H. (2005). The interview: From neutral stance to political involvement. In The Sage handbook of qualitative research. N. Denzin, and Lincoln, Y. (Eds.) Thousand Oaks, London and Delhi, Sage Publications.

Ganguly-Scrase, R., and Julian, R. (1998). Minority women and the experiences of migration. Women's Studies International Forum, 21(6): 633-648. 
Ganguly-Scrase, R. and Vogl, G. (2008). Ethnographies of gendered displacement: Women's experiences in South Asia under neo-liberal globalisation. Women's Studies International Forum, 31: 1-15.

Ghorashi, H. (2005). Agents of change or passive victims: The impact of welfare states (the case of the Netherlands) on refugees. Journal of Refugee Studies, 18(2): 181-198.

Ghorashi, H. (2007). Giving silence a change: The importance of life stories for research on refugees. Journal of Refugee Studies, 21(1): 117-132.

Giddens, Anthony (1991) Modernity and Self-Identity. Self and Society in the Late Modern Age. Cambridge, Polity.

Gilmartin, M. (2001). Making space for personal journeys. In Feminist geography in practice: Research and methods. P. Moss (Ed.) Wiley-Blackwell, Oxford, Massachusetts.

Goodkind, J. R. and Foster-Fishman, P.G. (2002). Integrating diversity and fostering interdependence: Ecological lessons learned about refugee participation in multiethnic communities. Journal of Community Psychology, 30(4): 389-409.

Gray, A. and Elliott, S. (2001). Refugee resettlement research project 'Refugee Voices': Literature review. New Zealand Immigration Service, Wellington.

Grbich, C. (2007). Qualitative data analysis: An introduction. London, Thousand Oaks, New Delhi, Sage Publications.

Green, E., and Kloos, B. (2009). Facilitating youth participation in a context of forced migration: A photovoice project in northern Uganda. Journal of Refugee Studies, 22(4): 460-482.

Grogan, P. (2008). Does a rising tide lift all boats? Refugee resettlement, integration and New Zealand's settlement strategy. Fulbright New Zealand, Wellington.

The Guardian (10 August 2010). Burmese election: neither free nor fair. Retrieved on 3 October 2010, from www.guardian.co.uk/commentisfree/2010/aug/10/ burmese-elections-neither-free-nor-fair

Haines, R. (2003) Gender-related persecution. In Refugee protection in international law: UNHCR's global consultation on international protection, Feller, 
E., Turk, V. and Nicholson, F. (Eds.) Cambridge University Press, Cambridge, England.

Hathaway, J. C. (2007). Forced migration studies: Could we agree just to 'date'? Journal of Refugee Studies, 349-369.

Hesse-Biber, S. H. and Leavy P. (2006). The practice of qualitative research. Thousand Oaks, London, New Delhi, Sage Publications.

Hulewat, P. (1996). Resettlement: A cultural and psychological crisis. Social Work, 41(2): 129-135.

Human Rights Commission (2009). Commission's submission: Composition of Refugee Quota 2010-13. Retrieved on 9 October 2010, from http://www.hrc.co. nz/newsletters/diversity-action-programme/te-punanga/2009/10/commissions -submission-composition-of-refugee-quota-2010-13/

Immigration New Zealand (2010). New Zealand Refugee Quota Intake 2000-2010. Retrieved on 10 September 2010, from www.immigration/govt.nz/ migrant/general/generalinformation/statistics/.

Immigration New Zealand (2011). Immigration New Zealand statistics. Retrieved on 2 November 2011, from www.immigration.govt.nz/ migrant/general/generalinformation/statistics

IMSED (2009). Looking back and building futures: Former refugees' views on settling in New Zealand (Summary report). Wellington, Department of Labour.

IMSED (2009). Quota refugees in New Zealand: Approvals and movements (19992008). Wellington, Department of Labour.

Ives, N. (2007). More than a 'good back': Looking for integration in refugee resettlement. Refuge, 24(2).

Kindon, S., Pain, R., and Kesby, M. (2007). Participatory action research: Origins, approaches and methods. In Participatory action research: Connecting people, participation and place. S. Kindon, Pain, R. and Kesby, M. (Eds.) Routledge, London.

Kolb, B. (2008). Involving, sharing, analysing - Potential of the participatory photo interview. Forum: Qualitative Social Research, 9(3). 
Korac, M. (2001). Cross-ethnic networks, self-reception system, and functional integration of refugees from the former Yugoslavia in Rome. Journal of International Migration and Integration, 2(1): 1-26.

Korac, M. (2003). The lack of integration policy and experiences of settlement: A case study of refugees in Rome. Journal of Refugee Studies, 16(4): 398-421.

Korten, D.C. (1995). When corporations rule the world. Kumarian Press, West Hartford.

Kunz, E. F. (1981). Exile and resettlement: Refugee theory. International Migration Review, 15(1/2): 42-51.

Lamba, N. K. (2002). Impact of capital on resettlement outcomes among adult refugees in Canada. (PhD thesis). University of Alberta, Edmonton.

Lamba, N. K. and Krahn, H. (2003). Social capital and refugee resettlement: The social networks of refugees in Canada. Journal of International Migration and Integration, 4(3): 335-360.

Lansner, T. R. (n.d.) Brief History of Burma. Retrieved on 7 April 2010, from http://journalism.berkeley.edu/projects/burma/history.html

Lev-Wiesel, R. (2003) Indicators constituting the construct of 'perceived community cohesion'. Community Development Journal, 38(4): 332-343.

Li, P. S. (2003). Deconstructing Canada's discourse of immigrant integration. Journal of International Migration and Integration, 4(3): 315-333.

Liev, M. H. (2008). Adaptation of Cambodians in NZ: Achievement, cultural identity and community development. (PhD thesis). University of Auckland, Auckland.

Lindgren, T. and Lipson, J.G. (2004). Finding a way: Afghan women's experience in community participation. Journal of Transcultural Nursing, 15: 122-130.

Longmore, M. (19 September 2009). A Parent's Nightmare. Dominion Post. Wellington.

MacDougall, N. (2008). Getting to know you: The journey from refugee to AfricanAustralian. (PhD thesis). Murdoch University, Perth. 
Madriz, E. (2000). Focus groups in feminist research. In Handbook of qualitative research methods. N. Denzin, and Lincoln, Y. (Eds.) Sage Publications, Thousand Oaks.

Maguire, P. (1996). Considering more feminist participatory research: What's congruency got to do with it? Qualitative Inquiry. 2(106): 106-118.

Mahmoodi, K. M. (1992). Refugee cross-cultural adjustment: Tibetans in India. International Journal of Intercultural Relations, 16: 17-32.

Malkki, L. H. (1995). Refugees and exile: From "refugee studies" to the national order of things. Annual Review of Anthropology, 24: 495-523.

Mason, J. (2002). Qualitative researching. Sage Publications, London, Thousand Oaks, New Delhi.

McIntyre, A. (2003). Through the eyes of women: Photovoice and participatory research as tools for reimagining place. Gender, Place and Culture, 10(1): 47-66.

McIntyre, A. (2008). Participatory action research. Sage publications, Thousand Oaks, California.

McSpadden, L. A., and Moussa, H. (1993). I have a name: The gender dynamics in asylum and in resettlement of Ethiopian and Eritrean refugees in North America. Journal of Refugee Studies, 6(3): 203-225.

Merriam, S.B. (2009). Qualitative research: A guide to design and implementation. John Wiley \& Sons, San Francisco.

Michalski, J. H. (2001). The challenges of resettlement among male, government-assisted Iraqi refugees in Canada. Journal of Social Work Research, 2(2): 207-226.

Miller, L., and Crabtree, B.F. (2004). Depth interviewing. In Approaches to qualitative research: A reader on theory and practice. Hesse-Biber, S. H. and Leavy P. (Eds.) Oxford University Press, New York.

Miller, S.M., Rein, M. and Levitt P. (1995). Community action in the United States. In Community empowerment: A reader in participation and development. Craig, G. and Mayo, M. (Eds.) Zed Books, London. 
Morgan, D. L. (2004). Focus Groups. In Approaches to qualitative research: A reader on theory and practice. Hesse-Biber, S. H. and Leavy P. (Eds.) Oxford University Press, New York.

Morris, M. D., Popper, S.T., Rodwell, T.C., Brodine, S.K. and Brouwer, K.C. (2009). Healthcare barriers of refugees post-settlement. Journal of Community Health, 34: 529-538.

Moss, P. (Ed.) (2001). Feminist geography in practice: Research and methods. Wiley-Blackwell, Oxford, Massachusetts.

Moussa, H. (1994). Sowing new foundations: Refugee and immigrant women and support groups. Refuge 13(9): 3-6.

Mullins, D. and Jones, P.A. (2009). Refugee integration and access to housing: A network management perspective. Journal of Housing and the Built Environment, 24: 103-125.

New Zealand Department of Labour (2010). Burmese refugees from the March 2010 refugee quota intake. Department of Labour, Wellington.

New Zealand Immigration Services (December 2002). Refugee voices interim report: A journey towards resettlement. Retrieved on 15 October 2010, from http://www.immigration.govt.nz/NR/rdonlyres/88DD11F7-107C-45A8-889FAAD0E01C6CA0/0/RefugeeVoicesInterimReportDecember2002.pdf

New Zealand Immigration Services (2004). NZ settlement strategy in outline. Wellington, Department of Labour.

New Zealand Immigration Services (2011). RQ1 - Refugee quota all years. Retrieved on 20 October 2011, from www.immigration.govt.nz/migrant/ general/generalinformation/statistics/

New Zealand Ministry of Foreign Affairs and Trade (n.d.). Burma (Myanmar). Retrieved on 20 November 2010, from www.mfat.govt.nz/Countries/AsiaSouth-and-SouthEast/Burma per cent20(Myanmar).php

New Zealand Ministry of Social Development (2008). Diverse communities Exploring migrant and refugee experience in New Zealand. Retrieved on 14 February 2010, from http://www.msd.govt.nz/documents/about-msd-andour-work/publications-resources/research/diverse-communities-migrantexperience/migrant-experience-report.pdf 
Noll, G. and van Selm, J. (December 2003). Rediscovering resettlement. Migration Policy Institute, Washington DC.

NZAID (2008). NZAID Human Rights Mainstreaming Guideline. Retrieved on 20 March 2011, from http://naidtools.nzaid.govt.nz/mainstreaming-humanrights

O'Leary, Z. (2010). The essential guide to doing your research project. London, Sage Publications, Thousand Oaks, New Delhi, Singapore.

O'Neill, M. and Spybey, T. (2003). Global refugees, exile, displacement and belonging. Sociology, 37(1), 7-12.

Orb, A., Eisenhauer, L. and Wynaden, D. (2001). Ethics in qualitative research. Journal of Nursing Scholarship, 33(1): 93-96.

Phillimore, J., and Goodson, L. (2008). Making a place in the global city: The relevance of indicators of integration. Journal of Refugee Studies, 21(3): 305-325.

Pressé, D. and Thompson, J. (2008). The resettlement challenge: Integration of refugees from protacted refugee situations. Refuge, 24(2).

Prosser, J. and Schwartz, D. (2001). Photographs within the sociological research process. In Image-based research: A source for qualitative researchers. J. Prosser (Ed.) Routledge, London, Philadelphia.

Punch, K. F. (1998). Introduction to social research: Quantitative and qualitative approaches. Sage Publications, London, Thousand Oaks, Delhi.

Putnam, R. (1995). Bowling Alone: America's Declining Social Capital. An interview with Robert Putnam. Retrieved on 3 March 2011, from http://xroads. virginia.edu/ hyper/DETOC/assoc/bowling.html

Refugee and Migrant Services (2004). Refugees in the New Zealand context. Retrieved on 27 February 2010, from http://www.refugeeservices.org.nz/ resources and links/?a=215

Refugee Health and Well-being Action Plan Inter-sectoral Working Group (2006). Wellington regional action plan for refugee health and well-being. Retrieved on 10 March 2011, from http://www.refugeeservices.org.nz/resources and links/?a=203 
Renganathan, S. (2009). Exploring the researcher-participant relationship in a multiethnic, multicultural and multilingual context through reflexivity. Qualitative Research Journal, 9(2): 3-17.

RefNZ Statistics (2010). New Zealand Refugee Statistics. Retrieved on 8 January 2011, from www.refugee.org.nz/Stats/ stats.htm\#Table per cent203

Refugee Services Aotearoa (2004). RMS refugee resettlement: Refugees in the New Zealand context. Retrieved on 12 February 2010, from http://www.refugee services.org.nz/resources and links/?a=215

Rother, T. (2008). A human rights-based approach to refugee resettlement. ChangeMakers Refugee Forum, Human Rights Commission and the Human Rights Foundation, Wellington.

Ryan, D., Dooley, B. and Benson, C. (2008). Theoretical perspectives on postmigration adaptation and psychological well-being among refugees: Towards a resource-based model. Journal of Refugee Studies 21(1): 1-18.

Sowa, G. R. (2009). Experiencing refugee resettlement in America: Exploring the impact of generalised policies and services. The Journal of Pan African Studies, 3(2): 102-118.

Speer, P. W. and Hughey, J. (1995). Community organising: An ecological route to empowerment and power. American Journal of Community Psychology, 23(5): 729-746.

Stein, B. N. (1981). The refugee experience: Defining the parameters of a field of study. International Migration Review, 15(1/2): 320-330.

Stevens, C. A. (2010). Lessons from the field: Using photovoice with an ethnically diverse population in a HOPE VI evaluation. Community Health, 33(4): 275-284.

Strategic Social Policy Group (2008). Diverse communities - exploring the migrant and refugee experience in New Zealand. Ministry of Social Development, Wellington.

Te Ara - The encyclopedia of New Zealand (n.d.). 1870s-2003: Refugee groups. Retrieved on 4 April 2010, from www.teara.govt.nz/en/refugees/2 
Tomlinson, F. and Egan, S. (2002). From marginalisation to (dis)empowerment: Organising training and employment services for refugees. Human Relations, 55(8): 1019-1043.

United Nations Development Programme (2010). Human Development Index 2010 Rankings. Retrieved on 11 January 2010, from http://hdr.undp.org/en/ statistics

UNFPA. State of World Population 2006. Retrieved 26 February 2010, from http://www.unfpa.org/swp/2006/english/chapter 4/print/chapter 4.html

United Nations Office of the High Commissioner for Human Rights (2010). Progress report of the Special Rapporteur on the situation of human rights in Myanmar. Retrieved on 3 October 2010, from http://www2.ohchr.org/ english/ bodies/hrcouncil/docs/13session/A.HRC.13. 48 en.pdf

UNHCR (1966). Convention and protocol relating to the status of refugees. Retrieved on 8 November 2010, from http://www.unhcr.org/3b66c2aa10.html

UNHCR (2002). Taking account of gender. In Refugee resettlement: $A n$ international handbook to guide reception and integration. Retrieved on 28 February 2010, from http://www.unhcr.org/3d98627f4.html

UNHCR (2007). Borders with Myanmar remain; no influx of refugees. Retrieved on 25 July 2010, from http://www.unhcr.org/print/470115292.html

UNHCR (2010). 2009 Global Trends: Refugees, asylum-seekers, returnees, internally displaced and stateless persons. Retrieved on 8 March 2010, from http://www.unhcr.org/4c11f0be9.html

UNHCR (2011). UNHCR Global Trends 2010. Retrieved on 9 November 2011, from http://www.unhcr.org/4dfa11499.html

Unite for Sight (n.d.). Module 1: Healthcare in refugee camps and settlements. Retrieved on 3 October 2010, from http://www.uniteforsight.org/refugeehealth/module1

Valtonen, K. (2004). From the margin to the mainstream: Conceptualising refugee settlement processes. Journal of Refugee Studies, 17(1): 70-96.

Van Tran, T. (1987). Ethnic community supports and psychological well-being of Vietnamese refugees. International Migration Review, 21(3): 833-844. 
Wang (n.d.). Photovoice. Retrieved on 17 June 2011, from http://people.umass .edu/afeldman/Photovoice.htm

Wang, C. and Burris, M.A. (1994). Empowerment through photo novella: Portraits of participation. Health Education and Behaviour, 21: 171-186.

Wang, C., Kun Yi, W., Wen Tao, Z. and Carovano, K. (1998). Photovoice as a participatory health promotion strategy. Health Promotion International 13(1): 75-87.

Wang, C. (1999). Photovoice: A participatory action research strategy applied to women's health. Journal of Women's Health, 8(2): 185-192.

Wang, C. and Redwood-Jones, Y. (2001). Photovoice ethics: Perspectives from Flint photovoice. Health Education and Behaviour, 28: 560-572.

Ward, C., Bochner, S. and Furnham, A. (2001). The psychology of culture shock. Routledge, East Sussex.

Westoby, P. (2006). The sociality of healing: Engaging Southern Sudanese refugees in an Australian context - a model of social healing. (PhD thesis). University of Melbourne, Melbourne.

Westoby, P. (2008). Developing a community-development approach through engaging resettling Southern Sudanese refugees within Australia. Community Development Journal, 43(4): 483-495.

Westoby, P. and Ingamells, A. (2009). A critically informed perspective of working with resettling refugee groups in Australia. British Journal of Social Work, 1-18.

Young, N. and Mortensen, A. (2003). Refugees and asylum seekers: Implications for ED Care in Auckland, New Zealand. Journal of Emergency Nursing, 29: 337-341. 